Roberto Rigobon

Sloan School of Management Massachusetts Institute of Technology

\title{
International Financial Contagion: Theory and Evidence in Evolution
}

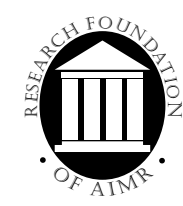




\section{Research Foundation Publications}

Active Currency Management

by Murali Ramaswami

Common Determinants of Liquidity and Trading by Tarun Chordia, Richard Roll, and Avanidhar Subrahmanyam

Company Performance and Measures of Value Added

by Pamela P. Peterson, CFA, and

David R. Peterson

Controlling Misfit Risk in Multiple-Manager

Investment Programs

by Jeffery V. Bailey, CFA, and David E. Tierney

Corporate Governance and Firm Performance

by Jonathan M. Karpoff, M. Wayne Marr, Jr., and

Morris G. Danielson

Country Risk in Global Financial Management by Claude B. Erb, CFA, Campbell R. Harvey, and

Tadas E. Viskanta

Country, Sector, and Company Factors in

Global Equity Portfolios

by Peter J.B. Hopkins and C. Hayes Miller, CFA

Currency Management: Concepts and Practices by Roger G. Clarke and Mark P. Kritzman, CFA

Earnings: Measurement, Disclosure, and the

Impact on Equity Valuation

by D. Eric Hirst and Patrick E. Hopkins

Economic Foundations of Capital Market Returns by Brian D. Singer, CFA, and

Kevin Terhaar, CFA

Emerging Stock Markets: Risk, Return, and Performance

by Christopher B. Barry, John W. Peavy III,

$\mathrm{CFA}$, and Mauricio Rodriguez

Franchise Value and the Price/Earnings Ratio by Martin L. Leibowitz and Stanley Kogelman

Global Asset Management and Performance Attribution

by Denis S. Karnosky and Brian D. Singer, CFA

Interest Rate and Currency Swaps: A Tutorial by Keith C. Brown, CFA, and Donald J. Smith
Interest Rate Modeling and the Risk Premiums in Interest Rate Swaps

by Robert Brooks, CFA

The International Equity Commitment

by Stephen A. Gorman, CFA

Investment Styles, Market Anomalies, and Global Stock Selection

by Richard O. Michaud

Long-Range Forecasting

by William S. Gray, CFA

Managed Futures and Their Role in Investment Portfolios

by Don M. Chance, CFA

Options and Futures: A Tutorial

by Roger G. Clarke

Real Options and Investment Valuation

by Don M. Chance, CFA, and

Pamela P. Peterson, CFA

Risk Management, Derivatives, and Financial Analysis under SFAS No. 133

by Gary L. Gastineau, Donald J. Smith, and Rebecca Todd, CFA

The Role of Monetary Policy in Investment Management

by Gerald R. Jensen, Robert R. Johnson, CFA, and Jeffrey M. Mercer

Sales-Driven Franchise Value

by Martin L. Leibowitz

Term-Structure Models Using Binomial Trees

by Gerald W. Buetow, Jr., CFA, and James Sochacki

Time Diversification Revisited

by William Reichenstein, CFA, and

Dovalee Dorsett

The Welfare Effects of Soft Dollar Brokerage:

Law and Ecomonics

by Stephen M. Horan, CFA, and

D. Bruce Johnsen 


\section{International Financial Contagion: Theory and Evidence in Evolution}


To obtain the AIMR Product Catalog, contact: AIMR, P.O. Box 3668, Charlottesville, Virginia 22903, U.S.A. Phone 434-951-5499; Fax 434-951-5262; E-mail info@aimr.org or

visit AIMR's World Wide Web site at www.aimr.org to view the AIMR publications list.

The Research Foundation of The Association for Investment Management and Research ${ }^{\mathrm{TM}}$, the Research Foundation of AIMR ${ }^{\mathrm{TM}}$, and the Research Foundation logo are trademarks owned by the Research Foundation of the Association for Investment Management and Research. CFA ${ }^{\circledR}$, Chartered Financial Analyst ${ }^{\mathrm{TM}}$, AIMR-PPS ${ }^{\circledR}$, and GIPS ${ }^{\circledR}$ are just a few of the trademarks owned by the Association for Investment Management and Research. To view a list of the Association for Investment Management and Research's trademarks and a Guide for the Use of AIMR's Marks, please visit our Web site at www.aimr.org.

(C) 2002 The Research Foundation of the Association for Investment Management and Research

All rights reserved. No part of this publication may be reproduced, stored in a retrieval system, or transmitted, in any form or by any means, electronic, mechanical, photocopying, recording, or otherwise, without the prior written permission of the copyright holder.

This publication is designed to provide accurate and authoritative information in regard to the subject matter covered. It is sold with the understanding that the publisher is not engaged in rendering legal, accounting, or other professional service. If legal advice or other expert assistance is required, the services of a competent professional should be sought.

ISBN 0-943205-58-1

Printed in the United States of America

August 2002

\section{Editorial Staff}

Bette A. Collins

Book Editor

Christine E. Kemper Assistant Editor

Kathryn L. Dagostino Production Coordinator
Jaynee M. Dudley

Production Manager

Kelly T. Bruton/Lois A. Carrier

Composition 


\section{Mission}

The Research Foundation's mission is to encourage education for investment practitioners worldwide and to fund,

publish, and distribute relevant research. 


\section{Biography}

Roberto Rigobon is assistant professor of economics at the Sloan School of Management at the Massachusetts Institute of Technology. He is also a faculty research fellow of the National Bureau of Economic Research and an associate professor at the Instituto de Estudios Superiores de Administracion (IESA). His research is concentrated in the areas of monetary policy and international finance. Professor Rigobon has written for the Journal of Finance, Journal of International Economics, and Journal of Development Economics. His two most cited papers are "No Contagion, Only Interdependence," co-authored with Kristin Forbes, and "Measuring the Reaction of Monetary Policy to the Stock Market," co-authored with Brian Sack. Professor Rigobon holds an M.B.A. from IESA and a Ph.D. in economics from MIT. 


\section{Contents}

Foreword $\ldots \ldots \ldots \ldots \ldots \ldots \ldots \ldots \ldots \ldots \ldots \ldots \ldots \ldots$ viii

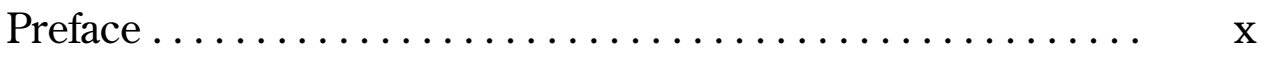

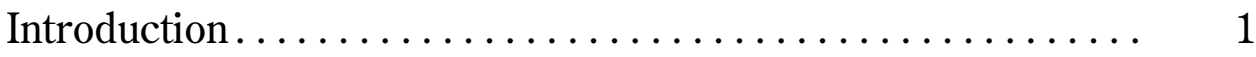

1. Fact and Theory $\ldots \ldots \ldots \ldots \ldots \ldots \ldots \ldots \ldots \ldots \ldots, 8$

2. Empirical Evidence ....................... 57

3. Conclusions and Implications................... 81

Appendix A. Markets in Sample .................. $\quad 85$

Appendix B. Statistical Model of Problems in

Use of Correlation Coefficients ............. 86

References.............................. 94

Selected AIMR Publications $\ldots \ldots \ldots \ldots \ldots \ldots \ldots \ldots . \ldots . \ldots . \ldots$ 


\section{Foreword}

Contagion is one of the most commonly referenced yet least understood notions in international finance. In the aftermath of the 1997 Asian crisis and the 1998 Russian debacle, investors saw contagion looming around every corner and began to question the benefits of international diversification-in particular, investment in emerging markets. Confusion about contagion threatened to shut off much needed investment in the developing world and potentially lead to suboptimal portfolio choices. As one of my first initiatives as Research Director of the Research Foundation, therefore, I sought to identify an expert who could shed light on this important topic. My inquiries all led to the same person, Roberto Rigobon, who as luck would have it, worked just down the street from me at MIT's Sloan School of Management.

Not surprisingly, economists have yet to settle on a precise definition of contagion; thus, Rigobon presents his own. He distinguishes between two types of contagion: pure contagion and shift contagion. He defines pure contagion as the propagation of shocks across markets by means outside of fundamental transmission channels. Shift contagion, according to Rigobon, refers to a change in the strength of the propagation of shocks.

Rigobon also presents a theoretical taxonomy to explain the various ways by which shocks are propagated across markets. The most obvious propagation channels are fundamental in nature, such as bilateral trade links. Less obvious are the various indirect trade relationships that propagate shocks. Even if two countries do not engage in bilateral trade, for example, a shock in one may be transmitted to the other through a third country that is a trade partner to both. Shocks are also transmitted through financial links; to wit, a shock in one country causes lenders to call loans in a different country to satisfy capital requirements. Investor behavior is yet another means of transmission. A shock in one country leads investors to reassess risk in other countries with similar characteristics. Finally, liquidity links transmit shocks across countries. A shock in one country triggers margin calls, which in turn, lead investors to liquidate assets in other countries as they rebalance their portfolios. Rigobon discusses all of these propagation channels within the context of historical events.

One of the most important lessons in this monograph is the insight that high correlations do not necessarily imply the presence of contagion. This issue is critical for risk management. If contagion were common, international diversification would be less effective in reducing risk than typically assumed. Rigobon uses an elegant and clever thought experiment to show that correlations rise with shocks, not because the transmission process has changed, but 
as an artifact of correlation mathematics. Although there have been clear episodes of contagion, Rigobon's experiment suggests contagion is less common than believed. International diversification, therefore, remains an effective means of risk control, even though we observe a rise in correlations around shocks.

The Research Foundation is especially pleased to present International Financial Contagion: Theory and Evidence in Evolution.

Mark Kritzman, CFA Research Director The Research Foundation of the Association for Investment Management and Research 


\section{Preface}

This Research Foundation monograph is the result of more than three years of empirical research in the area of contagion. It all started for me in a seminar where I was discussing an empirical fact based on a very innocent graph (similar to those presented in Chapter 2). I was showing the conditional covariance between the Mexican and Argentine stock markets, and I was puzzled by the increase in comovement during the major financial crises of the 1990s. I claimed that those changes were empirical support for one of my theoretical papers. The implication of this paper was that during financial turmoil, comovement should increase. Raman Uppal of the London Business School was in the audience, however, and he told me that the evidence I was using to support my contention was wrong and that the "facts" were missing an important statistical regularity. He was right.

Since then, I have repeatedly encountered in the literature mistakes similar to the one I made in that seminar. In the past three years, I have devoted part of my research (perhaps as revenge for what Raman did to me!) to highlighting what is wrong with the traditional econometric techniques used to measure contagion and to trying to find new methodologies to solve the problems. I think all of us involved in the search are getting closer. But we still have a long way to go.

This monograph is a summary of what we thought we knew, what we know, and what is yet to be known. The Introduction provides an overview of the monograph, so I leave the details of the organization for later.

I would like to thank Raman Uppal. Even though he has never worked in the area of contagion, and probably never will, his comments were the ones that motivated me to pursue this research. Without his insights, I am sure this monograph would not exist. My thanks go also to my colleagues Rudi Dornbusch, Kristin Forbes, and Tom Stocker, with whom I have had almost a continuous conversation on this topic.

In the last three years, I have benefited from comments in seminars and discussions at Brigham Young University (2000), the U.S. Federal Reserve Board (1998), Harvard University (1998, 1999, 2000), the International Monetary Fund (2001), the University of Michigan (2000), the Massachusetts Institute of Technology (1998, 1999, 2000), New York University (1998), Ohio University (1999), Princeton University (1999), the University of Rochester (2000), and Yale University (1999). I thank the participants of all those seminars.

I would also like to specially thank Mark Kritzman for all his comments and suggestions and, more importantly, for encouraging me to pursue this 
project. Financial support from the Research Foundation of AIMR is gratefully acknowledged.

Finally, I am incredibly indebted to my wife, Gaby, and my kids, Alexandra, Daniel, and Veronica for sharing their vacations with my writing. This monograph is dedicated to them.

Roberto Rigobon Massachusetts Institute of Technology

February 2002 


\section{Introduction}

Many people believe that every time one developing country sneezes, the rest of the world's emerging markets are likely to suffer from acute pneumonia. No matter how good their fiscal accounts are or how balanced the external accounts look, all countries are affected, at least to some degree, when a financial crisis hits somewhere across the globe.

This phenomenon has been called "financial contagion." A simple interpretation of this concept might be that financial shocks are transmitted across markets and countries around the world; why, when, and how the shocks are relayed is still an open question in the academic literature and for practitioners. The channels through which the shocks are transmitted continue to be a puzzle for many, and the extent and stability of the country relationships that explain contagion have still to be tested.

The objective of this monograph is to introduce the reader to this fascinating topic. In the process, I will try to answer several questions. What is contagion? When has contagion occurred? How does contagion occur and what theories exist to explain this phenomenon? What does the early evidence suggest? What are some of the problems in analyzing contagion, and what does more-recent evidence indicate? And finally, what questions should dominate future research and discussions? The remainder of this introduction briefly addresses these questions and provides a framework for the rest of the monograph.

\section{When Has Contagion Occurred?}

Two aspects of the contagion literature are striking. First, as Chapter 1 will make clear, strong agreement does exist among academics and practitioners on when contagion has occurred. In other words, most economists and practitioners agree that contagion occurred during the Mexican, Asian, and Russian crises. Yet, surprisingly, no overall agreement exists on a formal definition for contagion. Before considering the definitional issues, I review the cases in which most researchers-academic and practitioner-would agree that contagion, however defined, has occurred.

Although awareness of financial contagion was raised after the Asian crises of 1997 (the "Asian Flu"), these events were not the first occurrences of the phenomenon. Indeed, shocks were being transmitted internationally long before the Asian crises. Examples include the crises arising from the 
abandonment of the gold standard in 1933 and the breakdown of the Bretton Woods currency regime in 1973.

More recently, three major crises preceded the Asian Flu: the (Mexican) debt crisis of 1982, the exchange rate crises following the abandonment of the European Exchange Rate Mechanism (ERM) in 1992, and the "Tequila Effect" resulting from the Mexican peso devaluation in 1994. As I discuss in Chapter 1 , all three crises resulted in significant stock market corrections, interest rate movements, and losses in gross domestic product. This first set of more-recent international crises is very different from the second set that followed them: the Russian Cold, which arose from the collapse of the ruble in 1998, the Brazilian Sneeze in 1999, and the Nasdaq Rash of 2000.

The first set of crises differs from the second set in two distinct ways. First, the debt, ERM, and Mexican peso crises were mostly concentrated in particular regions, with the negative impacts limited primarily to neighboring countries. Second, even though the countries were economically heterogeneous, the channel through which the shocks were transmitted could easily be explained theoretically. The spread of the Asian and Russian collapses, in contrast, caught most academics and practitioners by surprise.

For example, the debt crises in the early 1980s were the result of massive national fiscal deficits being financed with external borrowing, primarily by the Latin American countries. These problems, however, did not spread to those countries that practiced sound economic management. The countries that ultimately accepted debt restructuring under the Brady plan were precisely those that were experiencing severe difficulties. ${ }^{1}$ Mexico's default was the trigger, but not the cause, of the subsequent speculative attacks on the countries that were suspected of economic mismanagement.

A similar situation preceded the ERM crisis of $1992 .^{2}$ By the early 1990 s, several European countries had high levels of unemployment and relatively strong currencies under the ERM. Were any countries that subsequently abandoned the ERM unfairly assailed? No-in most cases, the abandonment was economically justifiable. Indeed, what was difficult to rationalize was the continuation of the peg (in France, for example). ${ }^{3}$ In the end, the European central banks were facing a nonsustainable exchange rate path that would have eventually required an adjustment. The question was simply one of

1A description of the Brady plan and Brady bonds is available in the "Brady Bond Primer" at www.emgmkts.com/research/bradydef.htm.

2For a brief description of the ERM crisis, see the BBC News Online at news.bbc.co.uk/hi/ english/in_depth/europe/euro-glossary/newsid_1216000/1216833.stm.

3The high interest rates in Germany created a recession in all the countries in the ERM. The natural response was to devalue to allow employment to recover and reduce interest rates. 
timing; George Soros may have answered that question, but he was not the cause of the crisis itself.

And the Mexican peso crisis was similar to the debt crises, although it involved a different type of debt. ${ }^{4}$ Exchange rate and liquidity risks created by the Mexican government's use of dollar-denominated and short-maturity debt caused the country's central bank to suffer solvency problems when eventually faced with a liquidity shock. Once again, most of the countries affected by the crisis were vulnerable for the same reasons as Mexico.

For the first set of crises, the explanations behind the spread of the shocks had valid theoretical bases. An apt way to think about these crises might be in terms of the following parable:

Assume a man is deciding how to cross a frozen lake. He can walk around it, but that will take hours. Therefore, he decides to walk carefully across it. Suddenly, a truck passes by, and honks its horn. The ice breaks and the man drowns. Obviously, the moral of the story is that it is the truck's fault.

The countries in these crises were walking on thin ice. They were extremely vulnerable to any shock, to any sneeze. The international investors were simply the truck-a crucial part of the tragedy but not the cause. If a country can survive only on good news, it is clearly operating on thin ice.

The nature of the financial crisis changed with the Asian collapses beginning in 1997.5 Unlike the previously described crises, these crises were international in scope and their spread was difficult to explain using theories current at the time. In fact, it was almost impossible to predict which country would be attacked next. After Thailand's devaluation, several countries were subject to massive speculative attacks. Stock markets and exchange rates fell almost in perfect sequence, as if they belonged to a synchronized swimming team. Initially, most of the countries affected were in Southeast Asia, but shortly after the crisis in Hong Kong, the United States discovered it was not immune. The scope of this financial crisis was truly international.

Second, in this crisis, the countries under speculative pressure did not face the same economic difficulties or share the same infrastructure weaknesses. For the first time, the theories failed to account for, or at least partially explain, which countries were likely to be infected next. For example, several countries had no trade relationships with the initially affected countries, and their fiscal deficits were small or nonexistent, their external debts were

4See "The Mexican Economy since the Tequila Crisis" by William C. Gruben at www.dallasfed.org/htm/research/hot/bd1100.html.

5See "What Caused the Asian Currency and Financial Crisis? Part I: A Macroecnomic Overview” by Giancarlo Corsetti, Paolo Pesenti, and Nouriel Roubini at www.stern.nyu.edu/ globalmacro/. 
relatively low, and they did not suffer from any major unemployment problems. The cause of the spread of the Asian crises in these circumstances was, and continues to be, a challenging puzzle. For the moment, the best analogy is a virus. Thus, lacking a suitable explanation, this episode in financial history has been popularly designated the "Asian Flu" and the nickname given to the phenomenon in the literature is "contagion."

Not long after global financial markets recovered from the Asian Flu, the second massive international crisis erupted-the "Russian Cold" of 1998.6 Despite characteristics similar to those of the Asian Flu (international scope and relatively unpredictable), the Russian Cold could be considered more virulent than its predecessor. The impact was immediately international. The Russian Cold, together with the collapse of the U.S. hedge fund Long-Term Capital Management (LTCM), created a worldwide state of emergency. The possibility of an international meltdown was clearly not insignificant; thus, we saw concerted intervention by the international monetary community.

After a short lull, Brazil welcomed 1999 with a devaluation of the realleading to the contagion known as the "Brazilian Sneeze." 7 This exchange rate crisis was less infectious than the two previously discussed, and its impact on international markets was limited (although Argentina was enormously affected). Following closely on the heels of two massive crises, this crisis was expected to be the last straw for the international financial community. Most international markets at the time had little liquidity, so they were in a vulnerable position. Indeed, most analysts thought that a further drop in asset prices in another big emerging market would produce enough aggregate losses to hamper the functioning of capital markets. This crisis was not the last straw, however. No meltdown or major contagion occurred. Brazil's devaluation turned out to be expansionary, not recessionary, and more like the European devaluations at the beginning of the 1990s. In the end, from both a theoretical and an empirical point of view, the lack of contagion associated with the Brazilian Sneeze is as surprising as the excessive contagion of the Russian Cold.

At this writing, the world is still under treatment for the "Nasdaq Rash" (perhaps reinforced by what might be called the "Argentine Pampa Pest"), which has plagued the world since the spring of 2000.8 Since March of 2000 ,

\footnotetext{
6See "The Russian Economy: Comments and Articles” at www.russiaeconomy.org/comments / 062101.html.

7For a discussion of Brazil's rapid recovery, see "Brazil's Economic Reform and the Global Financial Crisis” by J.F. Hornbeck at www.twnside.org.sg/title/1848-cn.htm.

8 For more on Argentina's problems, see “Argentina's Financial Crisis: Floating Money, Sinking Banking” by Augusto de la Torre, Edwardo Levy Yeyati, and Sergio L. Schmukler at www.nber.org/ confer/2002/argentina02/schmukler.pdf.
} 
the increase in U.S. stock market volatility has altered the pattern of returns in almost every market in the world. The high volatility and the strong perception that only bad news awaits have forced local monetary authorities to intervene in their local markets. But health has not yet been restored.

\section{What Is Contagion?}

Few market observers would disagree strongly with the list of contagious events mentioned in the previous section, although some might drop the 1999 Brazilian devaluation. This consensus is quite surprising given that, as I discuss in Chapter 1, few of these observers agree on what exactly "contagion" means. Finding two economists who agree on a definition of contagion is almost impossible, and this disagreement is reflected in the fact that most papers in the area start with a virtual apology: Implicit in the opening "Our definition of contagion is ..." is the statement that "we are very sorry if you disagree." This divergence within the profession arises because the only definition upon which agreement can be reached cannot be tested empirically.

Most economists would define contagion as follows:

Contagion is the propagation of shocks among markets in excess of the transmission explained by fundamentals.

This definition is impossible to test because of its ambiguity. Which fundamentals are meant? Moreover, what does "in excess" mean? This ambiguity explains why there has been a proliferation of definitions in the empirical and theoretical literatures. Even worse, the definitions, almost by construction, are interpretations of this general definition and are thus bound to be controversial.

Nevertheless, the plethora of definitions can be classified into two broad categories. In the first are the definitions that relate to contagion as a change in the propagation mechanism around the crises. In other words, an increase in the strength of how shocks are transmitted across countries is evidence of contagion. In the second category, the definitions focus on the type of propagation mechanism driving the transmission. Proponents of this definition are concerned with how much of the shock is propagated through trade, how much by investor behavior, and so on. In general, the proportion of shock that is not transmitted through the "standard" channels (e.g., trade links) is considered contagion. I discuss the advantages and disadvantages of these definitions in Chapter 1 , but in these introductory comments, I want to make sure readers understand that this is my own method of categorization and other researchers may object. To be consistent with the literature, I say, "I'm very sorry if you disagree!" 


\section{Theories about Contagion}

The body of theoretical literature on contagion is large, with numerous theories explaining the various channels involved in the transmission of shocks from one country to another. In Chapter 1, I explain that the literature can be divided into four broad categories according to the types of links or channels of transmission: fundamentals based, financial, investor behavior, and liquidity based. The fundamental channels are the so-called real links between two economies. They include the transmission channels of trade and monetary and fiscal policies. The financial links focus on the channels associated with the organization and functioning of financial markets. For example, existing regulatory constraints may lead to significant comovement of crossborder lending. Theories about investor beliefs and expectations and how they drive contagion fall into the class of investor behavior theories. Finally, the liquidity-based theories focus on the constraints on the activities of security market participants and how these constraints affect the pricing and overall functioning of the securities markets.

A main disadvantage of the theoretical literature on contagion is that more stories about possible contagion exist than measurable events, so the rejection of some explanations has been almost impossible. Therefore, Chapter 2 turns to the development of the empirical literature on contagion.

\section{Empirical Tests of Contagion}

As noted, a key problem with studying contagion is the difficulty of empirically testing the various theories. Therefore, most of the attention of the earliest literature focused on determining whether contagion even existed. In doing so, the early researchers were attempting to answer one of two questions: (1) was the transmission mechanism stable during periods of financial turmoil or (2) how important were trade, macroeconomic similarities (such as tax and financial policies), and other channels in the strength of the propagation of the shocks? The literature produced two general findings, namely, that the propagation mechanism is not stable and that trade explains a sizable portion of the strength of the transmission.

Measuring contagion is one of the most difficult econometric exercises faced by researchers in the field of international finance. The problems arise because contagion is generally measured using daily data and the statistical properties of this high-frequency data make the standard techniques unsuitable for testing for the existence of contagion. From a financial markets perspective, daily returns have conditional and unconditional heteroscedasticity, are serially correlated, and are not normally distributed. From the macroeconomic point of view, international returns are simultaneously 
determined, and they are subject to common shocks that are unobservable, such as investor sentiment, shifts in risk aversion, and liquidity shocks.

Early researchers used a wide range of econometric methodologies, the most popular being correlation coefficients, principal components, linear regressions, and conditional probabilities. Unfortunately, these econometric techniques can deal with only one set of problems at a time. If the data problems are limited to those associated with the financial markets, some of the procedures can be adjusted to measure contagion. If the data are subject to both types of drawbacks, however, then correlations are meaningless, principal component decompositions are inappropriate, and ordinary leastsquare and probit regressions are biased. No single traditional procedure can provide an answer to the question of contagion.

Today, we know that most of these procedures are inappropriate for answering questions about contagion. Hence, the conclusions derived from this early research should be accepted cautiously. But it is important to remember that these papers were very influential in shaping the questions and introducing the puzzles and problems that we face today. They initiated interest in this topic and provided the first generally accepted facts that have been used for a decade. Without these early contributions, I believe strongly that the extant literature would not exist today.

\section{Recent Work}

The research on contagion is being written even as you read. The recent critiques of the old methodologies left researchers with few alternative hypotheses to test, and in fact, many working in the area are in the process of developing new techniques and procedures that can deal with the unresolved issues. In Chapter 2, I summarize some of the solutions that have been advanced as a result of the "new" empirical evidence on contagion. As will become clear in this chapter, several of the previous findings were weakened, even overturned, when the new methodologies were applied.

Finally, in Chapter 2, I also discuss four new procedures to test contagion. I describe some aspects in detail; for others, I summarize the explorations and findings in the text and either extend the approach in an appendix or refer the reader to the relevant papers. 


\section{Fact and Theory}

Initially, the most pressing issues in the literature on contagion were identifying when contagion had occurred, deciding what should be considered to be actual contagion, and explaining why contagion had taken place. This chapter addresses each of these questions beginning with a recounting of those episodes in the 1990s that are generally considered to exemplify contagion. I then turn to defining contagion and discussing the various theories behind this phenomenon.

\section{Generally Accepted Facts}

Academics and practitioners generally agree on when contagion has actually occurred. In this section, primarily anecdotal evidence of its occurrences is discussed; later sections address the more formal testing of its existence. I concentrate here on the performance of stock markets during recent financial crises because I believe stock market movements best illustrate international financial contagion. Stock market performance is not universally accepted, however, as the most accurate measure of contagion. High-frequency variables such as interest rates and exchange rates and low-frequency indicators such as output, investment spending, and capital flows have been considered by some to be better measures. Nevertheless, almost all speculative pressures and financial crises affect stock market returns, whereas not all pressures alter such indicators as interest rates or investment spending.

For example, assume a country faces a speculative attack on its currency. The central bank generally has the option of increasing interest rates, selling reserves, allowing the exchange rate to change, or some combination of all three. The choice of monetary policy is what determines how speculative pressures are manifested in these variables. More importantly, the effects on output, investment, and capital flows are also policy decisions. The return on the stock market, however, reflects policy actions; hence, stock market returns are a reasonable indicator of the degree of speculative pressure that is independent of the policy decision itself.

Several researchers have used indexes that incorporate interest rate, exchange rate, and international reserve changes; Eichengreen, Rose and Wyplosz (1996) made the first contribution along this line. In practice, the results obtained from the use of these indexes and those derived from stock market returns are almost identical, so attention here is devoted to the markets. 
Financial Crises of the 1990s. Even casual observers have come to recognize that during recent financial crises, the stock markets of countries that ex ante seemed to have little in common economically suddenly moved in concert. Furthermore, the analytical results obtained from stock market, interest rate, and exchange rate data were identical: The degree of comovement between markets during financial crises seemed to increase.

How can these results be explained? Is it a short-run phenomenon, or do these markets share hidden common characteristics? Is there any pattern in the relationships? These are the questions that have motivated researchers contributing to the contagion literature. To analyze their answers, I begin in this chapter by examining the degree of comovement experienced by a large number of stock markets around five recent international crises: the Tequila Effect of December 1994, the Asian Flu at the end of 1997, the Russian Cold of August 1998, the Brazilian Sneeze of January 1999, and the Nasdaq Rash that began in April 2000.

I describe these crises informally along three dimensions. First, I discuss the primary reasons behind each crisis. Second, I infer various statistical properties of each crisis by comparing the movements in key emerging and developed countries' stock market indexes that occurred at the time of crisis. Third, I approximate the scope of the contagion by determining the international impact of the crisis. This characterization is quite informal but surprisingly accurate.

All the figures in this section are based on daily data collected from Datastream between January 1, 1990, and December 31, 2000.1 The five figures display the stock market indexes of various countries: Figure 1 depicts five Latin American countries (Argentina, Brazil, Chile, Mexico, Venezuela); Figure 2 shows the stock market indexes of eight Southeast Asian markets (China, Hong Kong, Indonesia, Malaysia, the Philippines, Singapore, South Korea, Thailand); and Figure 3 shows the market indexes of most of the developed countries (members of the Organization for Economic Cooperation and Development, OECD).

- The Tequila Effect. The Mexican peso devaluation of December 19, 1994, was not entirely unanticipated. Some academics and market observers noted early warning signs, such as the evident overvaluation of the peso and the critical decline in Mexico's international reserves as a result of loose monetary policy. Moreover, the political pressures during an election year were severe, especially after the uprising in Chiapas and the assassination of presidential candidate Donald Collosio. When the devaluation came, it

1The data consist of Datastream stock market index prices for the countries listed in Appendix

A. The full data are available on my Web page: web.mit.edu/rigobon/www/. 
Figure 1. Selected Latin American Stock Market Indexes, 1990-2000
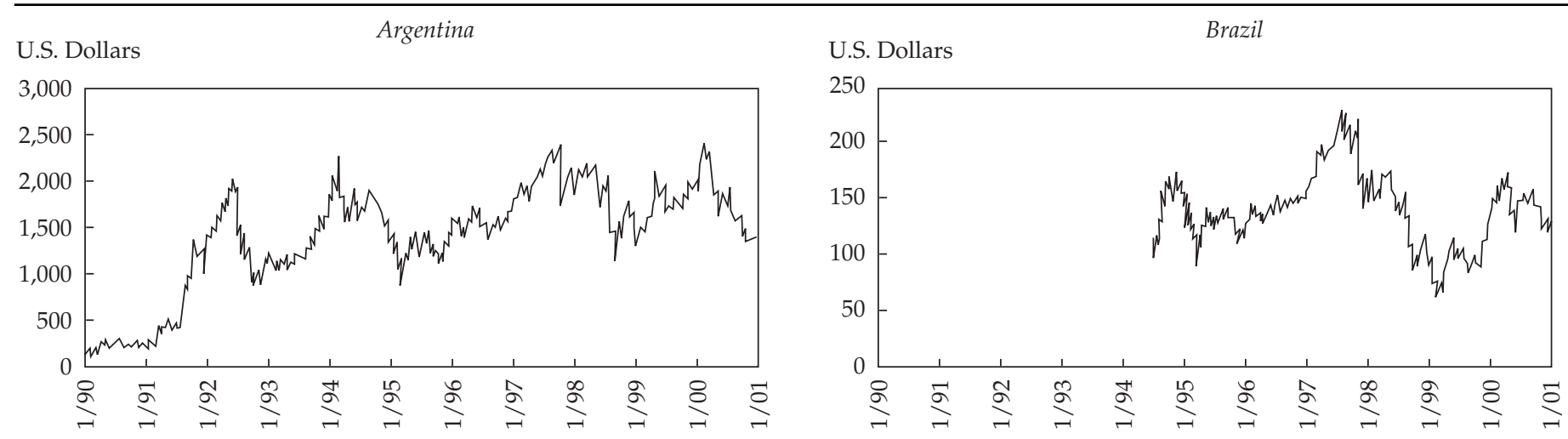

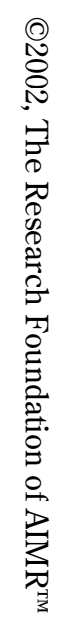

U.S. Dollars

Chile

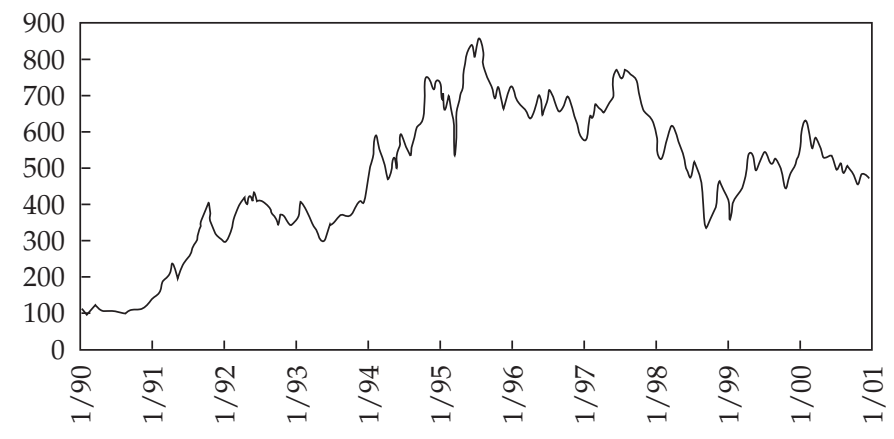


Figure 1. (continued)

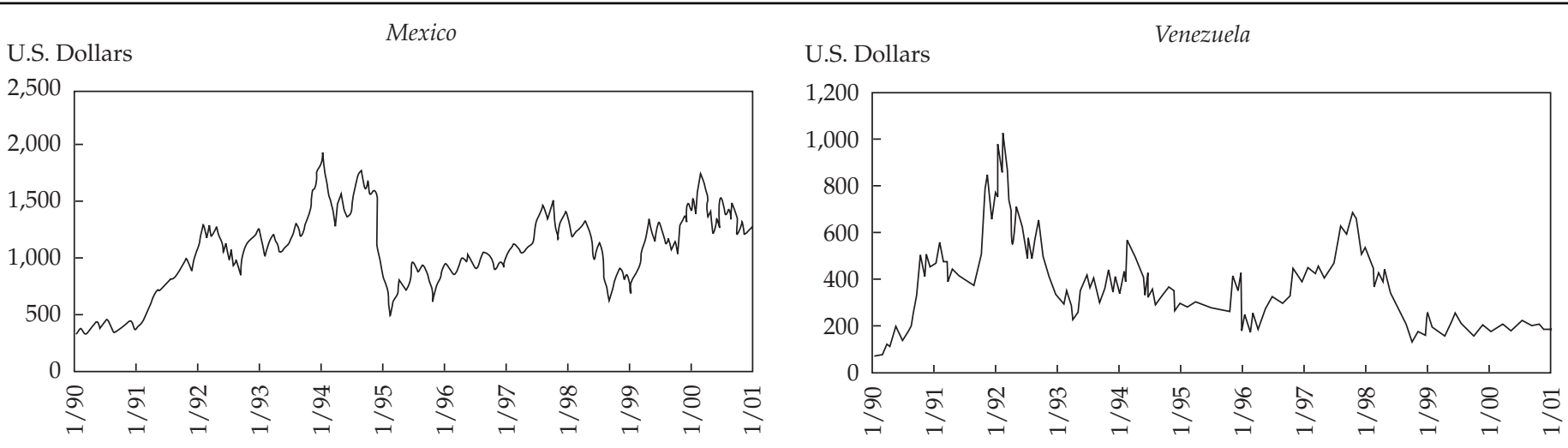


Figure 2. Selected Southeast Asian Stock Market Indexes, 1990-2000
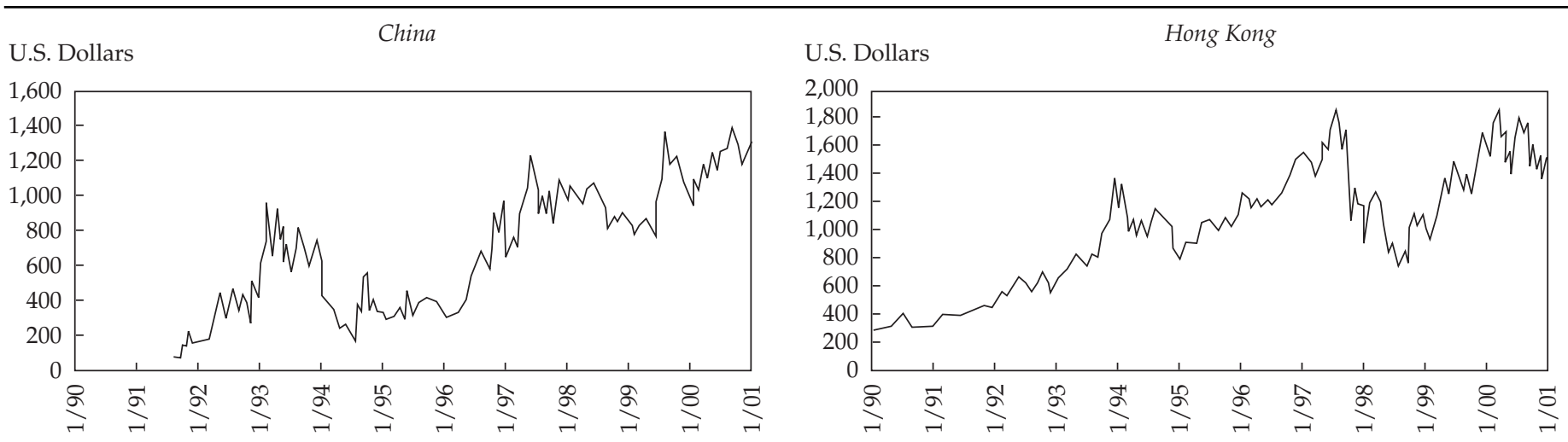

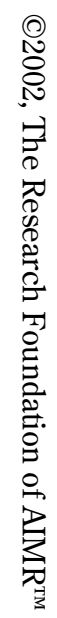
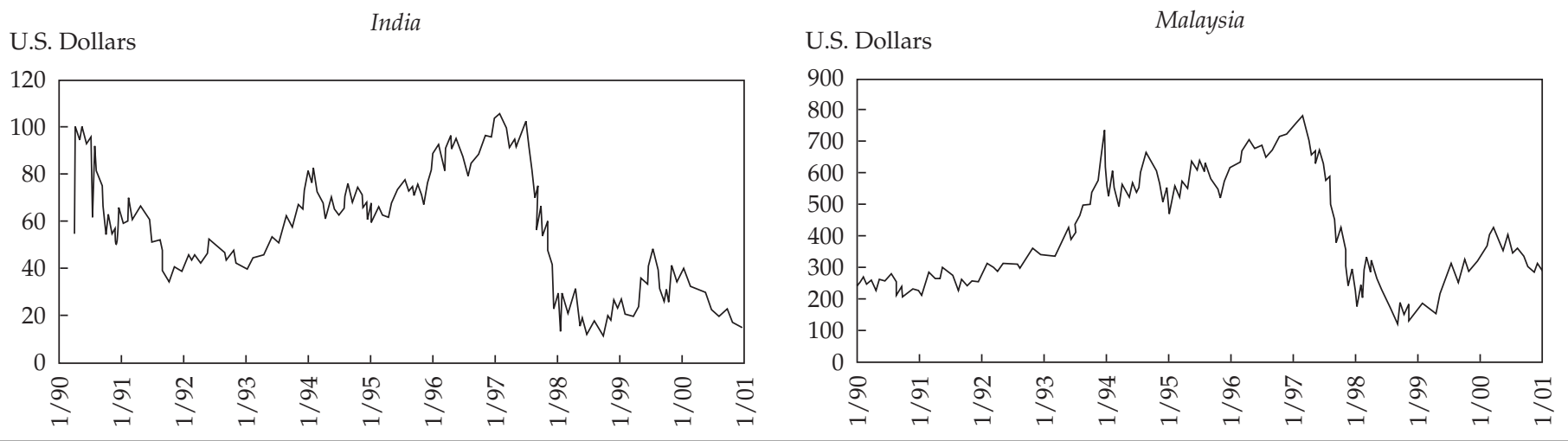
Figure 2. (continued)

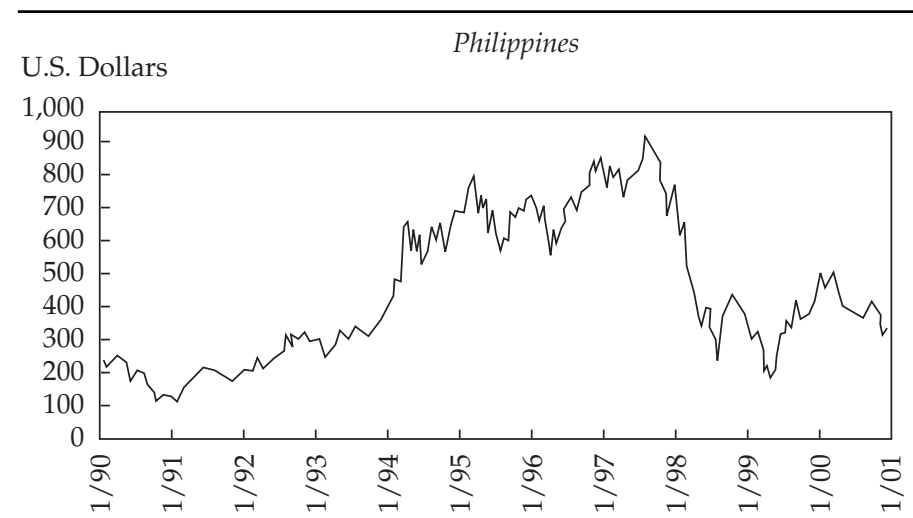

U.S. Dollars

Singapore

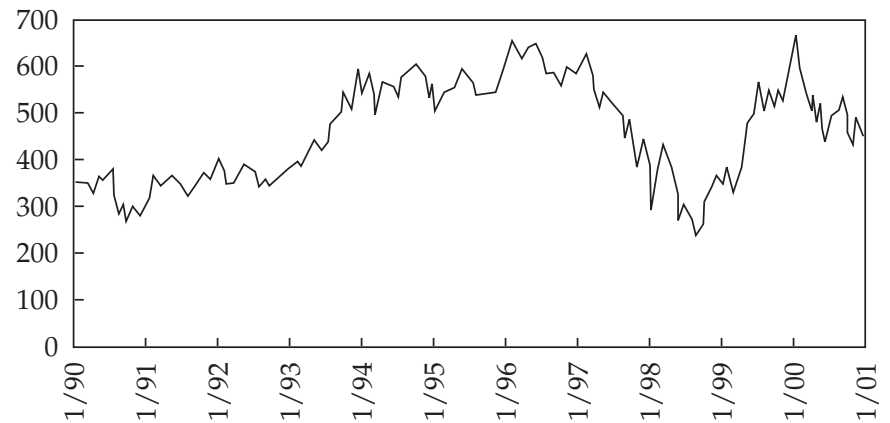

U.S. Dollars

South Korea

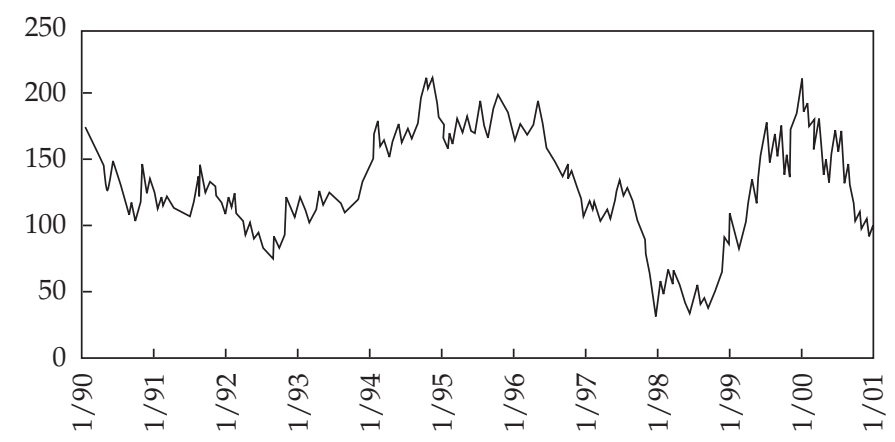

\section{U.S. Dollars}

Thailand

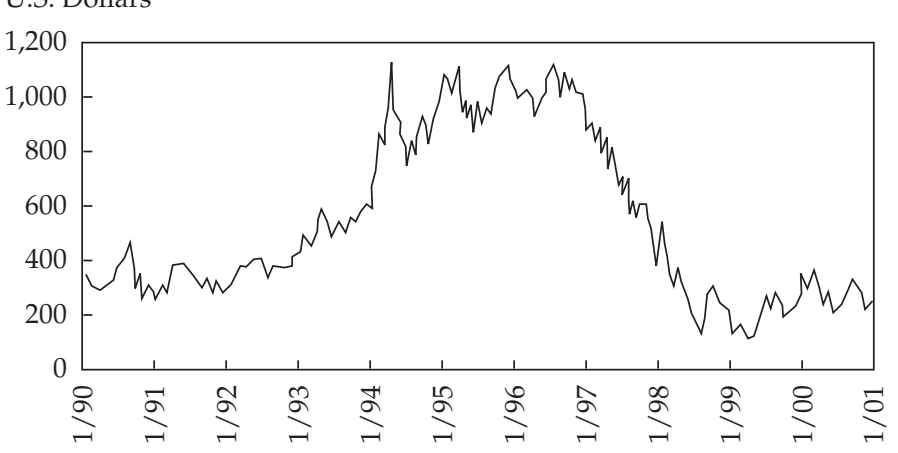


Figure 3. Selected Stock Market Indexes: OECD, 1990-2000

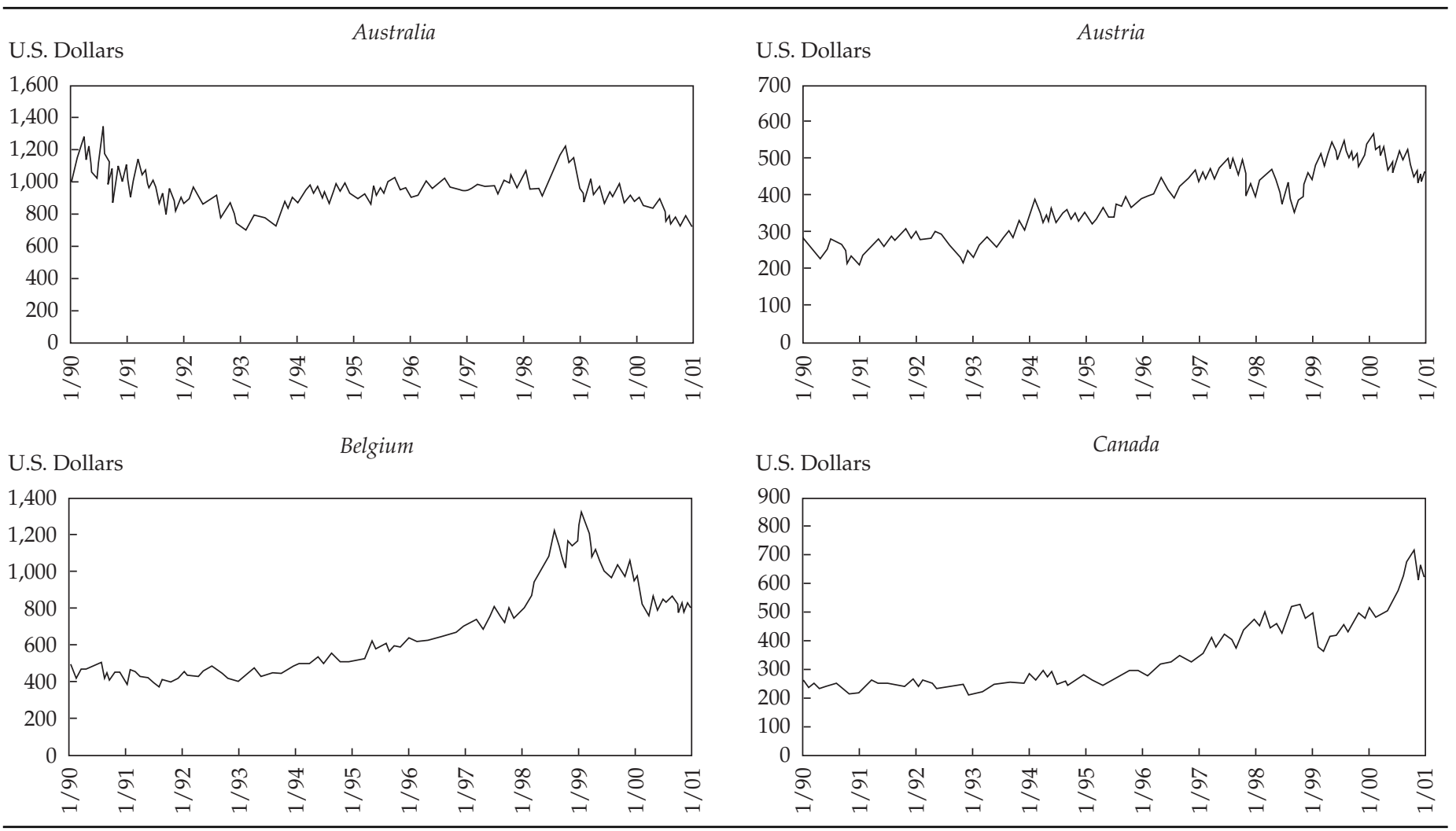


Figure 3. (continued)
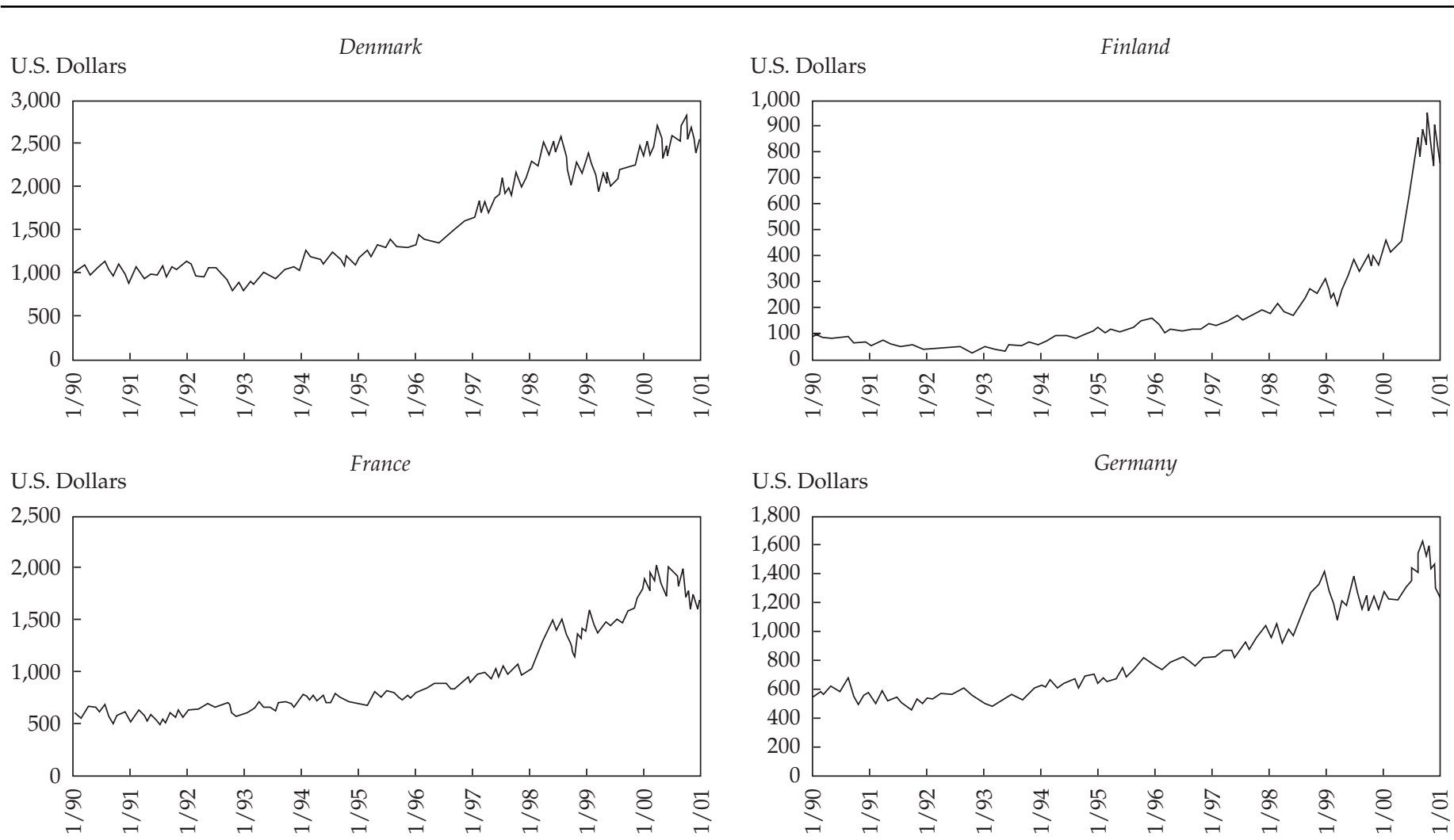
$\sigma$

Figure 3. (continued)
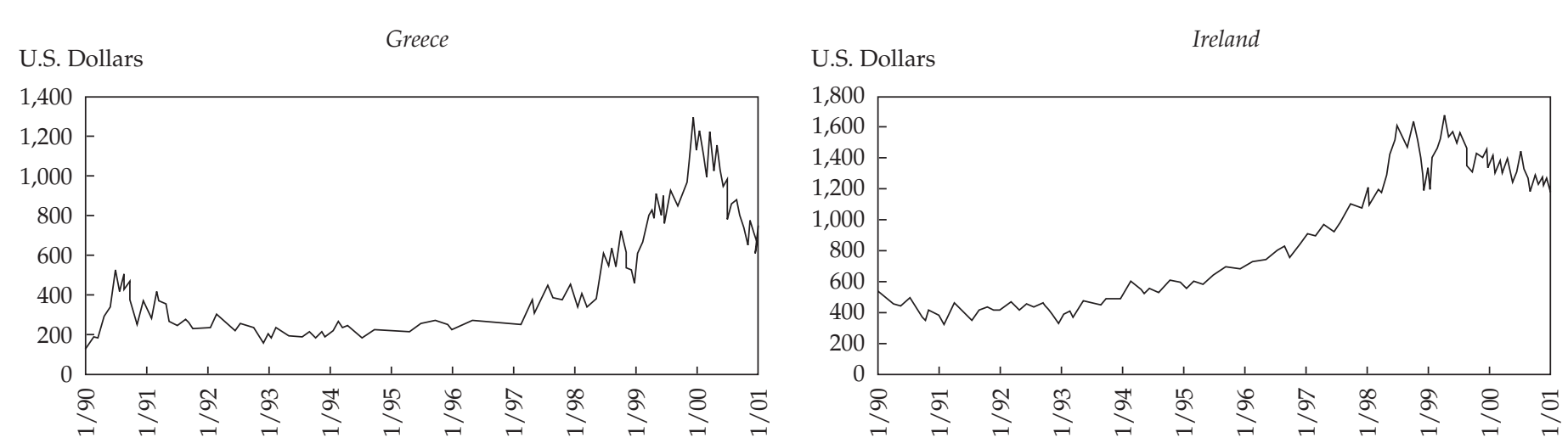

0
0
0
0
0
0
0
0
0
0
0
0
0
0
0
0
0
0
0
0
0
0
0
0
0
0
0
3

U.S. Dollars

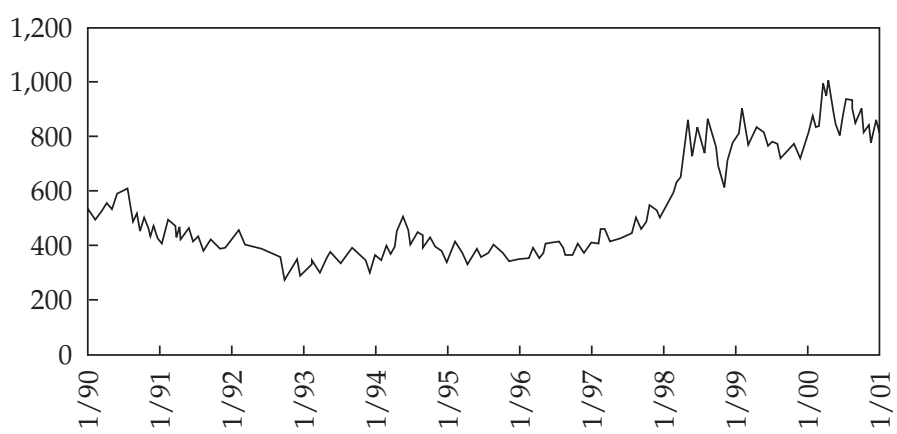

Japan

U.S. Dollars

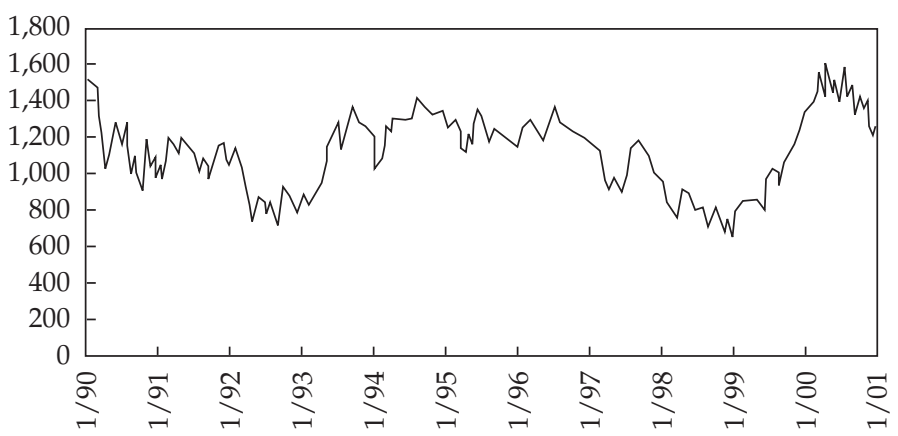


Figure 3. (continued)
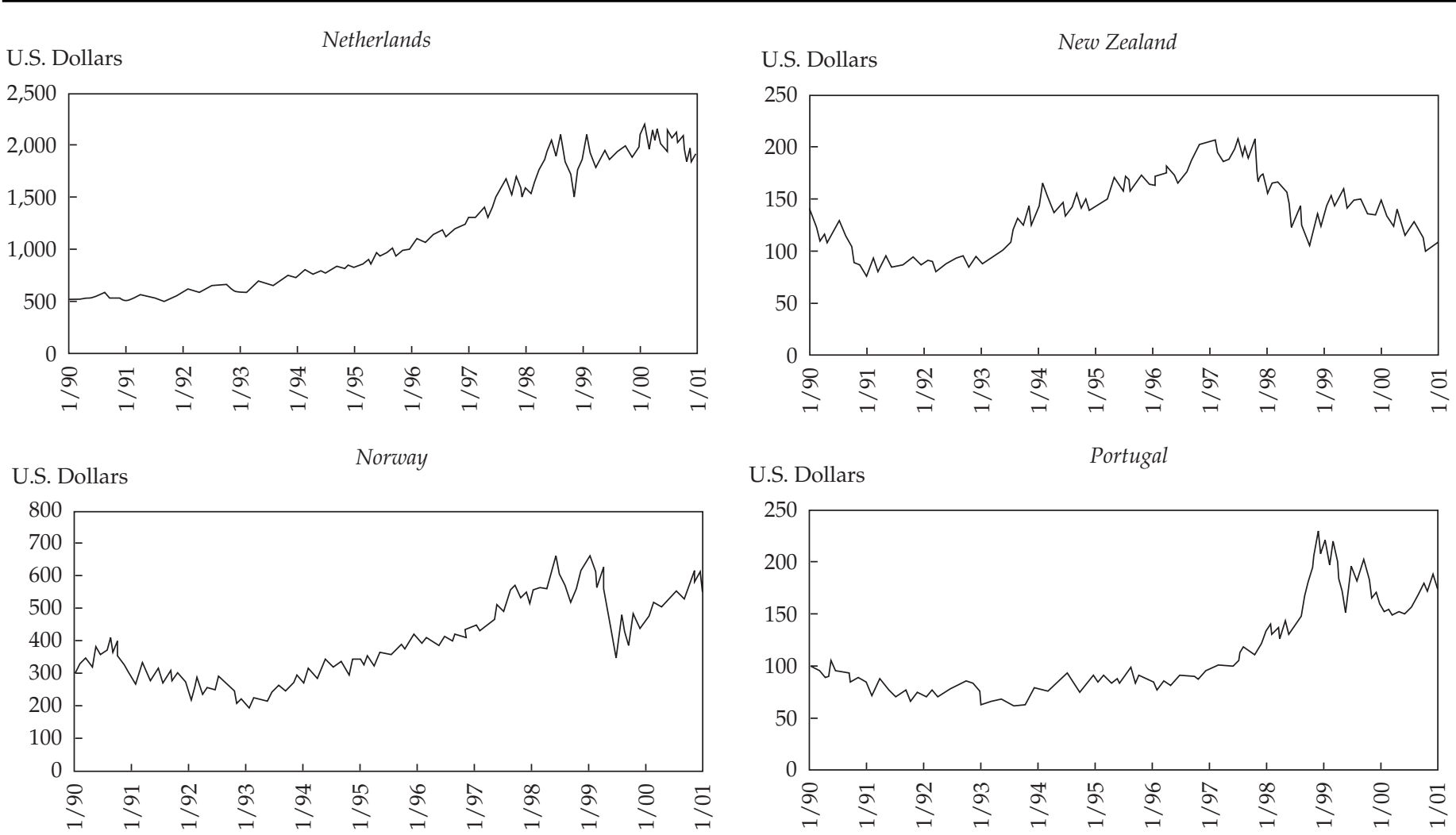
Figure 3. (continued)
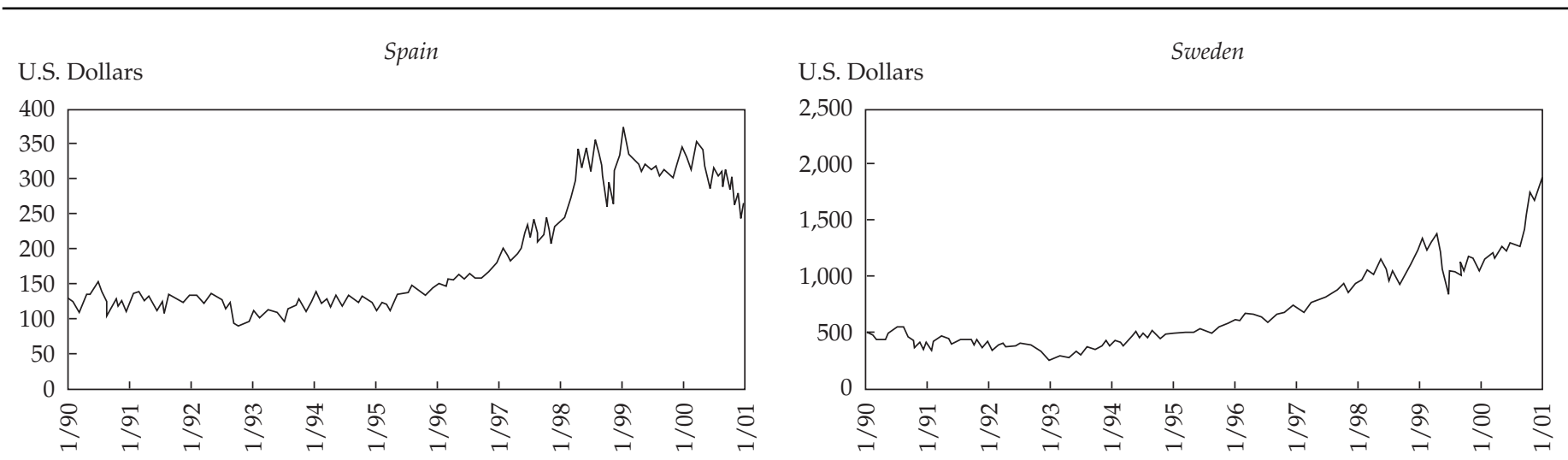

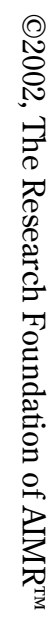

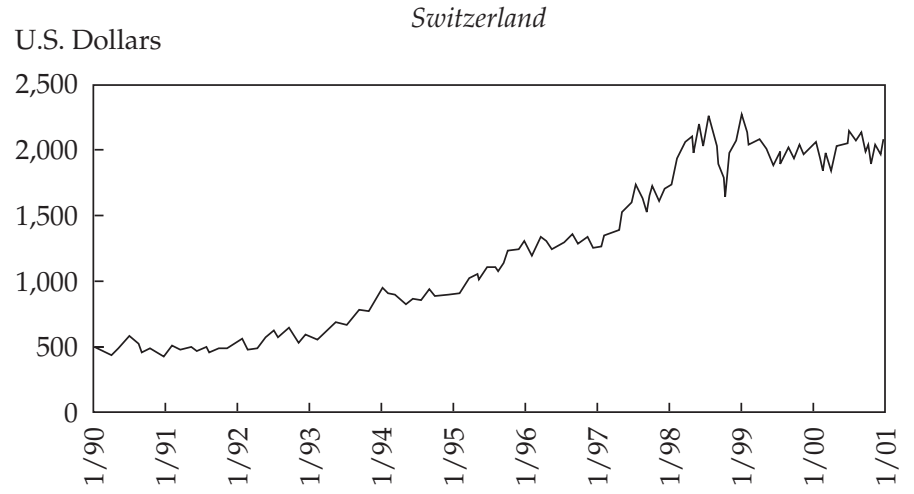




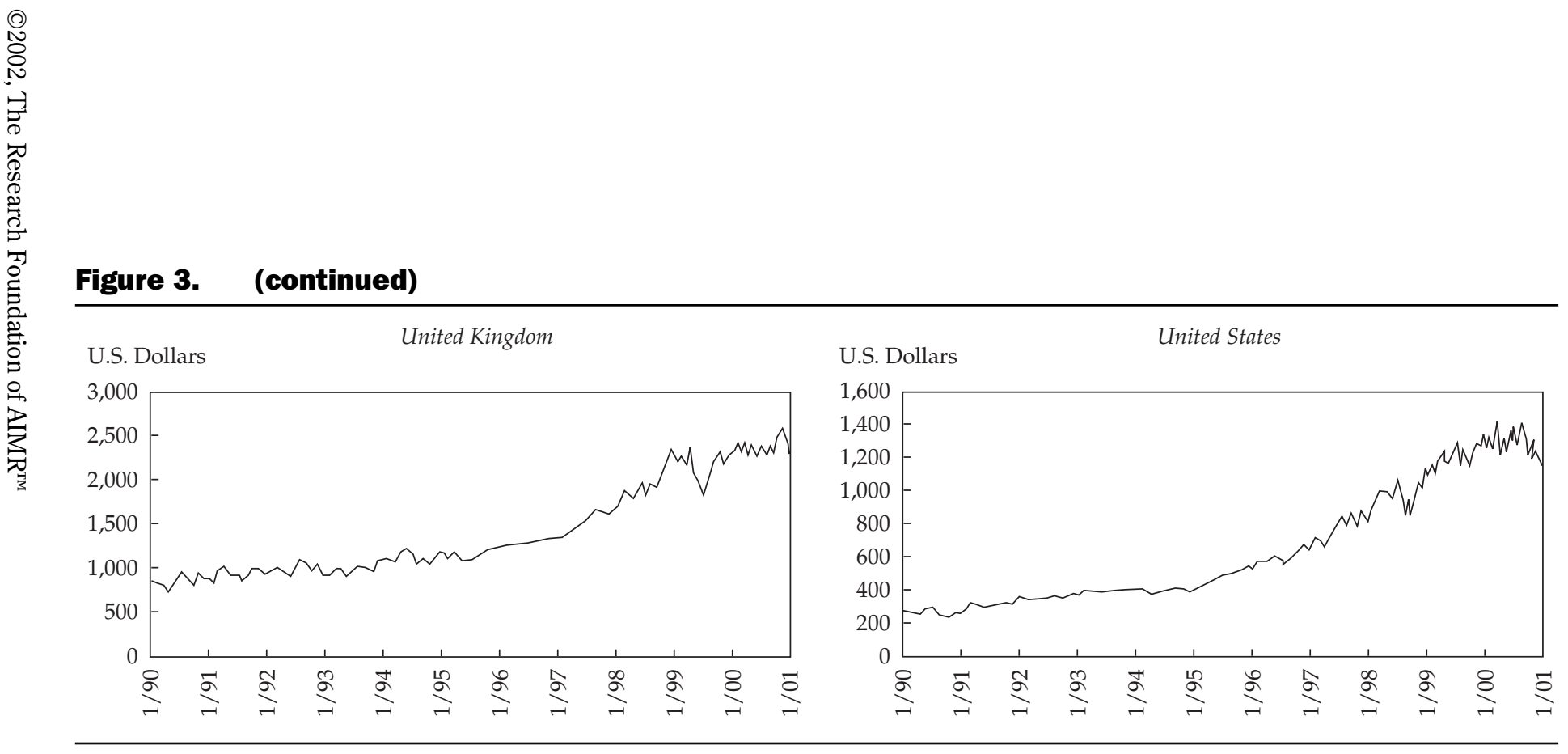

6 
appeared to be business as usual for Mexico-another devaluation after another election year. In the previous three currency crises, Mexico had an election and devalued the peso almost every six years. Devaluation occurred every time the real exchange rate appreciated toward the level that existed in August 1994. Thus, this devaluation should not have taken many by surprise.

For Argentina, Brazil, and several other Latin American countries, however, the impact of this peso devaluation was very different from those in the past. Argentine markets suffered a massive speculative attack that forced a large increase in domestic interest rates. By the end, Argentine output had fallen by nearly 4 percent, almost half the decline in Mexico's gross domestic product. Brazil's economy, although besieged to a lesser extent, still had to contend with an increase in interest rates and a significant decline in stock prices. The international impact of the 1994 crisis was thus very different from that of previous crises and led to this crisis being dubbed the "Tequila Effect," a term coined by economist Guillermo Calvo. ${ }^{2}$

A comparison of Figures 1-3 reveals most of the story: The contagion from the Tequila Effect was mainly regional. Several Latin American countries were severely affected, but any broader international impact was limited. The Argentine and Brazilian markets experienced major declines. Interestingly, the Chilean and Venezuelan stock markets did not suffer similar falls. Moreover, Figure 2 provides evidence that the Southeast Asian countries were apparently immune to the financial crisis - with the exception of China, which was suffering from its own earlier internal problems. Figure 3 indicates that the impact on the OECD countries' stock markets was virtually nil.

The scope of the Tequila Effect can be evaluated by comparing the paths of the market indexes of the various countries over time. Table 1 shows the percentage change in stock market indexes (in U.S. dollars) around December 19, 1994, for four event windows. The table includes Turkey, Poland, and South Africa as well as the Latin American and Southeast Asian countries. $T$ is the date of the peso devaluation (December 19, 1994); the minus day indicates the number of business days before $T$ in the measurement period, and the plus day is the number of days after $T$ in the measurement period. For example, the " $T-1, T+1$ " column computes the almost immediate impact on the stock markets; the " $T-20, T+1$ " column computes the change beginning 20 days before the Mexican devaluation to 1 day after devaluation; the " $T-1$, $T+20$ " column provides the change between the day before to a month after devaluation; and the last column is the cumulative change in the stock market

2The idea being that the propagation of shocks was so surprising at the time that, obviously, alcohol must have been involved. 
Table 1. Tequila Effect in Developing Countries

( $T=$ December 19, 1994)

\begin{tabular}{lrccc}
\hline Market & $T-1, T+1$ & $T-20, T+1$ & $T-1, T+20$ & $T-20, T+20$ \\
\hline Latin America & & & & \\
Argentina & $-2.4 \%$ & $-0.3 \%$ & $-10.6 \%$ & $-8.7 \%$ \\
Brazil & -0.9 & -1.0 & -10.3 & -10.4 \\
Chile & -1.2 & -2.5 & 0.5 & -0.9 \\
Mexico & -11.5 & -15.5 & -35.5 & -38.5 \\
Venezuela & -1.5 & 2.2 & -2.1 & 1.6 \\
& & & & \\
Southeast Asia & & & & \\
China & -3.1 & -5.3 & -13.7 & -15.7 \\
Hong Kong & 1.2 & -11.5 & -9.0 & -20.4 \\
Indonesia & 1.4 & -8.3 & -1.9 & -11.3 \\
Malaysia & 2.3 & -7.6 & -3.5 & -12.9 \\
Philippines & 1.2 & -3.4 & -8.4 & -12.6 \\
Singapore & 0.1 & -6.1 & -1.8 & -7.9 \\
South Korea & -1.4 & -10.5 & -12.3 & -20.4 \\
Taiwan & 1.9 & 7.7 & -3.8 & 1.6 \\
Thailand & 1.4 & -6.1 & -6.2 & -13.1 \\
Other & & & & \\
Poland & -0.6 & 8.5 & 1.8 & 11.1 \\
South Africa & 2.3 & -2.7 & -0.4 & -5.3 \\
Turkey & 1.7 & -0.3 & -9.9 & -11.7 \\
\hline
\end{tabular}

in the two months contiguous to the Mexican crisis. All the tables in this chapter have the same structure.

Table 1 provides a number of insights. The day of the devaluation shows practically no contagious effect. The two largest drops (excluding Mexico itself) are Argentina's and China's. China was facing its own internal problems; thus, the only puzzle might be the fall of the Argentine market. By the month after the devaluation, however, several emerging markets inside and outside Latin America had suffered a fall in their stock market indexes on the order of 10-15 percent. This evidence is consistent with the anecdotal evidence of the Tequila Effect. Most of the problems appeared after international markets were unwilling to roll over Mexican short-term debt in early January 1995, which created a liquidity squeeze in all the emerging economies that, in turn, showed up in the stock markets in the following month.

The Argentine and Brazilian stock markets experienced a fall close to onethird that of Mexico's, which was perhaps the catalyst for the creation of a literature on the phenomenon of contagion (see Calvo and Mendoza 2000). How could a 35 percent decline in the Mexican stock market lead to a 10 
percent fall in the markets of Argentina and Brazil? These countries maintain minimal trade relationships, and no explicit macroeconomic policy coordination was occurring at the time.

The regional concentration is an important aspect of the Mexican crisis. China and Korea are the only other two markets that experienced abnormally large drops in the 20 days following the Mexican devaluation. China was still experiencing the effects of its own 33 percent devaluation in 1994, which may help explain why the stock markets of Hong Kong, Korea, the Philippines, and Thailand also had negative returns during the period. Furthermore, the experience of the developed economies confirms the regional aspect of the Tequila Effect. As Table 2 shows, the OECD countries were not substantially affected by the Mexican crisis; most of the countries avoided negative returns even in the days surrounding the devaluation. In summary, the Tequila Effect appeared contagious but only within the Latin American region.

One explanation put forth for this particular crisis is that market speculators "attacked" those countries with current-account deficits resulting from

Table 2. Tequila Effect in Developed Countries ( $T$ = December 19, 1994)

\begin{tabular}{lcccc}
\hline Country & $T-1, T+1$ & $T-20, T+1$ & $T-1, T+20$ & $T-20, T+20$ \\
\hline Australia & $0.1 \%$ & $2.3 \%$ & $-2.9 \%$ & $-0.7 \%$ \\
Belgium & -0.5 & -1.2 & 1.6 & 0.9 \\
Canada & 0.5 & 0.0 & -0.2 & -0.7 \\
Denmark & -0.8 & -4.8 & 6.0 & 1.8 \\
Finland & 0.6 & -6.3 & 8.3 & 0.8 \\
France & -0.5 & -2.3 & 0.5 & -1.3 \\
Germany & 0.4 & -2.0 & 3.4 & 0.9 \\
Greece & 0.3 & 4.9 & -0.4 & 4.1 \\
Ireland & 0.5 & -2.6 & 6.4 & 3.1 \\
Italy & 0.6 & -7.6 & 13.5 & 4.3 \\
Japan & 0.9 & -1.3 & 2.4 & 0.2 \\
Netherlands & 0.4 & -0.7 & 3.6 & 2.5 \\
Norway & 0.2 & 3.7 & 4.3 & 7.9 \\
New Zealand & 0.0 & -2.6 & -0.1 & -2.8 \\
Portugal & -0.9 & -3.5 & 0.9 & -1.7 \\
Spain & -1.9 & -5.1 & -6.3 & -9.4 \\
Sweden & 0.2 & -6.0 & 5.6 & -1.0 \\
Switzerland & 0.3 & -0.6 & 2.7 & 1.8 \\
United Kingdom & 1.1 & -2.9 & 2.5 & -1.6 \\
United States & -0.3 & -0.4 & 2.7 & 2.6 \\
\hline
\end{tabular}


excessive levels of consumption (see Sachs, Tornell, and Velasco 1996). The theory is that an unsustainable level of consumption requires a currency devaluation or fall in domestic demand in the future in order to restore external equilibrium. Thus, an expected future change in policy becomes simply the trigger, or coordinating device, for the required adjustment to equilibrium. Sachs et al. made this point and warned market participants away from countries that had "dangerous" current-account deficits- that is, deficits produced from fiscal deficits or consumption booms. In 1994, most of the countries in Latin America had current-account deficits driven by large consumption booms.

The Asian Flu. In the patterns of the Asian Flu, a different picture emerges. Apparently unaffected by the Mexican crisis, the countries of Southeast Asia were considered "safe." At the same time Sachs et al. were warning about the dangers of current-account deficits arising from consumption booms in the Latin American countries, the authors claimed that current-account deficits driven by investment booms were safe. They argued that the currency markets of countries such as Indonesia, Korea, Malaysia, and Thailand were immune to speculative attacks because today's external deficits were financing higher output levels for the future. This widely accepted belief made it even more surprising when the Southeast Asian markets came under pressure.

The onset of the Southeast Asian crisis was more perplexing than those of previous crises. No general agreement on the reasons for the outbreak of the Asian Flu exists in the contagion literature. Some claim that the Asian economies were vulnerable and bound to crash (see Masson 1997). Others argue that the crises were the result of multiple equilibriums and the selffulfilling behavior of investors; 3 therefore, the countries were unfairly attacked. However, even the proponents of the latter argument agree that there were at least some signals of growing vulnerabilities in the economies of the region.

The first warning was delivered by Young (1995). He argued that the "growth miracle" of the previous decade was, at best, doubtful. The productivity increases he computed were not remarkably large, and in some countries, productivity actually declined over the period. According to Young, a considerable portion of the economic growth in the region was a result of disproportionate capital accumulation-a phenomenon known as "crony capitalism" in the economic literature. The consequence of crony capitalism is

3The term "multiple equilibriums" describes the existence of two (or more) intersections in a supply and demand model, in which case, individuals coordinate in one or the other. Multiple equilibriums arise when nonconvexities exist in the intermediation process. 
that investment is not as productive as it first appears. Current-account deficits that are the result of this type of capital accumulation do not end up financing significantly higher levels of output in the future. Hence, they are as unsustainable as those driven by excessive consumption or government expenditures.

Corsetti, Pesenti, Roubini, and Tille (2000) examined the growing number of signals prior to the onset of the Asian Flu. As early as 1995, some countries had begun to show signs of "exhaustion." For example, output and export growth in some of the Southeast Asian countries was slowing down. Newer investments were becoming less efficient, and belief in the economic "miracle" had begun to falter.

Today, few academics would agree with the statement that the Indonesian, Korean, Malaysian, and Thai markets were subject to unwarranted attacks, but there is still vigorous debate about the size of the attacks as well as the timing: Why did all these markets crash simultaneously?

The initial onset of the contagion occurred in Thailand. Having confronted several speculative attacks on the Thai baht at the beginning of 1997, by June of that year, Thailand's central bank was unable to cope with any further pressures on its currency. It devalued the baht and allowed the exchange rate to float. In principle, this decision should have been the end of the story, but it was not. Right after Thailand's devaluation, Malaysia's currency came under attack, and it was forced to devalue. Shortly, the currency in every market in the region was under heavy pressure. To various extents, Hong Kong, Indonesia, Korea, the Philippines, Taiwan, and Singapore found they had to manage capital outflows, interest rate increases, and stock market plunges. Some of them decided to defend the peg of their currency to the U.S. dollar (or to the British pound); others decided to devalue.

Later in 1997, the crisis spread out of the region to eventually affect almost all emerging markets and, at least to some extent, the developed markets.

Figure 2 shows the effects of the Asian Flu on the stock markets of Southeast Asia. First, the stock markets of Indonesia, Malaysia, the Philippines, and Thailand collapsed almost simultaneously in mid-1997. Second, although the effects on the Hong Kong and Korean markets were relatively small at the beginning of the crisis, both countries experienced significant declines later in the year, whereas China and Singapore were less affected by the shocks. ${ }^{4}$ All four stock markets had returned to their precrisis levels by the end of 1999, however, indicating the temporary nature of the Asian

4For more information, see "China and the Asian Crisis" in The New Australian: Asian Index (January 19-25, 1998) at www.newaus.com.au/asia6a.html. 
contagion in those countries. In contrast, the stock markets of Indonesia, Malaysia, the Philippines, and Thailand have not recovered as of this writing.

The spread of the Asian Flu was not limited to Southeast Asia. The markets of Argentina, Brazil, Chile, Mexico, and Venezuela were all affected at some point between July 1997 and March 1998 (see Figure 1). In addition, the volatility of these markets increased during the crisis period.

As for the OECD countries, Figure 3 shows that the developed economies were not heavily afflicted by the Asian Flu. The U.S. markets experienced an increase in volatility for only a couple of weeks after the Hong Kong crisis; the long-term consequences were negligible.

The actual end of the Asian Flu is difficult to identify. Several markets that were initially affected did not recover for a long time-for example, Indonesia and Thailand. In terms of overall emerging market volatility, however, the end may have come after the Korean market returned to stability at the end of March 1998.

The movements of stock markets in the developing markets during the Asian Flu are shown in Table 3, with the fall of the Hong Kong market on October 17, 1997, as T. (I chose the Hong Kong market crisis because it had the largest international shock, but remember that since June of that year, one crisis after another took place in the region. Thus, choosing one particular day as the crisis event is artificial.)

First, the declines in stock market prices were large for all these emerging markets. In the two months around the Hong Kong crisis, the stock markets of Hong Kong, Indonesia, Korea, Malaysia, and Thailand lost almost 30 percent of their value. The markets of China, the Philippines, Singapore, and (to a lesser extent) Taiwan were less affected but still suffered declines of approximately 10 percent.

Second, the stock markets of the Latin American countries of Argentina, Brazil, Chile, Mexico, and Venezuela fell between 10 percent and 30 percent during the same two months. Surprisingly, except for Chile, the rest of these countries had almost no direct trading relationships with the Southeast Asian region.

Third, the market index changes immediately around the date of the Hong Kong crisis appear to be significant. All the countries in Table 3 had negative market returns during this short period. Excluding China, all the stock markets had declines of more than 6 percent, and 7 out of 16 had double-digit plunges.

Table 4 shows that the short-run impact of the Hong Kong crisis was relatively large for the OECD countries. All the country stock markets in the table sustained negative returns, with 12 out of the 20 markets experiencing 
Table 3. Asian Flu in Emerging Markets

\begin{tabular}{lcccc}
\multicolumn{5}{c}{$(T=$ October 17, 1997) } \\
\hline Market & $T-1, T+1$ & $T-20, T+1$ & $T-1, T+20$ & $T-20, T+20$ \\
\hline Latin America & & & & \\
Argentina & $-7.5 \%$ & $-11.9 \%$ & $-11.7 \%$ & $-15.9 \%$ \\
Brazil & -8.7 & -13.3 & -21.2 & -25.1 \\
Chile & -6.0 & -11.8 & -7.8 & -13.5 \\
Mexico & -11.0 & -16.2 & -8.8 & -14.1 \\
Venezuela & -8.4 & -10.9 & -19.5 & -21.7 \\
Southeast Asia & & & & \\
China & -0.9 & 13.7 & -4.9 & 9.1 \\
Hong Kong & -17.2 & -38.9 & -4.5 & -29.6 \\
Indonesia & -12.6 & -27.3 & -16.0 & -30.2 \\
Malaysia & -7.0 & -22.9 & -19.5 & -33.3 \\
Philippines & -6.1 & -19.1 & 2.4 & -11.8 \\
Singapore & -6.1 & -20.9 & 8.8 & -8.4 \\
South Korea & -15.9 & -25.6 & -30.6 & -38.6 \\
Taiwan & -8.2 & -23.3 & -6.1 & -21.5 \\
Thailand & -9.7 & -25.0 & -19.8 & -33.4 \\
Other & & & & \\
Poland & -14.7 & -17.3 & -18.4 & -20.9 \\
South Africa & -19.4 & -18.2 & -11.8 & -10.5 \\
Turkey & -19.1 & 0.3 & -23.8 & -5.5 \\
\hline & & & &
\end{tabular}

falls greater than 5 percent, and 2 out of 20 suffering drops greater than 10 percent. Note the contrast of these effects with the results shown in Table 2 for the Tequila Effect, in which the markets of the OECD countries were barely touched.

Even though some initial losses in these markets were large, nearly all OECD markets recovered rapidly. Most experienced a reversion to precrisis values in the month after the crisis. Notable exceptions are the Australian and New Zealand markets, which came under massive speculative pressure during the Asian crisis. As Table 4 shows, these two markets experienced declines of greater than 15 percent during the 20 days after the Hong Kong crisis date. Two months out, Australia, Greece, Japan, and New Zealand were the only countries in which stock markets dipped more than 10 percent. Excluding Greece, the other countries had significant ties to the Southeast Asian economies.

In summary, unlike the Tequila Effect, the Asian Flu affected both emerging and developed economies inside and outside the region, albeit in some cases only temporarily. The impact on emerging stock markets was relatively 
Table 4. Asian Flu in Developed Markets

\begin{tabular}{lcccc}
\multicolumn{5}{c}{$(T=$ October 17,1997$)$} \\
\hline Country & $T-1, T+1$ & $T-20, T+1$ & $T-1, T+20$ & $T-20, T+20$ \\
\hline Australia & $-9.7 \%$ & $-18.9 \%$ & $-3.4 \%$ & $-13.2 \%$ \\
Belgium & -0.6 & -3.9 & 3.8 & 0.4 \\
Canada & -5.4 & -5.1 & -5.0 & -4.8 \\
Denmark & -5.6 & -6.8 & -0.9 & -2.2 \\
Finland & -11.0 & -8.6 & -8.5 & -6.1 \\
France & -4.1 & -8.9 & 1.2 & -3.9 \\
Germany & -7.5 & -9.0 & -2.4 & -4.1 \\
Greece & -0.4 & -4.3 & -14.8 & -18.1 \\
Ireland & -5.7 & -3.5 & -0.7 & 1.6 \\
Italy & -6.8 & -8.1 & -2.2 & -3.6 \\
Japan & -3.2 & -7.1 & -8.1 & -11.8 \\
Netherlands & -3.7 & -6.7 & 0.2 & -3.0 \\
Norway & -6.6 & -3.8 & -7.3 & -4.6 \\
New Zealand & -11.6 & -16.2 & -5.7 & -10.6 \\
Portugal & -5.4 & -6.7 & 0.7 & -0.7 \\
Spain & -6.0 & -14.1 & 2.8 & -6.0 \\
Sweden & -7.6 & -12.3 & -1.7 & -6.7 \\
Switzerland & -3.4 & -4.7 & 2.3 & 1.0 \\
United Kingdom & -2.1 & -4.5 & 1.6 & -0.9 \\
United States & -2.5 & -3.3 & 0.3 & -0.6 \\
\hline
\end{tabular}

large and persistent. The virus also affected the developed countries' markets, but for most, the impact was temporary, so these markets were in some sense immune to the Asian Flu.

The Russian Cold. The Russian Cold differed from previous contagions in two key respects. First, it can be argued that market participants anticipated the collapse. Not only were interest rates perceived as unsustainably high, but Russian politicians were unable to provide solutions to the country's problems. In addition, the International Monetary Fund (IMF) provided an emergency package just prior to the crash that ultimately proved ineffective. In the end, Russia defaulted on its debt, quickly following with a devaluation of the ruble. The result was a massive drop in the valuation of the Russian stock market.

Second, and more important, the Russian Cold had a surprisingly large international impact. The Russian stock market was (and continues to be) very small relative to total global market capitalization. Given the experience with the Asian Flu, market expectations were that the Russian collapse would be primarily an emerging market phenomenon. In a short time, however, these expectations were proved incorrect. After the Russian default, almost all 
markets around the world faced heavy selling pressures. In fact, the Russian Cold is easy to discern by observing in Figures 1, 2, and 3 the date on which each country had a significant drop in its stock market indexes-between August and September 1998. The initial date of the Russian crisis, however, is hard to pin down because three major events could have started it-a large negative shock in the Russian sovereign bond market occurred early in August, followed (two days later) by the drop in Russia's stock market prices and (four days later) the exchange rate depreciation. I chose August 3, 1998 (the sovereign bond shock), as the initial date, but similar conclusions can be derived by using either of the other two events.

Table 5 provides data on developing country stock market returns around the period of the Russian bond default and devaluation. The Russian Cold was felt in all these emerging markets. The immediate effect of the Russian Cold was smaller than that of the Asian Flu; all the developing countries had negative returns, but most of them faced only 3-4 percent drops in two days. The most dramatic effects can be seen in the market changes between the day before and the month after the bond shock (the " $T-1, T+20$ " column). All the Latin American countries had large one-month drops in their stock market prices; Chile's was the smallest at 24 percent; the others dropped by about a third. The last column shows that over the month before and the month after the Russian default, Venezuelan stock prices dropped a whopping 43 percent. The Southeast Asian stock markets were slightly less affected than the Latin American markets by the Russian Cold, but nevertheless, in the month following the Russian default, markets in developing Asia fell 10-27 percent. Finally, the stock market reactions in Poland and Turkey were even larger than those in Latin America and Southeast Asia-more than a 33 percent decline for Poland and more than a 40 percent decline for Turkey.

A puzzling aspect is that the immediate effect of the Russian Cold was smaller than that of the Asian Flu but its longer-term consequences were much more important than those of previous crises. Several explanations may lie behind the limited initial effect. First, it may be a consequence of incorrectly specifying the initial start date. Thus, the reduced effect may be simply the outcome of misspecified windows. This explanation is not likely, however, because looking at the two-day period around the possible three start dates does not clearly show one date on which the largest market declines occurred.

Another explanation is that the cumulative effect of the three events constituting the Russian crisis drove the markets down. My opinion is that this explanation accounts for little of the propagation because the three events were so close in time and the cumulative effect was very small. 
Table 5. Russian Cold in Emerging Markets

( $T$ = August 3,1998$)$

\begin{tabular}{lccll}
\hline Market & $T-1, T+1$ & $T-20, T+1$ & $T-1, T+20$ & $T-20, T+20$ \\
\hline Latin America & & & & \\
Argentina & $-4.9 \%$ & $-3.3 \%$ & $-30.6 \%$ & $-29.5 \%$ \\
Brazil & -4.4 & 2.0 & -30.9 & -26.3 \\
Chile & -1.8 & 3.0 & -24.2 & -20.5 \\
Mexico & -4.0 & -6.6 & -32.7 & -34.5 \\
Venezuela & -3.8 & -11.0 & -38.4 & -43.0 \\
Southeast Asia & & & & \\
China & -2.0 & -1.0 & -13.6 & -12.8 \\
Hong Kong & -4.0 & -11.0 & -10.1 & -16.7 \\
Indonesia & -3.0 & 10.9 & -18.0 & -6.2 \\
Malaysia & -4.6 & -15.9 & -27.1 & -35.7 \\
Philippines & -5.8 & -18.5 & -27.3 & -37.1 \\
Singapore & -1.4 & -4.6 & -14.9 & -17.7 \\
South Korea & -3.8 & 15.8 & -18.1 & -1.4 \\
Taiwan & -0.7 & -3.4 & -16.6 & -18.8 \\
Thailand & -1.9 & -2.2 & -22.4 & -22.7 \\
Other & & & & \\
Poland & -3.4 & -0.2 & -33.4 & -31.2 \\
South Africa & -1.6 & 2.5 & -35.5 & -32.8 \\
Turkey & -4.9 & -12.1 & -41.0 & -45.5 \\
\hline
\end{tabular}

Finally, the true shock may have been the collapse of Long-Term Capital Management, not the sequence of shocks to the Russian markets. Indeed, the largest negative changes to stock market indexes occurred after the LTCM collapse. Proponents of this hypothesis argue that the LTCM crash created a liquidity crisis in world markets with a subsequent impact on stock markets. Unfortunately, separating the two crises is empirically impossible because of their nearness in time. Furthermore, we are not even sure these two events were really separate. Some researchers think so, and certainly a lot of research has been conducted to try to disentangle them, but the question is obviously open for discussion. My opinion is that the LTCM problems were caused by the Russian default and its effect on interest rates. 5

The developed stock markets were clearly not immune to the Russian crisis. As Table 6 shows, the initial impact on the OECD stock markets was

5The Russian crisis moved interest rates in Europe temporarily apart. LTCM was betting that the interest rates would converge (as they ultimately did) and were exposed to this risk. The capital losses of that transitory movement drove the hedge fund into bankruptcy. 
Table 6. Russian Cold in Developed Markets

( $T$ = August 3,1998$)$

\begin{tabular}{lcccc}
\hline Country & $T-1, T+1$ & $T-20, T+1$ & $T-1, T+20$ & $T-20, T+20$ \\
\hline Australia & $-1.3 \%$ & $-4.4 \%$ & $-12.7 \%$ & $-15.5 \%$ \\
Belgium & 0.6 & 3.0 & -8.8 & -6.6 \\
Canada & -3.6 & -11.1 & -22.0 & -28.1 \\
Denmark & -2.0 & 0.0 & -10.8 & -9.0 \\
Finland & -1.3 & 2.7 & -19.4 & -16.2 \\
France & -3.2 & -4.8 & -11.3 & -12.7 \\
Germany & -2.0 & -1.2 & -15.5 & -14.8 \\
Greece & 0.1 & 6.8 & -21.6 & -16.3 \\
Ireland & -0.6 & -3.1 & -15.3 & -17.5 \\
Italy & -1.9 & 0.6 & -13.2 & -11.0 \\
Japan & -2.7 & -4.8 & -10.2 & -12.2 \\
Netherlands & -1.5 & -2.0 & -11.5 & -11.9 \\
Norway & -3.3 & -3.6 & -26.6 & -26.9 \\
New Zealand & -1.5 & -0.6 & -17.8 & -17.1 \\
Portugal & -1.5 & -0.8 & -11.9 & -11.2 \\
Spain & -0.1 & 0.6 & -18.7 & -18.1 \\
Sweden & -1.2 & -2.9 & -16.2 & -17.7 \\
Switzerland & -1.4 & 1.7 & -15.7 & -13.0 \\
United Kingdom & -1.7 & -4.7 & -8.7 & -11.5 \\
United States & -4.3 & -7.5 & -14.9 & -17.8 \\
\hline
\end{tabular}

smaller than the impact of the Asian Flu. The two-day change in the indexes was about 1-3 percent for the Russian Cold (during the Asian Flu, these numbers were twice as large); note that the largest change was the -4.3 percent in the U.S. market. So, in the developed markets (as in the developing markets), the full effect of the Russian Cold took some time to show up. One reason for the lag is that the sovereign bond shock affected mostly noninvestment-grade instruments. Only when the impact was transmitted to interest rates and to the LTCM default were the developed markets seriously affected.

In summary, the distinguishing feature of the Russian Cold is that its effect on developed markets was more than a short-term bump. The Asian Flu was a short-term virus, but the Russian Cold had all the ingredients of chronic pneumonia. Markets around the world became jittery, and intervention was required (and expected) to restore calm. This episode was the first time a small-market collapse made developed markets look vulnerable. In the end, the international monetary authorities did intervene to reestablish tranquility in the financial markets: The U.S. Federal Reserve coordinated the private 
rescue of LTCM and, at the end of 1998 , also relaxed monetary policy by reducing interest rates. This policy move was followed later by the central banks in other OECD countries.

The Brazilian Sneeze. In October 1998, while international markets were recovering from the Russian Cold, Brazil was faced with a massive speculative attack. In the span of two weeks, Brazil's central bank reserves fell dramatically and interest rates rose sharply. Although the central bank was able to defend the currency and claimed victory over the crisis, in early January 1999, investors assaulted Brazil again. This time, little more could be done, and on January 13, the Brazilian real was devalued.

Table 7 provides the stock market data for the emerging markets during the period of the Brazilian Sneeze. A significant feature in the data is that the immediate reaction of the Latin American stock markets was large and negative. Brazil's market declined almost 18 percent, and the stock markets of Argentina, Mexico, and Venezuela fell more than 5 percent. Interestingly,

Table 7. Brazilian Sneeze in Emerging Markets

$$
\text { ( } T \text { = January 13, 1999) }
$$

\begin{tabular}{lcccc}
\hline Market & $T-1, T+1$ & $T-20, T+1$ & $T-1, T+20$ & $T-20, T+20$ \\
\hline Latin American & & & & \\
Argentina & $-11.0 \%$ & $-14.4 \%$ & $1.0 \%$ & $-2.8 \%$ \\
Brazil & -17.5 & -24.1 & -13.9 & -20.8 \\
Chile & -6.4 & -8.9 & 4.5 & 1.7 \\
Mexico & -7.4 & -14.3 & 11.2 & 2.9 \\
Venezuela & -5.5 & -11.0 & -5.5 & -11.0 \\
& & & & \\
Southeast Asia & & & & \\
China & -0.1 & -1.5 & -5.0 & -6.4 \\
Hong Kong & -5.4 & 0.4 & -15.8 & -10.7 \\
Indonesia & -13.1 & -10.1 & -14.4 & -11.4 \\
Malaysia & 0.2 & 9.1 & -6.6 & 1.7 \\
Philippines & -5.2 & 12.7 & -12.6 & 3.9 \\
Singapore & -3.0 & 4.4 & -14.1 & -7.6 \\
South Korea & -4.9 & 17.8 & -16.1 & 4.0 \\
Taiwan & -1.6 & -3.6 & -6.7 & -8.5 \\
Thailand & -5.3 & 11.1 & -26.3 & -13.5 \\
Other & & & & \\
Poland & -10.5 & 9.0 & -2.3 & 19.1 \\
South Africa & -7.0 & 7.5 & -1.4 & 13.9 \\
Turkey & -3.0 & 6.4 & 5.3 & 15.5 \\
\hline
\end{tabular}


Argentina and Mexico recovered their losses in less than 20 days; Venezuela, however, which was independently experiencing an internal political crisis, did not recover so quickly. A second notable point is that, although some Southeast Asian stock markets suffered a negative correction, no clear pattern of causality emerges from the data. Moreover, the markets of Hong Kong, Korea, the Philippines, Malaysia, Taiwan, and Thailand experienced positive returns between December 1998 and March 1999, reflecting the transitory impact of the Brazilian crisis.

Similarly, Table 8 shows that the impact on the OECD countries was small. Although the stock markets of 20 out of 21 countries declined over the two-day period, the negative returns were less than 3 percent and within 2 standard deviations of historical daily movements. Over the longer (monthly) period, 18 countries had negative returns but only 6 were declines greater than 5 percent. Remember that during this period, the dollar was appreciating vis-à-vis the European currencies and the real exchange rate appreciation was larger than 5 percent. Thus, the negative returns may have been the result of

Table 8. Brazilian Sneeze in Developed Markets

( $T=$ January 13, 1999)

\begin{tabular}{lcccc}
\hline Country & $T-1, T+1$ & $T-20, T+1$ & $T-1, T+20$ & $T-20, T+20$ \\
\hline Australia & $-2.8 \%$ & $6.0 \%$ & $2.3 \%$ & $11.6 \%$ \\
Belgium & 0.5 & 4.6 & -4.0 & -0.1 \\
Canada & -2.5 & 6.6 & -1.9 & 7.1 \\
Denmark & -1.0 & 3.8 & -5.8 & -1.3 \\
Finland & -1.9 & 12.4 & -8.3 & 5.1 \\
France & -1.2 & 6.7 & -4.3 & 3.4 \\
Germany & -2.9 & 5.5 & -7.3 & 0.7 \\
Greece & -2.3 & 18.1 & 5.2 & 27.2 \\
Ireland & -1.2 & 9.1 & -3.9 & 6.1 \\
Italy & -2.5 & 6.2 & -7.9 & 0.3 \\
Japan & -0.1 & 0.3 & 0.4 & 0.8 \\
Netherlands & -2.0 & 2.6 & -5.3 & -0.9 \\
Norway & -3.6 & 14.5 & -3.2 & 14.9 \\
New Zealand & -2.4 & 12.6 & -0.8 & 14.5 \\
Austria & -2.1 & -1.5 & -4.6 & -4.0 \\
Portugal & -1.9 & 6.7 & -4.9 & 3.5 \\
Spain & -5.1 & 0.3 & -5.0 & 0.5 \\
Sweden & -1.5 & 8.8 & -1.3 & 9.1 \\
Switzerland & -1.8 & 2.0 & -7.5 & -4.0 \\
United Kingdom & -1.6 & 2.5 & -3.2 & 0.9 \\
United States & -2.2 & 5.6 & -1.7 & 6.1 \\
\hline
\end{tabular}


exchange rate movements in Europe, not the Brazilian shock. Finally, international monetary authorities made no attempt to control the contagion.

The impact of the Brazilian Sneeze was smaller than that of either the Asian or Russian crises, perhaps because it differed from the Asian Flu and the Russian Cold in several ways. One important difference is that the previous two crises involved a financial crisis together with a currency crisis. In the case of Brazil, however, the banking sector was only slightly affected by the devaluation of the real and no financial meltdown occurred. Also, the real's devaluation did not instigate a collapse in gross national product growth, which was actually slightly positive for 1999 . In all previous crises, from the Tequila Effect to the Russian Cold, GNP fell by 8-10 percent in the countries whose currencies were devalued.

Of course, during Brazil's devaluation, several elements previously associated with contagions were missing. First, Brazil did not have a major financial market crisis; it had a currency crisis. Second, no financial catastrophe occurred at the time that was equivalent to the LTCM collapse. Third, the previous attack (October 1998) may have signaled the domestic banking sector and the international financial sector that a devaluation was around the corner. In that case, the Brazilian devaluation would not have been a total surprise and the exposure of investors would have been small. Regardless of the explanation, the lack of contagion in this case could help investigators determine the importance of various channels of contagion.

The Nasdaq Rash. The last of the contagious episodes in this period occurred in mid-April 2000 with the arrival of the Nasdaq Rash. The drop in the Nasdaq index and the rise in its volatility affected all equity markets in the world, as Figures 1-3 show. The data in this monograph end in December 2000 , but keep in mind that the turmoil set off by this U.S. market correction continued well into 2001 .

As can be seen in Table 9, all the emerging stock markets (except Turkey 6 ) experienced negative returns in the 20 days following the initial shock, which I have set as April 15, 2000. Moreover, the markets of 11 of the 17 countries listed lost more than 10 percent in those 20 days. Of the remaining countries, two had losses larger than 5 percent. In comparison, the U.S. S\&P 500 Index suffered a 9 percent loss in the same period. In other words, 12 of the 17 emerging economies tracked in these data lost more than the U.S. market did. This crisis is the first of the recent crises in which the countries infected by a contagious crisis experienced a stock-price drop larger than that in the country that started the sickness.

6Turkey suffered its own financial crisis at the end of 2000 but recovered rapidly with the help of the IMF. 
Table 9. Nasdaq Rash in Emerging Markets ( $T=$ April 15, 2000)

\begin{tabular}{lcccc}
\hline Market & $T-1, T+1$ & $T-20, T+1$ & $T-1, T+20$ & $T-20, T+20$ \\
\hline Latin America & & & & \\
Argentina & $-2.9 \%$ & $-10.0 \%$ & $-16.0 \%$ & $-22.2 \%$ \\
Brazil & -5.5 & -7.7 & -17.1 & -19.0 \\
Chile & -1.7 & -2.1 & -9.4 & -9.7 \\
Mexico & -4.7 & -12.7 & -16.1 & -23.2 \\
Venezuela & -2.2 & -7.0 & -0.1 & -4.9 \\
& & & & \\
Southeast Asia & & & & \\
China & 1.4 & 8.9 & -3.4 & 3.7 \\
Hong Kong & -0.8 & -2.4 & -12.7 & -14.2 \\
Indonesia & -0.7 & -4.0 & -19.6 & -22.3 \\
Malaysia & -0.2 & 0.9 & -0.5 & 0.6 \\
Philippines & -1.5 & 4.6 & -13.7 & -8.3 \\
Singapore & 1.4 & 1.6 & -5.5 & -5.3 \\
South Korea & -2.0 & 4.4 & -11.4 & -5.6 \\
Taiwan & -4.6 & 11.1 & -15.5 & -1.5 \\
Thailand & 4.2 & 9.2 & -17.1 & -13.1 \\
Other & & & & \\
Poland & -3.1 & -9.4 & -13.5 & -19.1 \\
South Africa & -5.2 & -11.8 & -10.4 & -16.7 \\
Turkey & 5.3 & -3.3 & 0.7 & -7.5 \\
\hline
\end{tabular}

The implications for the OECD markets were as important as they were for the developing countries. As Table 10 indicates, in the month after the crisis (column " $T-1, T+20$ "), every stock market in the OECD experienced negative returns. Four countries (Greece, New Zealand, Portugal, and Spain) had market corrections larger than the 9 percent of the United States. Additionally, 16 markets of the 21 countries had losses that were at least half of the U.S. loss and 9 fell more than three-quarters of the U.S. fall.

Thus, a particularly puzzling aspect of this crisis is that a large fall in one U.S. stock market (the Nasdaq) concentrated in a narrowly defined sector (technology) produced not only an important drop in the overall U.S. stock market (as tracked by the S\&P 500) but had a larger effect on broad markets in the rest of the world than within the United States. How could a shock in the technology sector have such a sizable impact in other markets?

In summary, the Nasdaq Rash has several characteristics that make it worthy of research. It affected a major market, so the spread of the contagion is not surprising at all. But the propagation of shocks was greater than one to one; that is, the fall in the countries affected was larger than the fall 
Table 10. Nasdaq Rash in Developed Markets

( $T=$ April 15, 2000)

\begin{tabular}{lrccc}
\hline Country & $T-1, T+1$ & $T-20, T+1$ & $T-1, T+20$ & $T-20, T+20$ \\
\hline Australia & $-2.0 \%$ & $-4.5 \%$ & $-7.4 \%$ & $-9.7 \%$ \\
Belgium & 1.4 & 7.3 & -7.2 & -1.8 \\
Canada & -4.5 & -3.2 & -4.5 & -3.2 \\
Denmark & 0.6 & -3.5 & -2.4 & -6.4 \\
Finland & -3.4 & -9.2 & -3.1 & -8.9 \\
France & -0.9 & -0.9 & -5.1 & -5.0 \\
Germany & -1.6 & -3.3 & -8.4 & -10.0 \\
Greece & -5.1 & -2.3 & -14.5 & -12.0 \\
Ireland & 0.3 & 5.8 & -6.3 & -1.2 \\
Italy & -0.1 & -6.7 & -3.9 & -10.3 \\
Japan & -1.7 & 2.2 & -5.0 & -1.3 \\
Netherlands & -1.0 & 0.8 & -5.3 & -3.5 \\
Norway & -1.7 & -4.8 & -5.2 & -8.2 \\
New Zealand & -2.5 & 9.1 & -9.3 & 1.4 \\
Austria & -0.3 & -0.3 & -3.4 & -3.3 \\
Portugal & -1.2 & -8.5 & -10.0 & -16.7 \\
Spain & 0.3 & -2.8 & -10.5 & -13.2 \\
Sweden & -5.2 & -8.6 & -6.7 & -10.0 \\
Switzerland & 0.0 & 8.9 & -3.7 & 5.0 \\
United Kingdom & -0.5 & -0.7 & -8.1 & -8.3 \\
United States & -4.7 & 0.3 & -9.0 & -4.2 \\
\hline
\end{tabular}

experienced by the country that generated the shock, which demands an explanation. The reasons are open to future investigation.

Lessons. This section has focused on the effects of recent shocks on stock market levels. Almost the same conclusions would be derived from analyzing indexes of domestic interest rates or exchange rates. Some of the numbers would change, but the qualitative characteristics of each crisis would remain the same. Moreover, if volatility movements instead of price shifts were studied, although the conclusions about the propagation might be more difficult to document, the overall message would hold.

The lessons that can be extracted from this casual observation of the data are as follows: First, the Tequila Effect was local, in the sense that the contagion occurred mainly within the Latin American region. Second, the Asian Flu was broader in its scope but still mostly affected emerging economies. Even though some contagion was perceived in the developed economies, it was short lived. Third, the Russian Cold punished every market. Fourth, the Brazilian Sneeze passed with almost no contagion, which should be as surprising as the intensity of the transmission of the previous crises. 
Finally, the Nasdaq Rash hit (and, as of this writing, continues to affect) all countries' markets; indeed, some non-U.S. markets have suffered more than the U.S. markets.

\section{Definitions}

For the purpose of this monograph, it is impossible to state all the extant definitions in the literature or their empirical implications. Nevertheless, the definitions can be divided into two broad categories. The first considers contagion to be equivalent to a change in the strength of the propagation of cross-country shocks. The second considers contagion to be associated with the channel through which the shocks are transmitted.

The first strain of contagion theory developed in the literature is closely linked to the original definition that appeared in the finance literature (see King and Wadhwani 1990). The intuition is that if there is a shift in the strength of the propagation of shocks during a period of turmoil relative to a period of tranquility, then that shift is considered contagion. The empirical tests of this definition used correlation coefficients. The theory was that a change in the estimated correlation of two countries' market movements implied a shift in the strength of the transmission of shocks from one country market to another. Later, similar tests were performed with the use of more sophisticated methods-principal components, co-integrating relationships, and so on. All of these tests have the same spirit: to determine whether or not the propagation of shocks is stable around the time of a currency, market, or economic crisis. If the propagation of shocks is not stable, then this instability is considered to be an indication that contagion has occurred.

The second strain of contagion analysis developed in the literature rests on the idea that several transmission mechanisms are relatively well understood (from the theoretical point of view). These "standard" fundamentals of cross-country transmission of financial, economic, and market information should not be considered contagion. ${ }^{7}$ For example, in a general equilibrium model, shocks can be transmitted across countries because the countries share trade relationships or common capital markets. The transmission that takes place through these channels should not be identified as contagion. It is the transmission of shocks that takes place in excess of these fundamental transmissions that is considered contagion.

In practice, the empirical implementation of testing for this second definition is difficult. For example, consider trade. Trade propagates shocks

7In this case, no clear initial paper can claim ownership of the idea. Among the primary contributors to work on this class of definition, however, are Gerlach and Smets (1995) in the theoretical literature and Eichengreen et al. in the empirical literature. 
across countries because a devaluation of one country's currency makes the exports of other countries less competitive. The improvement in the trade balance of the country devaluing its currency is counterbalanced by the deterioration in the current accounts of the other countries, which forces them to either devalue as well or face a short-term recession. The closer the trading relationships of the respective countries, the more sensitive the countries to this transmission mechanism. Not all the interrelated transmissions associated with trade can be accounted for, however, in a single empirical model. The information required to model all possible trade connections among multiple nations is as yet unavailable. Hence, the literature has concentrated on bilateral relationships; in a few cases, researchers have introduced a third party, a major market (such as the United States). The limitation of the analyses to two or three countries means that the explanatory power of trade is underestimated as a source of contagion.

Each of the two accepted definitions of contagion-defined in this monograph as shift contagion (changes in the strength of the transmission mechanism) and pure contagion (transmission occurring through nonfundamental channels) - has advantages and disadvantages. To understand them, we begin by using our prior information ("priors") to consider various two-market sets and conclude whether contagion was likely to have been present. In other words, we use common sense to determine the presence and type of contagion. Then, we compare the results of this intuitive analysis with information from tests based on the formal definitions of contagion. This exercise will highlight the limitations of the two generally accepted definitions.

The first two markets to be analyzed here are those of Mexico and Morocco. Given our knowledge of and experience with these countries, we would probably expect these two markets to have only a small correlationperhaps less than 10 percent.

Consider, however, the impact of the Tequila Effect on the Moroccan markets. A 10 percent drop in Mexico's stock market from the Tequila Effect led to a 5 percent decline in Morocco's stock market; that is, Morocco's stock market experienced comovement equal to 50 percent of the movement of Mexico's stock market. Similarly, an increase of 100 basis points in the yield of Mexico's sovereign debt was correlated with an increase of $96 \mathrm{bps}$ in the yield of Morocco's sovereign debt. This high degree of comovement in the stock and bond markets of the two countries is surprising. And during this period, no negative news was reported about Morocco or any action taken by Morocco's central bank that would justify the concurrent decline in Morocco's markets. The comovement appears to have been solely related to contagion from Mexico. How, when the ex ante correlation of these two countries' 
markets is judged to be negligible, could they be moving together to such a degree?

Now consider a second set of markets-in this case, two indexes that represent the U.S. stock market: the Nasdaq and the S\&P 500. If a correction of 10 percent occurred in the S\&P 500, would we intuitively expect a correction of similar magnitude, say 9 percent, in the Nasdaq? After all, these two markets are in the same economy, and they should be highly correlated.

Similarly, what relationship would we anticipate between the stock markets of the United States and Canada? If the S\&P 500 fell by 10 percent, we would not be puzzled by a decline of 9 percent on the Toronto Stock Exchange. Would we have the same reaction if the two markets were Austria and Germany, or the Netherlands and Germany? The answer is that we would probably not be surprised at strongly correlated movements between any of these combinations of markets. Intuitively, a high degree of comovement is likely.

The reason the high degree of correlation between Morocco and Mexico is surprising whereas the high degree of correlation in the other country pairs is not is that the priors for the Morocco-Mexico relationship are different from the priors for the relationships of the two U.S. indexes, the United States and Canada, and so on. Our assessment of the existence of contagion depends on what we think, or believe, is the natural interrelationship of the markets we are studying. The priors for Morocco and Mexico indicate that only minimal correlation exists. As a result, a 50 percent pass-through in movement from Mexico to Morocco is perceived as extreme. Yet, the priors for the U.S. and Canadian stock markets suggest that these two markets behave as if they are effectively in the same economy. Thus, a 90 percent pass-through from one market to the other is reasonable.

These examples help explain the derivation of the two definitions of international financial contagion. The first assumes that ignorance about the transmission of shocks across countries does not allow the formation of reasonable priors. We should, therefore, take into account this lack of knowledge in the empirical implementation of tests of contagion transmission.

Contagion as Increase in Strength of Propagation. The proponents of the first definition (shift contagion) interpret the propagation of shocks in tranquil times as a measure of the natural channels through which the countries' economies function. Only the transmission in excess of the natural, or normal, degree of propagation should be considered contagion. Using only the change in the propagation to be contagion is a "safe" definition. Certainly, few academics would disagree that an increase in the transmission of shocks in the short run should be considered contagion. Interpreting these 
abnormal shifts to be the result of normal changes in trade patterns, monetary policy, fiscal policy, and so forth, would be irrational.

This first definition of contagion has two main advantages. The first advantage is that it is relatively easy to test empirically. Even though we cannot observe all the possible connections between the countries, this definition takes this constraint into account by using the information provided by the data during the tranquil times. For example, assume that Mexico and Morocco have no bilateral trade but that their main exports to the United States are in the same manufacturing sector. In this case, a devaluation in Mexico's currency would make the goods from Morocco less competitive in the United States. The deterioration in Morocco's trade balance, in the end, would produce a devaluation in its currency, or an increase in its interest rates. In either case, a decline in Morocco's stock market would be expected. Nothing about this transmission mechanism is abnormal.

The second advantage of the first definition of contagion is that if the propagation of the shocks is found to be unstable, the significance and extent of the contagion can be easily determined. For example, the empirical tests for contagion can assess the degree of correlation between the two markets and how much more vulnerable each is to the other's crises.

The disadvantage of this first definition of contagion is that it is restrictive; that is, the definition is applicable only in the affirmative, not in the negative. In particular, as mentioned, almost all economists would concur that a shift in the strength of the propagation mechanism signals contagion. The agreement disappears, however, on the counterargument: Does the lack of a shift in the strength of propagation indicate that contagion does not exist? Most economists would answer, "It depends." This definition of contagion does not allow proof of the absence of contagion because we cannot construct transmission channels that are not based on ongoing fundamental relationships-which is where the second definition of contagion (pure contagion) comes into play.

Contagion as Change in the Channels of Propagation. Contagion depends on how it is transmitted. For example, assume that Mexico and Morocco have almost no trade relationships; that is, they neither have major bilateral trade nor do their exports compete with each other. But assume also that their sovereign debts are traded in a common market. 8 Now, assume that market participants price Morocco's debt with the following rule: "Morocco's debt always trades 50 bps below Mexico." In this case, a financial collapse in

8Indeed, both countries participate in the Brady Plan (see the "Brady Bond Primer" at www.emgmkts.com/research/bradydef.htm), and their sovereign debts are noninvestment grade. 
Mexico that increases its interest rate will also raise interest rates in Morocco. The increase in the interest rate on Morocco's sovereign debt puts pressure on domestic interest rates in Morocco, and its stock market falls. The transmission in this example is caused by a pricing rule. If the mispricing is hard to arbitrage away (as it would be in a segmented market), most of the comovement in the prices is given by this rule. The pricing rule is not a fundamental channel between the economies and thus cannot be considered a natural transmission mechanism. Therefore, this example is a case of contagion.

The relationship is as strong in tranquil times, however, as it is in crisis periods. So, if it remains constant through time, proponents of the first definition of contagion would erroneously conclude that contagion does not exist, because no shift in the strength of the propagation mechanism occurred.

The problem with the first definition is that it is unable to detect contagion when the source of the contagion is always present. The second definition of contagion tries to solve this dilemma. Several examples can be given of markets that tend to move together more than we would expect given our prior knowledge of their relationships. My preferred example is sovereign debt markets. Sovereign bonds of Brazil and Bulgaria have a correlation of 93 percent, those of Mexico and Morocco have a correlation of 97 percent, and those of Peru and the Philippines have a correlation of 96 percent. What do these countries have in common (other than the fact that their names begin with the same letter) to explain the high correlations? The debt yields are supposed to represent the country risks. How can default probabilities of such seemingly unrelated countries be so synchronized?

The main advantage of the second definition is that it takes a broad view of contagion. In practice, however, the same advantage turns out to be a disadvantage: The empirical findings are always controversial. In most of the empirical implementations, contagion has been treated as the residual of a regression (i.e., the propagation not explained by the channels that are explicitly modeled). Therefore, if some of the fundamental channels have not been fully taken into consideration in the specification, the conclusions of the empirical analysis will be biased. Moreover, in the applied work, this second definition of contagion is almost impossible to implement empirically. For example, setting up all the possible trade channels in a multicountry model is computationally intractable.

I cannot resolve the shortcomings in how contagion is defined in this monograph, but keep in mind that each has advantages and disadvantages. I use both definitions: (1) shift contagion-changes in the strength of the transmission mechanism, which cause the propagation of contagion, and (2) 
pure contagion-contagion passed through nonfundamental transmission channels. The next section summarizes the literature that has developed around these definitions of contagion but does not attempt to settle the issue of which is correct.

\section{Theories}

The theoretical literature on contagion is extensive. ${ }^{9}$ It can be divided into four broad classes-theories in which the contagion is based on (1) fundamentals, (2) financial links, (3) investor behavior, and (4) liquidity links.

Fundamentals-Based Links. The theories based on fundamental channels are the oldest and best understood of all the theories explaining contagion. The general idea is that links across countries exist because the countries' economic fundamentals affect one another. These theories are usually based on standard economic mechanisms, such as trade, monetary policy, and common shocks (oil prices). In this section, I analyze these mechanisms in detail.

Trade. Trade has been one of the favorite theories in explaining the transmission of financial, market, and economic shocks across countries. In the context of the devaluation of the Swedish krona in 1992, Gerlach and Smets (1995) developed a simple model that uses bilateral trade as the conduit of shocks. Their intuition was that if two countries share an important bilateral trade relationship, a currency devaluation in the home country will reduce the cost of home goods vis-à-vis foreign goods. The change in relative prices shifts demand toward home goods and away from foreign goods. The foreign country faces a deterioration in its current account as its exports fall while its imports rise. Therefore, to reestablish external equilibrium, the foreign country is required to devalue its currency. This is the theory behind competitive devaluations. Competitive devaluations have been viewed as such an important component of the exchange rate mechanism (ERM) collapses at the beginning of the 1990s that those countries joining the European Monetary Union do so only under the condition that they avoid competitive devaluations both prior and after their EMU tenure.

The original model by Gerlach and Smets was criticized because it was based entirely on a bilateral trade relationship. Such a basis was reasonable for European countries, but it is inappropriate as applied to the transmission of contagion in the recent international financial crises of Mexico, Russia, Asia, and so on. In the case of the Mexican debt crisis, the amount of trade between Mexico and the rest of the Latin American countries was small. And in the

${ }^{9}$ Recent work in this field is well summarized in Claessens, Dornbusch, and Park (2000). 
other cases, the amount of trade among Southeast Asian countries and between Russia and Latin America was also negligible, but contagion was nonetheless transmitted between and among these countries. Corsetti et al. responded to this phenomenon by adapting the bilateral trade model of Gerlach and Smets to explain the transmission of shocks between countries that do not share bilateral trade relationships but that export similar goods to common third markets (technically considered substitute goods). Corsetti et al. were motivated by the Southeast Asian crises, in which bilateral trade relationships were negligible but the export of similar goods to common large markets was abundant, especially in the technology sector.

The idea is as follows: Assume that two small countries, A and B, export substitute goods to a larger third market, Country C. If Country A devalues, then goods from Country B are less competitive in the common market. The demand in Country $\mathrm{C}$ shifts towards goods produced in Country A and away from goods produced in Country B. This swing in demand creates a balanceof-payments problem in Country B. To return to external equilibrium, Country $\mathrm{B}$ will either devalue or experience a recession (or both).

Trade is an extremely appealing mechanism for the transmission of contagion. It is simple, and based on standard economic thinking, contagion through trade must exist. Trade is a fundamental aspect of globalization, a trend driving both the spread of contagion itself and the need to understand its transmission. Therefore, the attention it has received in the literature is not surprising.

Readers should note, however, that most of the empirical papers tend to underestimate the importance of trade in explaining the propagation of shocks. Good data exist on bilateral trade, but bilateral relationships are only part of the transmission mechanism. Extending the models to complex multicountry trade patterns has proven to be a difficult task. For instance, how substitutable are exports from Malaysia and Thailand? Furthermore, how large does this substitutability have to be to cause a speculative attack on one country once the other country has devalued its currency by 30 percent? These questions are difficult to answer with the theoretical models-and much harder in applied work.

Macroeconomic policy. The second theory that has received significant attention in the literature is macroeconomic policy coordination. The theory is that stock prices and interest rates of countries that share similar macroeconomic policies tend to move together. Furthermore, if two countries have open capital accounts, policy actions by one of the countries will limit the choice of policy actions by the other country. This propagation mechanism was first documented in Robert Mundell's seminal contribution on currency 
unions, and it has been recognized as a powerful transmission channel through which contagion appears, even in the absence of trade.

The most transparent example of the transmission of contagion by macroeconomic policy arises when countries have a fixed exchange rate and high capital mobility. Consider the case of Germany and Spain in the early 1990s. Germany was facing inflationary pressures because of German reunification. Accordingly, Germany tightened monetary policy, thereby increasing interest rates in Germany and in the rest of the countries in the ERM. In response to the interest rate increase, Spain had three options-fiscal policy restraint, contractionary monetary policy, or devaluation.

First, Spain could have decided to maintain low interest rates by restricting fiscal policy. If Spain had kept interest rates constant with an unchanged fiscal stance, the increase in interest rates in Germany would have led to a capital outflow with a loss in reserves for Spain. In other words, because the exchange rate was fixed, arbitrage opportunities would have arisen. With German bonds paying a higher interest rate than Spanish bonds and no risk of devaluation because of the fixed exchange rate, arbitrageurs would have sold Spanish bonds and bought German bonds, thus producing a capital outflow from Spain to Germany. Spain could have coped with the capital outflow, at first, by accepting a loss in reserves, but such a policy was clearly transitory in the context of fixed exchange rates. Reserves last a finite amount of time, and in the long run, the capital outflow would not have been sustainable. Therefore, Spain would have had to contract domestically through fiscal restraint. In the end, the country could finance the lower interest rate only with a larger unemployment rate.

Second, Spain could have matched Germany's interest rate increase by tightening its monetary policy. The resulting hike in Spanish interest rates would have reduced domestic demand, causing a recession and further increasing unemployment. The outcome would have been similar to the fiscal contraction described for the first choice, at least along the dimension of unemployment.

Third, Spain could have devalued, which at that time meant abandoning the ERM. A devaluation would have lowered domestic interest rates, avoided capital outflows, and avoided reserve losses. The devaluation would have created a fall in aggregate demand as in the previous two choices, but unemployment would not necessarily have increased.

In summary, tightening fiscal and monetary policies would have meant an increase in unemployment and devaluation would have meant a reduction in the wealth of Spanish workers-not a pretty picture for Spain and several other countries that belonged to the ERM and shared a border with Germany at that 
time, such as France. The regime of fixed exchange rates imposed important constraints on the sovereignty of the ERM countries in regard to fiscal and monetary policies. Through this entity, the countries around Germany shared some of the costs of German reunification by either devaluing their currencies or increasing their unemployment rates.

Other forms of policy coordination exist that are not exclusively related to exchange rate policy but are explicit statements of monetary, fiscal, or currency policy coordination among nations. For example, a trade agreement might include a clause in which lax monetary policy in one country allows other member countries to raise trade barriers against that country. This situation is similar to the program supported by Domingo Cavallo in Argentina in 2001.10

The most interesting cases occur when such agreements are implicit. Drazen (1998) studied perhaps the best example-the European devaluations in 1992-1993 that destroyed the ERM. In his model, central bank presidents are under political pressure to maintain their countries' fixed exchange rates. Because the political pressure is almost entirely driven by peer pressure, the abandonment of the fixed rate by one country may motivate other countries to devalue. Drazen called this theory "club formation" because the behavior of members and aspiring members alike is influenced by the benefits accruing to identification with and participation in the "club." In the theory, constraints on members arise from the degree of representation the club provides. If everybody wants to be a member of the club, the members, and especially those who want to join, are under a lot of pressure to accept the club's conditions for membership. If the club loses its "coolness," members will decide to drop out and, even worse, nonmembers will no longer want to join.

Drazen assumed that the central bank presidents in the ERM faced political pressures to maintain the fixed exchange rate. When all the central bank presidents were fighting to maintain their exchange rate pegs, it was in the best interest of every member to do so. Conversely, when no country was defending its currency, the other countries had no reason to protect their currencies. In other words, when countries abandon a fixed regime, the political cost of the next country abandoning it is reduced.

One of the most interesting implications of Drazen's model is that exchange rate crises may be bunched together because of a political process, not because something fundamental is driving the crisis (as in the trade theories). The economies may be entirely independent from the trade point

10See "Confident Cavallo Buys More Time for Argentina's Economy" by Thomas Catán at FT.com (Financial Times online, August 24 and 25, 2001). 
of view, but the decision to join or abandon the club pulls them in the same direction.

This theory can also be used to explain the adoption of policies in emerging markets in the 1990s. In Latin America, for example, countries commonly implemented coordinated policies. Trade openings, tax reforms, financial reforms, and the opening of capital accounts are examples. Drazen's model rationalizes this behavior: If a reform in one country is perceived as positive, then it is in the best interest of the rest of the countries to follow suit.

An alternative explanation is that policymakers learn from each other what the most effective policies are. But the learning process appears to be extraordinarily synchronized when all countries adopt reforms within two years of each other. In particular, I believe that an explanation based on peer pressure most easily accounts for the facts in the case of the synchronized policy changes occurring in Latin America in the 1990s.

These two studies of policy coordination (the ERM countries in 1992-1993 and Latin America in the early 1990s) highlight how rich the literature is from a theoretical standpoint. From an empirical point of view, however, testing any of the theories has been difficult. In practice, the comparison of policies among countries is complicated, so most of the applied papers compare macroeconomic performance rather than policies. Unfortunately, two countries can have similar macroeconomic results in terms of inflation, interest rates, currentaccount deficits, and growth but follow very different policies. So, the same performance on the part of two countries says little about the degree of coordination in their macroeconomic policies. Hence, not surprisingly, the empirical literature has found little support for "macro similarities." Of course, lack of support is not evidence against macroeconomic policy coordination.

Common shocks. The theories based on trade and macroeconomic policy coordination usually highlight the bilateral aspects of the relationships between countries. That is, the shock is generated in one of the countries under analysis and then spreads. In the "common shocks" theory, the shocks are exogenous to the countries under investigation.

The common shocks theory goes beyond the idea of aggregate, observable shocks. In the past 30 years, the world has seen several aggregate shocks-such as the oil price increases in the 1970s, the U.S. interest rate increases in the 1980s, and in the case of European countries, German reunification in the early 1990s - that could explain the comovement of asset prices. The transmission mechanism of these kinds of shocks could be either trade or macroeconomic policy coordination. What differentiates the common shocks literature from the previous two theories is the nature of the shock. 
For example, in the Corsetti et al. model, a drop in Country C's demand requires a fall in real wages in all the countries trading substitutable products with Country $\mathrm{C}$ (that is, it requires a real devaluation in Country A and Country B). The adjustment does not have to occur through exchange rate devaluation; it might happen through movements in domestic interest rates and stock market prices. The important implication is that Country A and Country B are reacting to the same shock and their prices tend to move together.

The early theories that studied common shocks assumed that the shock was observable. Recent research in this area, however, has highlighted different and more sophisticated mechanisms in which the shocks are not observable-liquidity shocks, changes in investor sentiments, and shifts in risk preferences. I will address several of these shocks in separate sections.

New theories have increased the complexity of the procedures to test for the existence and importance of this channel. The main inconvenience in such testing is that the presence of unobservable common shocks would invalidate most of the empirical procedures used to test and measure contagion.

Financial Links. After the crises in Asia, a new generation of theories emerged in which models of contagion are based on financial links. Basically, in this approach, shocks can be transmitted to economies that in principle are unrelated through two financial channels. One arises from banking regulation and the existence of a common lender, and the other is the result of moral hazard, such as implicit guarantees.

Common lender. The first research on the "common lender" theory was carried out by Kaminsky and Reinhart (1998). They argued that an important source of comovement is the existence of a common lender and the regulatory environment in which lenders operate.

Assume that a Japanese bank lends to the private sector in two other Asian countries. The bank is subjected to standard banking regulations. For simplicity, assume that the only regulatory requirement is that the market value of the bank's loans cannot fall below some minimum value of its capital.

Now assume that a major shock occurs in one of the countries that the bank lends to, which increases the nonperforming loans the bank holds and increases the default risk of the bank's private debt portfolio. The result is that the market value of the Japanese bank's lending portfolio falls. Hence, to comply with the banking regulations, the bank can either (1) increase its capital position or (2) sell some assets and use the proceeds to restore the market value of its loans-to-capital ratio.

If the bank chooses to increase its capital to satisfy the regulations, that is the end of the story: The potential shock is stopped in its tracks. If the bank decides to sell assets (loans), however, the question is which loans to sell. 
Selling the loans that belong to the country in crisis would create an even larger capital loss for the bank because it is unlikely that the loans could be sold to the domestic banking sector at fair market value. So, the bank decides to sell, or call back, the outstanding loans in the country that has not experienced a shock. The outcome of this choice is equivalent to a capital outflow in the second country and requires a policy adjustment if equilibrium is to be restored. That adjustment is usually a currency devaluation on the part of the second country.

So, a shock from the banking sector in one country can be transmitted to another country, even though the two countries' fundamentals are unrelated, because a third country's regulatory environment requires a portfolio recomposition. Eventually, the capital outflow from the noncrisis country causes all the asset classes in that country to suffer a liquidity shock, which in the short run is passed to other countries in the region, causing their stock markets also to fall in value.

Although Kaminsky and Reinhart developed this model for the Asian Flu, its applicability goes beyond regional financial collapses. The regulatory implications of their model in other circumstances have yet to be explored.

Moral hazard. ${ }^{11}$ A second group of theories grounded in financial links is based on the moral hazard that can affect financial markets. The common lender theory assumes that domestic and foreign banks are not subject to moral hazard. But some observers have claimed that implicit guarantees by governments induced overborrowing in the financial sector that caused the Asian collapses of 1997.

The first proponents of the moral hazard theory were McKinnon and Pill (1996, 1998). 12 They assumed that the existence of implicit bailout guarantees to depositors provides the wrong incentives to domestic bank managers. Because bank owners bear only a fraction of the cost of mismanagement, they have incentives to take excessive risk. Either they borrow beyond their repayment capacity, or they take too much credit and currency risk. This theory explains the size of the losses in GNP observed in Asia; it has not been extended to account for the contagion of the collapses.

The following example illustrates the moral hazard that deposit guarantees create. Assume a bank is choosing between two projects-one risky and the other riskless. Both require an investment of 100 (in some currency).

11Moral hazard is the risk that a party to a transaction has not entered into a contract in good faith, has provided misleading information about its assets, liabilities, or credit capacity, or has an incentive to take unusual risks in a desperate attempt to earn a profit before the contract settles.

12See Krugman (1998) for a simplified version of McKinnon and Pill's model. 
There are two possible states of the world. In the "good" state, the risky project has an expected return of 130; in the "bad" state, the expected return is 50. The probability of each state of the world is 0.50 . The riskless return always produces 110 .

Returns are summarized in Table 11. Note that the average expected return of the first project is 90 , whereas the return of the second project is 110 in good times or bad. I deliberately chose the returns in such a way that Project 1 is an extremely bad idea; on average, it produces a loss on the investment. Therefore, even a risk-neutral agent should choose the riskless project.

\section{Table 11. Project Expected Returns}

\begin{tabular}{lcc}
\hline Project & Good & Bad \\
\hline 1 (risky) & 130 & 50 \\
2 (riskless) & 110 & 110 \\
\hline
\end{tabular}

Now assume that deposit insurance exists, so if the bad state is realized and the value of the assets in the bank become smaller than the bank's capital, the government provides the extra cash to calm depositors. In other words, profits go to the bank manager and costs are borne by the taxpayers. With the deposit insurance, the manager faces the project returns in Table $\mathbf{1 2}$.

\section{Table 12. Project Expected Returns with Insurance}

\begin{tabular}{lcl}
\hline Project & Good & Bad \\
\hline 1 (risky) & 130 & 100 \\
2 (riskless) & 110 & 110 \\
\hline
\end{tabular}

In this scenario, for the manager, the expected average return of the risky project is 115 , as opposed to 110 for the riskless project. Therefore, the manager will invest in the risky project-with negative social net present value. 13

Basis of the links. In conclusion, both of the theories based on financial links (common lender and moral hazard) emphasize a deficiency in bank regulations. In the first case, the lack of sensitivity of the regulation toward

13Social net present value is the NPV of the project's net benefits to society discounted at a rate that reflects the riskiness of the expected future net benefits. 
the business cycle creates the comovement in asset prices. In the second case, the abuse by managers of implicit guarantees crafts the conditions for an exchange rate crisis. This line of research has heavily influenced the way we think about the international financial architecture.

Investor Behavior. The theories of contagion based on multiple equilibriums, herding, and pure learning highlight propagations that occur through investors' expectations and behavior. In this literature, the "real" channels, such as trade or common lenders, are not required to explain the comovement of asset prices among countries.

Multiple equilibriums. After the Asian Flu occurred, theories based on multiple equilibriums gained strong support in explaining both the collapses and the clustering of the collapses. These theories acknowledge that a shock in one country can hit other economies through "real" channels-trade, monetary policy coordination, or financial links. However, the theorists note that the Asian countries had little in common along these dimensions. The theories based on multiple equilibriums offer an alternative and viable explanation of the events observed.

From the theoretical point of view, the theories of contagion based on multiple equilibriums were the first to look seriously at the behavior of investors as the engine of propagation. The best example of this literature is Masson.

The basic intuition underpinning the research is as follows. Assume that in each economy, two equilibriums exist. In the good equilibrium, investment is high, economic activity is strong, interest rates are low, and asset prices are elevated. In the bad equilibrium, investment is low, economic activity is weak, interest rates are high, and asset prices are depressed. Additionally, assume that the conditions in the country are such that investors' beliefs determine which equilibrium the economy operates in. On the one hand, if investors believe that the economy will be in the good equilibrium, they provide capital inflow (or financing) and, because financing is cheap and there are no liquidity problems, a high level of economic output and low interest rates result. On the other hand, if investors think the economy will be in the bad state, they pull their resources out of the country and the demand for investment collapses. This fall in investment lowers overall economic demand, economic output, and asset prices, thus producing (in a self-fulfilling manner) the bad equilibrium.

In this model, if investors use the crisis in one country as a signal that they should shift their thinking to expect the bad equilibrium in another country, the crises occur almost at the same time, even though the economies may be completely unrelated. The propagation occurs because a crisis in one country 
colors investor expectations for another economy; investors then behave so as to shift the other economy from a good to a bad equilibrium, which causes further collapses. 14

The beauty of the multiple equilibriums theory as an explanation of the propagation mechanism is that it explains both the collapses and their bunching together. Moreover, the theory allows countries to be independent and still share crises.

A critique of Masson's argument is that his model depends on very particular assumptions of how investors anticipate equilibriums. Mullainathan (1998) provided a solution to this dilemma. He argued that investors imperfectly recall past events, and therefore, a crisis in one country triggers a memory of past crises. The memory causes investors to recompute their prior assumptions (about such variables as debt default) and assign a higher probability to a bad state. The resulting downward comovement in prices occurs because memories (instead of fundamentals) are correlated.

Finally, the theories involving multiple equilibriums can explain why speculative attacks occur in economies that appear to be fundamentally sound. This point has been raised by, among others, Radelet and Sachs (1998a, 1998b) and Sachs et al. In their research, the shift from the good to the bad equilibrium resulting from a change in investor expectations synchronizes the fall in asset prices in several countries, creating the excess comovement.

Herding. The contagion theories based on investor herding are similar to those in the next subsection based on pure learning. Both theories assume that investors have informational problems in making a decision. The herding theory, however, posits that investors coordinate their behavior, which results in the wrong outcome, whereas the learning theory does not make this assumption.

In the international macroeconomic context, the best examples of herding theory that relate to exchange rate crises are Chari and Kehoe (1999) and Calvo and Mendoza.15 These models share two main characteristics. First, individuals have private information about the prospects of investment. Second, they observe the actions of others but not their information.

A simple example (based on Banerjee 1992) can illustrate how the herding problem arises: Assume that several individuals decide to have lunch in a new restaurant. Two opinions on the quality of the food are possible-a good

14In his influential paper, Masson argued that only the multiple equilibriums aspect of the propagation constitutes contagion. One could argue that this definition is close to the definition of shift contagion.

15The original theoretical papers are by Banerjee (1992) and Bikhchandani, Hirshleifer, and Welch (1992). 
review and a bad review. Moreover, the average review is an unbiased indicator of the quality of the restaurant. In other words, if the restaurant receives more good than bad reviews, the food is good, and vice versa.

If all reviews are released and summarized in one single statistic, such as the net number of good reviews, then depending on that net number, an individual will go or not go to the restaurant to eat. Furthermore, this outcome is an efficient allocation, in the sense that no food will be eaten if it is of bad quality.

Now, assume that each individual reads only one review and it is the only information available to that individual. If the review is good, the individual will eat at the restaurant; otherwise, the individual will not eat there.

Assume that the individuals are standing quietly in line waiting to enter and eat at the new restaurant and they can observe the decision every individual before them makes. Hence, they know what each of the previous individuals did-decide to eat or not. Moreover, each good review cancels a bad one, and to make things simple, assume that if the individual has the same number of good and bad signals, the individual will choose to eat.16 A couple of example observations will highlight the problems with the information aggregation.

First, the reviews that each individual in the line reads are in the following sequence:

B, G, G, G, G, G, G,

which means that the first individual read a bad review and the rest read good reviews. Obviously, the quality of the food is good, and everybody should eat there.

But what if the information is not released instantaneously? What happens in the following scenario?

- The first individual sees the B and thus gets a bad signal from the review and decides not to eat.

- The second individual sees the first individual decide not to eat, so he knows that she got a bad signal. But he also has a good signal. Thus, under our assumptions, he has the same number of good and bad signals and decides to eat.

- The third individual must solve the following problem: She knows the first one got a bad signal because that individual left. Additionally, she knows that the second individual must have had a good signal; otherwise, he

16This is an assumption that allows us to solve the learning problem easily. It is fudging the algebra required to formally find a solution, but the intuition remains the same if this assumption is relaxed. 
would have left. Thus, when she makes her decision, she knows there are two good reviews and one bad review. Thus, she eats.

If we repeat this iteration for all individuals in the line, we can easily confirm that, except for the first individual, all of them eat. In this example, most of the individuals decide in favor of the efficient allocation.

Now explore the case in which the individuals produce the wrong outcome. Assume the reviews are in the following sequence:

G, B, B, B, B, B, B.

In this case, the quality of the food is bad. Hence, individuals should not eat. But the guidelines in the learning problem result in every individual choosing to eat at the restaurant:

- The first individual got a good signal so, given our assumptions, decides to eat.

- The second individual sees that the first individual decided to eat, so although he also got a bad review from the first individual, the good one and the bad one cancel each other, and this individual eats.

- The third individual has the following problem: She knows for sure that the first individual, because she ate, got a good signal. She has no way to know what signal the second one got because the second individual would eat regardless of his signal-a good signal (two goods) and he eats, a bad signal (canceling reviews) and he also eats. Thus, the eating of the second individual provides no information to any of the individuals left in line. This third individual knows that the first one read a good review, has no information from the actions of the second individual, and has the review she has read, which is bad. Under the assumptions, however, her bad signal and the first individual's good signal cancel each other. So, she decides to eat too!

- Now, the fourth individual sees all three prior individuals eating and solves a similar problem. The fact that the second individual and the third individual are eating provides no information on the signals they received; therefore, the fourth individual and all who come after him eat at the bad restaurant.

As can be seen, individuals can make the wrong choices because the actions they see do not fully reveal the private information of other individuals. This problem can place the sphere of activity in the wrong equilibrium.

In this example, the "fudge" assumption that individuals eat when the observed action contradicts private information is not creating the problem. The same bad outcome can be found if the model is extended to deal with the assumption that the individual does not eat when she/he gets corroborating 
signals. If the first two individuals get a good signal and the rest read bad reviews, still, everybody eats.

Banerjee's model has been criticized on several grounds. First, the assumption that investors decide in sequence is not realistic in international markets, and second, the assumption that their actions would be discrete is unlikely when the issue is portfolio flows. The model was extended, however, by Chari and Kehoe with most of the assumptions relaxed. The general conclusion holds under relatively general conditions.

These models of herding have been used to explain the recent financial crises. Indeed, this characteristic explains several aspects of the Asian Flufor example, the massive capital outflows in the region, the aggressiveness that characterized the speculative attacks, and the near impossibility of predicting which countries were next in line. One of the most important implications of these models is that the aggregation problem creates the possibility that investors will attack a currency even though this action might not be optimal had all the pertinent information been revealed. Such a result is clearly an inefficiency; if it is true, countries would be better off coordinating the release of information.

Pure learning. The theories of contagion based on investor learning assume that a shock in one market can change the valuation of other markets because investors eventually learn about macro variables relevant to investment decision making in both countries. These theories were developed primarily to explain the Russian crisis, but they can be applied to other instances of contagion.

In the period leading up to the Russian Cold following the Mexican and Asian crises, the international community had been heavily criticized because their policies implied a full bailout of governments and investors in the event of a financial or market crisis. Even though the IMF was heavily attacked on these grounds, there was no indication that the IMF heeded the criticism. Indeed, prior to the Russian crisis, the IMF provided a rescue package of almost US\$40 billion to the Russian government.

Regardless of the criticism, the IMF had no option other than to bail Russia out. Russia was emerging from a massive restructuring of its economy; it was changing its political, social, and economic institutions to be closer to those of the West. How could the international community say no to Russia when it needed help? From the point of view of political economy, 17 not supporting Russia would have been a major mistake.

17Political economy is the study of the natural laws governing the production and distribution of wealth and referring to the "economy" of a community or nation-state-in contrast to the "economy" of an individual or a household. 
In the end, as several observers correctly predicted, the Russian economy collapsed. The country defaulted on its debt, and the currency was heavily devalued. So, what, if anything, can be learned from the Russian Cold about the spread of contagion? Specifically, can anything be learned about the spread of the Russian Cold to Brazil?

The Russian crisis made evident that there is a limit to how much an economy-even one with tremendous political importance-can be bailed out. Investors learned that the extent of the implied bailout by the international community for nations in crisis was not as generous as they had thought. Hence, the market's valuations of other countries once propped up by the implied bailout suffered a correction, and the countries with the weakest fiscal accounts-Brazil, Ecuador, and Venezuela-experienced the largest declines, as should have been expected.

Kodres and Pritsker (2001) and Rigobon (1998) formalized this intuition. They argued that investors apply the lessons learned in one country to other countries with similar macroeconomic structures and policies. This argument has been extended along several dimensions-the adoption of similar macroeconomic policies, comparable financial regulations, the implementation of structural reforms that are alike in principle, and so on. The general idea of the extensions is that countries that are in the process of economic and market development are essentially small "black boxes" about which investors have to make asset allocation decisions based on imperfect information. The rational decision in such an environment is to use the performance of one country to evaluate and reevaluate others, which is why asset prices are correlated.

Liquidity Links. Finally, theories based on liquidity links have received plenty of attention since 1999. Since the Russian Cold, contagion based on liquidity links has become one of the most influential theories in the literature. This group of theories can be divided into two strains-one strain in which margin calls are the source of the liquidity shocks and another strain in which wealth shocks are the source of the liquidity shocks.

Margin calls. The best example of the theory of margin calls as the source of contagion is Calvo (1999). He developed a model based on asymmetric information in which shocks in one country create margin calls, with the result that market participants are forced to sell other assets. 18 The following example summarizes the intuition behind the theory.

Assume that there are two countries, Country R and Country S, and three types of agents:

18Calvo's 1999 paper did not fully solve certain problems with the model, but it provided most of the intuition as to how it works. See Yuan (2000) for a formal solution. 
- domestic agents in Country $\mathrm{R}$ that trade only Country $\mathrm{R}$ debt and are uninformed,

- domestic agents in Country S that trade only Country S debt and are uninformed, and

- an international agent (a hedge fund), $\mathrm{H}$, that trades in both markets and has private information about the value of the debt of each country.

Hedge Fund $\mathrm{H}$ is subject to margin calls; therefore, it could be constrained if asset prices fall so that its cash reserves are insufficient to cover the margin call.

What happens if Hedge Fund H suddenly becomes a net seller? First, consider each market separately. Consider Country S: Agents in Country S know that the hedge fund has private information about the value of the debt in Country S. Assume that we start at a point at which no trading is taking place and, then, Hedge Fund $\mathrm{H}$ is suddenly a net seller. What should agents in Country S infer?

The hedge fund could be selling because it had a wealth shock and is thus reducing its positions in all assets. If so, its selling should have no price impact. Probably, however, the hedge fund received information that the price of the debt in Country $\mathrm{S}$ is too high, so it is selling to realize its profits. Because agents in Country S do not know the reason behind Hedge Fund H's action, they assign some probability that it is the result of private information. Hence, upon the net selling by the hedge fund, the price of the debt in Country S drops. If the uninformed agents have an indication that the hedge fund is selling because of liquidity reasons, the price drop will be small, but if the uninformed agents participate in a market where private information is extensive, the agents will assign a high probability to private information and the hedge fund's action will have a large impact on prices. This intuition is consistent with the findings of Kyle (1989).

Now, extend the model to reproduce Calvo's intuition: Assume the same two countries and assume that Country R receives a negative shock. The drop in Country R's debt produces some losses to Hedge Fund H. In general, the effect is a margin call, and the hedge fund is forced to provide cash. Assume the hedge fund sells the debt of Country $\mathrm{S}$ to generate liquidity. Because agents do not know the reasons behind Fund H's decision to sell, the price of Country S's debt falls.

The intuition in the example is simple, but the assumptions are unrealistic. The story seems plausible, but it fails to account for several aspects observable in the recent crises. First, it assumes that agents from Country S do not observe the crash in Country R. Otherwise, the price sensitivity to the net selling of the hedge fund would be small, not large. In other words, if agents 
in Country $\mathrm{S}$ assign a high probability that the hedge fund is selling because it has liquidity problems, not because it has advantageous information, the price fall will be smaller than if the shock to Country R had not occurred.

Yuan (2000) formally solved this problem. Her results indicate that if uninformed agents know the hedge fund is under liquidity constraints, the reaction of prices to the net sell-off will be small. If agents are uncertain about whether the hedge fund is liquidity constrained, price elasticity could be larger. In other words, Yuan assumed that the margin call is unobservable. Again, this assumption is not realistic in the case of the Russian Cold or the meltdown of LTCM.

Wealth effects. A second strain in the literature on liquidity mechanisms concentrates on exogenous liquidity shocks that have been called "wealth effects." Whereas in Calvo's model the source of the liquidity shock is the drop in the price of one of the assets, Valdés (1997) developed a model in which investors are subject to exogenous liquidity shocks that could be interpreted as pure wealth shocks. This model is similar to the margin call model, but the assumptions about the distribution of information are much closer to what occurs in the financial markets. The wealth shocks are, in general, less likely to be observable than the events that set off a margin call.

In terms of the previous example, the Valdés model works as follows: Assume that Hedge Fund $\mathrm{H}$ receives a shock that creates a need to liquidate some of its wealth. Thus, it reduces its holdings in the (segmented) markets of Country R and Country S. Agents in Country R and Country S observe the hedge fund being a net seller in both markets but have no information as to why. Thus, they have to infer the probability that it is acting (1) on the basis of liquidity issues or (2) on the basis of information. So, they assign some probability to the price of the debt in both countries being too high (because the hedge fund is a net seller), and as a result, the hedge fund is arbitraging. The result is a drop in the prices of debt in both countries.

In the Valdés model, the liquidity shock causes investors to reallocate their portfolio and sell assets in all markets. The reasons for selling are either to satisfy margin calls or to meet regulatory requirements. The transmission mechanism for the liquidity shock is the need to rebalance portfolios, not private information. Thus, the mechanism is similar to the Kodres-Pritsker propagation mechanism. 


\section{Empirical Evidence}

After analyzing the generally accepted facts, definitions, and theories about contagion in the literature, we are ready to tackle the empirical evidence to answer the difficult questions: Does contagion exist? In which form(s) does it exist-shift contagion, pure contagion, or both? How much is explained by each of the theories?

The empirical literature on contagion is large and almost impossible to summarize in a reasonable number of pages. Very different methodologies have been used to answer these questions, and the conclusions of the different methodologies rarely coincide. In fact, few of the unanswered questions have received an adequate resolution.

The empirical literature was developed in two distinct phases. In the first phase, the aim was to determine from the data whether or not contagion existed. The research in these papers on the early evidence of contagion used an intuitive procedure to test for contagion. Today, researchers consider most of the econometric techniques in the early papers to have been inappropriate. Nevertheless, these papers generated the questions and highlighted the puzzles that motivated further research in this area.

The second phase of the literature started with a series of papers that criticized the empirical methods of the early literature. These devastating critiques showed that under plausible and general conditions, the conclusions could be reversed. This literature went on to provide new procedures and conclusions regarding the questions of contagion. As I summarize these results, the reader will clearly see that the literature is still in its infancy-and that more questions have been raised than answers given.

\section{Early Evidence}

The early evidence on contagion can be divided into studies that examined shifts in correlations and studies that examined the propagation channelshow and why shocks are transmitted among countries.

The most influential result in the early literature is without a doubt the research of King and Wadhwani (1990). King and Wadhwani defined contagion as a significant change in the correlation between two markets (which coincides with the definition of shift contagion used in this monograph). The implied assumption is that if the correlation increases, the relationship between the markets is stronger. King and Wadhwani found a change in the 
correlation coefficients between developed markets after the U.S. 1987 stock market crash. Such a finding of increased correlations is very robust in the global equity return data. In fact, whenever a crisis occurs, correlations almost always increase, and increases in correlation coefficients during and after recent international crises have been repeatedly found in different markets and asset prices. This regularity requires an explanation if it is not going to be considered contagion.

The second group of papers examines the channels in crisis propagation by examining concurrent realizations of extreme events as support for contagion. The most significant contribution in this literature and the first attempt to understand the channels of contagion is that of Eichengreen, Rose, and Wyplosz (1996). They computed the likelihood of a country facing speculative pressure on its currency conditional on other countries having suffered such pressure. The definition of contagion in this case is closer to the "pure contagion" term used in this monograph. Eichengreen et al. found that trade explains a sizable portion of the propagation whereas macroeconomic similarities explain little.

The remainder of this section considers these two approaches to contagion in more detail.

Correlations in Stock Markets. To test for shifts in correlations, I replicated the King and Wadhwani study but used the recent financial crises in Mexico, Asia, Russia, Brazil, and the Nasdaq. To save space, I report only the correlations between the country in crisis and the Latin American countries in the sample; however, I obtained similar results for the broader set of countries. ${ }^{1}$ In the construction of the tables reporting results, the "tranquil" period corresponds to the three months prior to the devaluation and the crisis period is (except for the Russian Cold) the 20 business days following the devaluation. The whole period is January 1990 through December 2000.

Tequila Effect. Panel A of Table 13 shows the correlations of the Mexican stock market with the markets of Argentina, Brazil, Chile, and Venezuela for three sample periods-the tranquil period prior to the Mexican crisis of December 1994, the 20 days of the crisis (after December 19), and the whole period. The correlation coefficients between each of the four countries and Mexico increased between the tranquil and crisis periods. Even the change in the correlation coefficient for Argentina, which experienced the smallest increase, is statistically significant. Forbes and Rigobon (forthcoming 2002) computed such tests for 37 stock markets. They showed that in more

\footnotetext{
1 Results for the full sample are available on request.
} 
Table 13. Correlations: Latin America

\begin{tabular}{|c|c|c|c|}
\hline Country & Tranquil & Crisis & Whole \\
\hline \multicolumn{4}{|c|}{ A. During the Tequila Effect: With Mexico } \\
\hline Argentina & 0.4290 & 0.5830 & 0.5030 \\
\hline Brazil & 0.0840 & 0.5890 & 0.4760 \\
\hline Chile & 0.3330 & 0.4970 & 0.4230 \\
\hline Venezuela & 0.1210 & 0.3450 & 0.1390 \\
\hline \multicolumn{4}{|c|}{ B. During the Asian Flu: With Hong Kong } \\
\hline Argentina & 0.1694 & 0.1759 & 0.1738 \\
\hline Brazil & 0.1132 & 0.2655 & 0.2047 \\
\hline Chile & 0.1487 & 0.6408 & 0.3935 \\
\hline Mexico & 0.2922 & 0.5612 & 0.4425 \\
\hline Venezuela & 0.0624 & 0.3831 & 0.2346 \\
\hline \multicolumn{4}{|c|}{ C. During the Russian Cold: With Russia } \\
\hline Argentina & 0.0774 & 0.3825 & 0.1792 \\
\hline Brazil & 0.0133 & 0.4479 & 0.2464 \\
\hline Chile & 0.0596 & 0.4872 & 0.2664 \\
\hline Mexico & 0.1125 & 0.3712 & 0.0206 \\
\hline Venezuela & 0.1536 & 0.2842 & 0.1974 \\
\hline \multicolumn{4}{|c|}{ D. During the Brazilian Sneeze: With Brazil } \\
\hline Argentina & 0.7700 & 0.6784 & 0.7200 \\
\hline Chile & 0.5838 & 0.4707 & 0.5333 \\
\hline Mexico & 0.6922 & 0.6469 & 0.6547 \\
\hline Venezuela & 0.2685 & 0.1945 & 0.2355 \\
\hline \multicolumn{4}{|c|}{ E. During the Nasdaq Rash: With United States (represented by S\&P 500} \\
\hline Argentina & 0.2892 & 0.7095 & 0.4197 \\
\hline Brazil & 0.5413 & 0.7427 & 0.6063 \\
\hline Chile & 0.4242 & 0.5027 & 0.4432 \\
\hline Mexico & 0.5793 & 0.7659 & 0.6490 \\
\hline Venezuela & 0.0416 & 0.0496 & 0.0423 \\
\hline
\end{tabular}

than half of the pairs, it is possible to reject the hypothesis that the correlation was stable during the Tequila Effect.

Asian Flu. Panel B of Table 13 reports results of the same exercise for the Asian Flu set off by the Hong Kong currency crisis of late 1997. Note that, again, correlations jumped during the crisis period. Chile's and Venezuela's correlations with Hong Kong increased more than four times, and Mexico's correlation coefficient almost doubled. Moreover, if Mexico is excluded, the typical correlation between Hong Kong and the Latin American countries in the tranquil period was about 10 percent, which is close to what we would have 
guessed it to be, given our prior knowledge of the relationships between Hong Kong and these countries. ${ }^{2}$ It increased to an average of 30 percent, however, during the Asian Flu.

Russian Cold. For the Russian crisis, the conclusions are similar. Panel $\mathrm{C}$ of Table 13 reports the correlations in the three periods between the Latin American countries in the sample and Russia during the Russian Cold of August 1998. For this particular case, I extended the crisis period to 40 business days; hence, the collapse of Long-Term Capital Management (LTCM) is included in the turmoil period. As can be seen, correlations prior to the crash are relatively low; the average correlation is on the order of 10 percent. When the Russian Cold appears, however, the average correlation jumps to almost 40 percent. Indeed, excluding Venezuela (whose correlation almost doubled), all the countries' correlation coefficients with Russia more than tripled.

- Brazilian Sneeze. The story is different for the Brazilian crisis at the beginning of 1999. Panel D of Table 13 indicates that the correlations during the turmoil period and the tranquil period are similar. In fact, some of the correlations went down. This evidence supports the lack of contagion during Brazil's devaluation of the real. Not only did the Brazilian Sneeze not have a major impact internationally, even its regional impact was small.

Nasdaq Rash. For the Nasdaq Rash that started in April 2000, reactions returned to the typical pattern of increasing correlations during times of turmoil. From Panel E of Table 13, we can see that correlations with the S\&P 500 Index during tranquil times were already relatively high for all the Latin American countries except Venezuela. In particular, the correlations with the United States for Brazil and for Mexico were more than 50 percent; for Chile, more than 40 percent. Nevertheless, the correlations increased during the crisis: Correlations of Argentina, Brazil, and Mexico with the broad U.S. market rose to more than 70 percent.

In summary, these tests based on the correlation coefficient produce the same result: During periods of turmoil, correlations tend to go up significantly. This regularity in crisis periods is in accordance with the conclusions of King and Wadhwani.

2 In my M.B.A. classes, I always start with a survey. I ask what the students think the correlation between Mexico and the United States is, and in general, they say something close to 40 percent. Next, I ask about the relationship between Mexico and Canada, Mexico and the rest of the Latin American countries, Mexico and Europe, and Mexico and the Asian countries. Invariably, my students have the right order of magnitude for these correlations-40, 20, 20, 15 , and 10 . I then proceed to show them that they are correct, but only during tranquil times. 
Extreme Events. The second approach to contagion in the empirical literature-the channels in crisis propagation-studies the concurrent realizations of extreme events (or "extreme realizations"). In the research reported here, I define extreme events as those in which large movements in stock market, exchange rates, or other macroeconomic variables in one country drive other countries to have similar large movements. The definition of "large" depends on the specific country being analyzed and is usually based on the standard deviation of the particular market returns or on a clear change in economic policy, such as a devaluation. In addition to determining whether contagion existed, the researchers in this strain of the literature have also been interested in finding the channel through which shocks are transmitted.

This research is more mathematically complex, in the sense that it involves estimating probit regressions instead of simple correlations. ${ }^{3} \mathrm{~A}$ technique is available, however, that replicates most of the results from probit regressions without the complexity. The technique is based on the conditional probabilities of large shocks. I use this technique in this section rather than replicating the probit estimations. 4

The idea in computing conditional probabilities is to study the likelihood that one country experiences a "large" shock, or enters into a crisis, given that another country has done so. By choosing the time intervals properly, we can draw some conclusions about the scope and size of the contagion. For example, Table 14 contains the conditional probabilities that countries in each of the regions experienced large movements for each of the recent crises. In the calculations for Panel A, a large movement was defined as a change in the stock market return larger than 1.5 standard deviations from the market return during the tranquil period. In other words, I computed the standard deviation for monthly returns prior to the crisis and for one month after the start date of the crisis and asked whether the drop in returns one month after the crisis was larger than 1.5 times that standard deviation. I compared the results country by country and computed the number of extreme events relative to the total countries in that region. The result could be interpreted as the probability of infection of a country in that region. 5

\footnotetext{
3 Probit analysis is a form of regression analysis appropriate for cases in which the dependent variable is dichotomous (e.g., the event either is or is not likely to occur). Probit coefficients are estimated by maximizing a likelihood function and are indicative of how a particular variable affects the probability of an event occurring.

4 Readers will find excellent treatments of the subject in Eichengreen et al. and Glick and Rose (1999).
}

5The process I describe is obviously an extremely simplified procedure. 
Table 14. Conditional Probability of Large Movements

\begin{tabular}{lcccc}
\hline Crisis & Latin America & Asia & OECD & Other \\
\hline A. Threshold 1.5 standard deviations & $60 \%$ & $33 \%$ & $5 \%$ & $0 \%$ \\
Tequila Effect & 100 & 44 & 29 & 100 \\
Asian Flu & 40 & 0 & 33 & 0 \\
Russian Cold & 20 & 33 & 10 & 0 \\
Brazilian Sneeze & 80 & 56 & 62 & 67 \\
Nasdaq Rash & & & & \\
B. Threshold 2.0 standard deviations & $11 \%$ & $0 \%$ & $0 \%$ \\
Tequila Effect & $20 \%$ & 44 & 14 & 0 \\
Asian Flu & 80 & 0 & 14 & 0 \\
Russian Cold & 0 & 22 & 0 & 33 \\
Brazilian Sneeze & 0 & 44 & 38 & \\
Nasdaq Rash & 80 & &
\end{tabular}

For example, during the Tequila Effect, were countries in Latin America more likely to have an extreme event than were the Asian countries? Comparing the conditional probabilities provides a partial answer. 6 Panel A of Table 14 indicates that the Tequila Effect corresponded to a large fall in stock market returns for 60 percent of the Latin American countries in the sample. The effect in Latin America was twice as large as it was for an Asian country and 12 times larger than it was for an Organization for Economic Cooperation and Development (OECD) country. Another way to interpret the conditional probabilities is that there was a 60 percent chance that a Latin American country was infected by the Tequila Effect and only a 33 percent chance that an Asian country was infected. These results clearly show the regional character of the Mexican peso crisis.

For the Asian Flu, note that not only countries in Asia but also countries in Latin America and "Other" countries (that is, Poland, Russia, South Africa, and Turkey) had large drops in their stock market returns. Almost half of the Asian countries received a large shock. Indeed, Panel A of Table 14 implies that contagion of the Asian Flu was stronger outside the region than inside. However, we should not interpret the data this way. The number of countries infected in Asia is large and the reported conditional probability is small for two reasons. First, this sample includes China, India, and Singapore, which

${ }^{6}$ In Table 14, all countries in the OECD were used for the calculations in that column; for the regions, I used only a few representative countries for the calculations. So, I am making an inference about the whole region by looking at this restricted sample. Nevertheless, the general message from a larger sample would be the same. Bae, Karolyi, and Stulz (2000) used a larger sample and a far more careful procedure than the one described here but found similar results. 
felt limited effects from the Hong Kong crisis (as shown in Table 3). Second, some countries in the sample were already in turmoil and had experienced market corrections before the Hong Kong crash. Thus, the number of countries in distress is underrepresented.

Confirming the international scope of the Asian Flu is the 30 percent chance that countries in the OECD had of being infected. In short, by looking only at the conditional probabilities in Panel A of Table 14, we could claim that (1) the Asian Flu was more virulent than the Tequila Effect, (2) its regional propagation was less important than that of the Mexican peso crisis, and (3) it affected countries everywhere whereas the Tequila Effect was mainly local.

In the case of the Russian Cold, keep in mind that no major events surrounded the Russian crash. The main reason is that the markets were already in turmoil before the precipitating event (the August 3, 1998, sovereign bond shock). The impact of the Russian Cold on the OECD markets, however, was larger than the impact of the Hong Kong crisis, which explains why the international community reacted to the Russian Cold and not to the Asian Flu.

As can be seen from the conditional probabilities of large events during the Brazilian Sneeze, the devaluation in Brazil had a limited impact on all the countries in the sample. This crisis has the lowest conditional probabilities of all the crises reported in Panel A of Table 14. Some contagion occurred in Asia and Latin America but not much. The only country affected in Latin America was Argentina (see Table 7). These results are consistent with the outcome of the empirical test of correlations for the Brazilian Sneeze.

Finally, the last row in Panel A presents the results for the Nasdaq Rash. Here, we can see the massive effect it had on all markets; almost 60 percent of the Asian and OECD countries experienced large negative shocks. (If the data for the first quarter of 2001 were included, these conditional probabilities would be even higher.)

Computing the conditional probabilities of large negative realizations paints a picture similar to that painted anecdotally and by the analysis of the stock market correlations: The Tequila Effect was mainly a Latin American event; countries in other regions were not heavily influenced by the Mexican devaluation. The Asian Flu produced international consequences; almost all the emerging markets were affected, but the OECD stock markets were only slightly affected. The Russian Cold had large effects in the OECD countries as well as in the emerging markets. The Brazilian Sneeze was almost undetected. Finally, the Nasdaq Rash degenerated into acute hives in all markets.

To make this analysis comprehensive and check the robustness of the findings, Panel B of Table 14 reports the conditional probabilities when the 
definition of a large event was changed from 1.5 to 2.0 standard deviations. The results are qualitatively the same as in Panel A.

Note that most of the literature has studied the contribution that trade and regional variables make in the spread of crises. Using the conditional probability as the dependent variable, a simple regression shows that trade (and other regional variables) explains $40-50$ percent of the transmission of shocks.

The conclusions drawn from the conditional probabilities are similar to those that could be obtained by estimating probit equations. In general, in studies using conditional probabilities, trade explains some (about one-third) of the propagation of these shocks. If the exchange rate mechanism (ERM) collapse and the debt crises of 1982 were included in the analysis, the regional/trade mechanisms of transmission would be even larger.

\section{Problems with the Early Evidence}

The procedures used in the early empirical literature on contagion had some limitations that could have produced misleading conclusions. Contagion was measured in the various studies by different empirical techniques-for example, correlation coefficients and conditional probabilities (replicated in the previous section), principal components, ordinary least squares (OLS), generalized autoregressive conditional heteroscedasticity $(\mathrm{GARCH})$, and probit procedures. The intent of all was to determine (1) whether contagion exists and (2) what is the channel of transmission. Each methodology has a limitation. Measuring correlation coefficients, principal components, and conditional probabilities in the presence of heteroscedasticity (residuals with changing values-e.g., volatility) produces untrustworthy results, and the problems of endogenous variables (variables caused by one or more variables in the model) or omitted variables make the other techniques (e.g., OLS, probit, GARCH) inappropriate. The only methodology that survives the problems in the data is co-integration, but if contagion is considered a short-term event, then co-integration (which examines long-term relationships) may not provide enough evidence of the importance of contagion.

Nature of the Problem. The data by which contagion is usually measured suffer from conditional and unconditional heteroscedasticity. In addition, important variables (such as risk preferences and liquidity shocks) are omitted. And almost by construction, international asset prices are endogenously determined. These three properties invalidate the econometric techniques discussed in the previous section.

Of course, the same critique could be applied to any area in macroeconomics and international economics. So, if we must throw out the conclusions 
in the contagion studies, should we not disregard all the conclusions that have been reached so far in economics? Well, no. It is true that every regression has issues of endogenous variables and omitted variables. Also, most daily data have heteroscedasticity problems. In most macroeconomic applications, however, the presence of these problems does not affect, at least not dramatically, the conclusions. But in several of the theories in the contagion literature, the variables that are omitted or included and the question of heteroscedasticity are the essence of the theory. Not taking them into consideration in the empirical implementation is forgetting part of the explanation.

For example, approximately 60 percent of the theoretical papers on contagion use an omitted variable, such as learning, liquidity, or investor sentiment, to explain the propagation of shocks. So, not taking into account such channels in the empirical implementation is unacceptable, especially when including them in the empirical specification changes the results.

In addition, contagion is associated with short-term movements and is usually measured by the use of daily data. Therefore, the fact that the data are characterized by strong conditional and unconditional heteroscedasticity must be taken into consideration. Most of the techniques used in macroeconomics and finance deal with the issue of heteroscedasticity, but most of the techniques that have been used in the contagion literature do not.

I discuss the problems with the early evidence by using a gamble on coin tosses to indicate why using correlation coefficients and conditional probabilities is wrong. A simple statistical model showing why the statistical procedures are generally not correct is provided in Appendix B. The material in Appendix B is far more technical than the rest of this monograph, but I advise readers who are interested in this topic to invest the time to understand the formal models presented there.

Coin-Toss Examples. Heteroscedasticity creates problems when the correlation coefficients or principal components are the methods of analysis. Let us start by defining exactly what heteroscedasticity is. Data suffer from heteroscedasticity when the volatility of the data is not constant (i.e., there are times of high variance, or volatility, and times of low variance). The two primary forms of heteroscedasticity are conditional and unconditional, but for the purpose of this section, the distinction is irrelevant. The objective is to show that correlations and conditional probabilities are biased in the presence of heteroscedasticity.

A coin-toss exercise provides a simple example: Assume we are interested in determining whether changes occur in cross-country transmission mechanisms in crises, and assume the country returns can be described by the 
following coin tosses. ${ }^{7}$ In the first of the two (related) games, you toss one coin. If it is heads, you win the coin; if it is tails, you lose the coin. The game can be played with either a penny or a special $\$ 100$ coin. In the second game, you also toss a coin and win with heads or lose with tails but the coin is always a quarter and the payoff of a toss depends on the outcome of the first game. For simplicity, assume that the second gamble always collects or pays 10 percent of the outcome of the first game plus the outcome of the second game.

So, if the first game is played with a penny, the possible payoffs (in cents) after both games have been played are given in Panel A of Table 15. When the first game is played with a $\$ 100$ coin instead of a penny, the possible payoffs (again in cents) are given in Panel B.

\section{Table 15. Second Game Payoffs}

\begin{tabular}{|c|c|c|c|c|}
\hline \multicolumn{5}{|c|}{ A. First toss of a penny } \\
\hline \multirow{2}{*}{ 2nd coin heads } & \multirow{2}{*}{+25} & 1 st coin heads & +0.1 & $=+25.1$ \\
\hline & & 1st coin tails & -0.1 & $=+24.9$ \\
\hline \multirow{2}{*}{ 2nd coin tails } & \multirow{2}{*}{-25} & 1st coin heads & +0.1 & $=-24.9$ \\
\hline & & 1st coin tails & -0.1 & $=-25.1$ \\
\hline \multicolumn{5}{|c|}{ B. First toss of $\$ 100$ coin } \\
\hline \multirow{2}{*}{ 2nd coin heads } & \multirow{2}{*}{+25} & 1st coin heads & $+1,000$ & $=+1,025$ \\
\hline & & 1st coin tails & $-1,000$ & $=-975$ \\
\hline \multirow{2}{*}{ 2nd coin tails } & \multirow{2}{*}{-25} & 1st coin heads & $+1,000$ & $=+975$ \\
\hline & & 1st coin tails & $-1,000$ & $=-1,025$ \\
\hline
\end{tabular}

Under the rules and with these setups, let us compute the correlations and conditional probabilities.

Correlation. On the one hand, when the first gamble is played with pennies, because the final payoff is equal to the outcome of the second game (25 cents) plus or minus 0.1 of a penny, the outcome of the first coin toss has a negligible impact on the payoff of the second toss. For example, if you were playing the second gamble, you could ask yourself the following question: If I know that the first gamble is being played with a penny, do I care about its outcome? Probably not.

Note that when the first game is played with a penny, the correlation between the two games is close to zero ( 0.4 percent to be exact) and the outcomes of the two games are almost independent.

7This example is an extension of the example in Forbes and Rigobon (2000). 
On the other hand, when the first gamble is played with the $\$ 100$ coin, the final payoff of the second game is equal to the 25 cents plus or minus $\$ 10$ (10 percent of \$100). In this case, the outcome of the second toss, instead of the first one, has a negligible effect on the payoff of the second gamble. The correlation between the two games is now almost 1 (97 percent), and the outcomes of the two games are clearly dependent on each other. In thinking about this exercise, when you are playing the second gamble and you know that the first gamble is played with $\$ 100$ coins, the question you would ask yourself is whether you care about the outcome of the second toss. Probably not.

The critical point of this exercise is that in both the 1 cent and the $\$ 100$ scenarios, the propagation of shocks from the first game to the second is always 10 percent. No shift occurs in the magnitude of transmission, yet the correlation coefficient increases from almost 0 in the 1 cent case to almost 1 in the $\$ 100$ scenario.

The main reason for this result is that correlation coefficients are not robust to changes in volatility. Technically speaking, the correlation is not an unbiased estimator. This property casts significant doubt on how correlations should be used to assess contagion. Crises are always accompanied by increases in volatility, and this exercise shows that correlations shift as volatility changes. How should we interpret the early evidence in light of this heteroscedasticity?

If we are in search of shift contagion, we are interested in changes in the strength of the transmission. For example, we would like to know whether the shocks during turmoil are propagated in excess of 10 percent. This example indicates that changes in correlation could be misleading as to change in propagation. Massive changes in the correlation could be explained by changes in the relative volatilities and have nothing to do with the coefficient.

If we are in search of pure contagion, we are interested in understanding the propagation channels, so we care about the size of the correlation coefficient. Suppose that 10 percent is a reasonable propagation of shocks given our prior knowledge. The problem is that if we assess the size of the transmission mechanism by looking at the correlation coefficient in this exercise, we have the wrong inference: The 0.4 percent is extremely low and the propagation is too weak, but the 97 percent is too high and the propagation is too strong. In this example, however, by construction, the relationship between the gambles coincides with our prior knowledge, 10 percent! The problem is that the correlation does not allow us to measure the transmission properly.

This coin example is directly applicable to measuring the transmission of shocks among countries. The first coin toss represents a country that is 
susceptible to a crisis. When the country is stable, volatility is low, which is the scenario when the first game is played with a penny. When the economy suffers a crisis, volatility increases, which is the scenario when the first game is played with the $\$ 100$ coin. The crisis actually occurs when the outcome of the $\$ 100$ coin is tails. The second toss represents another country (or the rest of the world); this round is always played with a quarter, but the payoff depends on the outcome in the first country.

Tests for contagion based on GARCH models are subject to the same bias because the variance-covariance matrixes central to the tests are directly comparable to correlation coefficients. In both types of tests, an inaccurate finding of contagion results from the heteroscedasticity in returns between the two different states (i.e., the two different coins for the first toss).

A number of researchers have criticized the use of correlation coefficients in the assessment of contagion. Ronn (1998) provided the original discussion of the problems of the correlation coefficients; Boyer, Gibson, and Loretan (1999) and Forbes and Rigobon (2000) offered critiques in the context of the contagion literature.

Extreme realizations. Although heteroscedasticity also biases tests for contagion that use probit models or conditional probabilities, the bias works through a slightly different mechanism. Conditional probability is commonly used in the contagion literature when the researcher is interested in answering questions intended to discover the concurrent realizations of extreme events:

- What is the probability that one country will devalue when another country has already devalued?

- What is the probability of a large (2 standard deviation) negative realization in Country B when Country A had a crash larger than 2 standard deviations?

- What is the probability that Country B will be subjected to a speculative attack if Country A has already been under attack?

- What is the probability of Country B increasing the interest rate if Country

A has already done so?

In all these questions, the answer is a conditional probability. A minor variant on the coin game will show that conclusions based on these probabilities can be misleading: Assume you are interested in determining when a gamble produces losses - that is, you want to know only whether the payoff from the game is positive (labeled 1) or negative (labeled 0). The first gamble is clear: Whenever you get tails, the outcome is negative. The second gamble, however, is conditional on the realization of the first one. Playing the first gamble with a penny produces the gains/losses for the second gamble shown 
in Panel A of Table 16. The second gamble produces losses, regardless of the outcome of the first gamble, only when you throw tails. Assuming the coin tosses are fair, each of the cells has a 25 percent chance of occurring.

\section{Table 16. Conditional Probabilities for Second Coin Toss}

\begin{tabular}{lcc}
\hline & \multicolumn{2}{c}{ First Toss } \\
\cline { 2 - 3 } & Heads & Tails \\
\hline A. Toss of a penny on first toss & 1 & 1 \\
Second toss heads & 0 & 0 \\
Second toss tails & & \\
B. Toss of $a$ \$100 coin on first toss & & 0 \\
Second toss heads & 1 & 0 \\
Second toss tails & 1 & \\
\hline
\end{tabular}

The unconditional probability that the second gamble will produce a loss is one half. The question is, then, what is the probability that the second gamble will have a negative realization if the first coin toss was heads. 8 To answer this question, we have to compute the conditional probability of the second gamble producing losses when the realization in the first gamble is heads; so, we focus on only the first column of Panel A in Table 16. We can see that the second gamble has a positive outcome if the second coin toss is heads and has a negative outcome if it is tails. Hence, the chances are driven exclusively by the second coin. The probability that the second gamble will have a negative realization given that the first toss was positive is 50 percent, which is the same as the unconditional probability. Therefore, the two gambles (in this dimension) are independent. The explanation is simple: When the first gamble is played with a penny, the outcome of the first gamble is not large enough to overturn the result of the second toss. Thus, the two gambles appear to be independent.

The conclusion changes if the first gamble is played with $\$ 100$ coins. In this case, the outcomes of the second gamble are as shown in Panel B of Table 16 . Note that now the second gamble produces a loss only if the first toss is tails. In other words, the probability of losing in the second gamble is 0 if the result of the first gamble is heads whereas it is 1 if the first toss was tails. In

8If the two probabilities are the same, the conclusion is that the first gamble and the second gamble are independent because conditioning on the first gamble had no effect on the outcome of the second one. 
this case, the two gambles are perfectly synchronized. Both either lose together or produce profits together. As in the case of the correlation coefficient, we have moved from gambles that appear to be independent to a pair that appears to be the same. The propagation of shocks, however, continues to be 10 percent.

In both examples (correlations and the concurrent realization of extreme events), heteroscedasticity increases the proportion of the common component, making the gambles move together.

The translation of these results into terms of exchange rate, interest rate, or stock market movements would state that in periods of low volatility, the countries look unrelated. But when one country experiences a large shock (devaluation, increase in interest rates, or fall in stock market prices), its volatility increases and the likelihood that the second country will suffer a large movement rises.

These examples based on coin tosses are clearly simplifications of the real-world transmission of shocks among countries. Moreover, the examples are extreme because the variance of outcomes increases by $10^{8}$ when the fictitious country moves from the stable to the volatile state (i.e., when we switch from a penny to a $\$ 100$ coin in the first gamble). Nevertheless, the point is undeniable: Tests for contagion based on using correlation coefficients or conditional probabilities are inaccurate because of the heteroscedasticity in the data.

\section{Adjustments and New Approaches}

The recent empirical literature on contagion has provided criticism of the old results and offered some new approaches. In this section, I first provide an analysis of the literature that has improved the tests based on the correlation coefficient. Then, I summarize the results of two new procedures intended to answer the questions as yet unanswered by the contagion literature.

Adjusting Correlation Coefficients. The early literature in finance defined contagion as a significant increase in the correlation between two countries. As the previous example showed, however, an increase in correlations may be explained by changes in volatility, not by a shift in the parameters. To illustrate this point, Figure $\mathbf{4}$ shows the rolling correlations between Mexico and four Latin American countries computed in rolling windows of 60 business days before, during, and after the Tequila Effect (December 1994). Additionally, the variance of the Mexican stock market in the same period is shown.

Notice that the changes in correlations occur almost at the same time the variance of Mexico is increasing, which coincides with the result of the coin- 
Figure 4. Variance for Mexico and Correlations between Mexico and Latin American Countries, August 24, 1994, through April 26, 1995

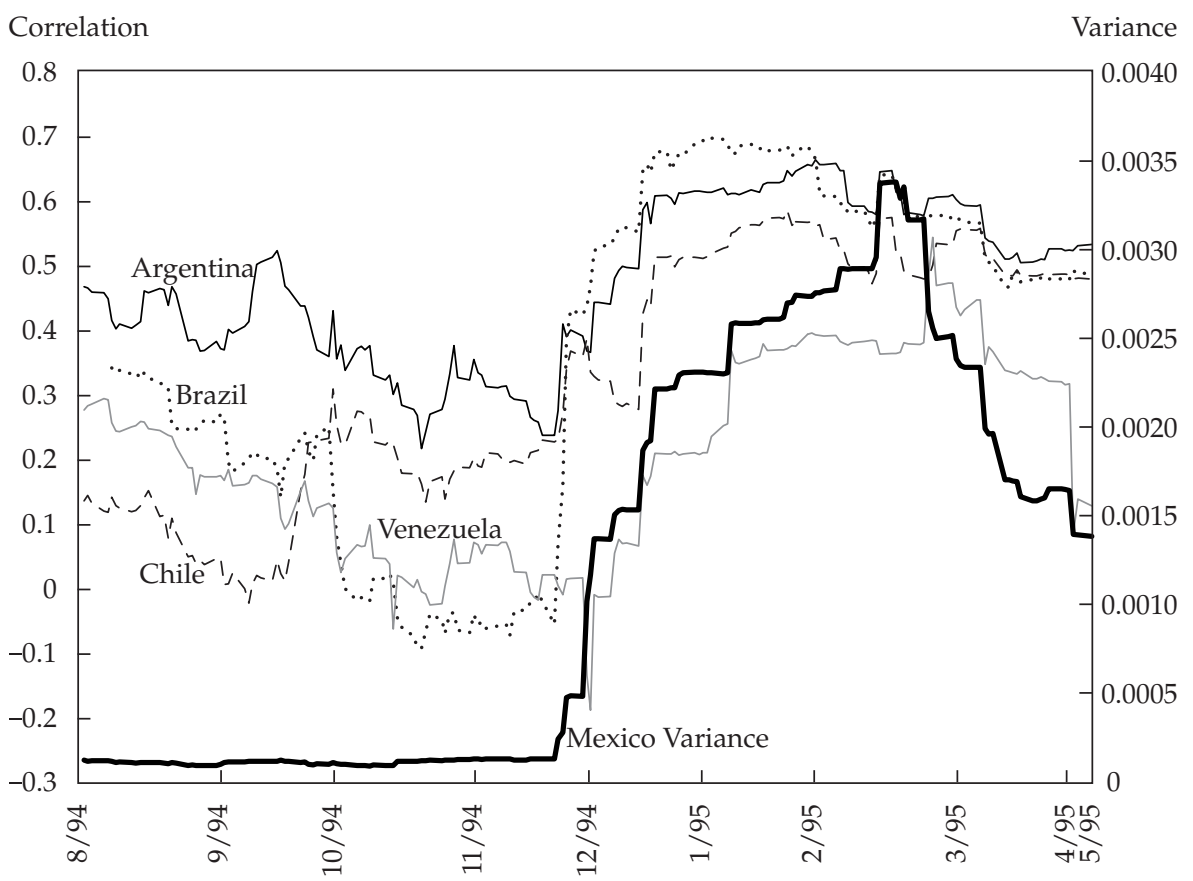

Note: Dates are end of month.

toss example. Ronn, Boyer et al., and Forbes and Rigobon (2000) offered an adjustment to solve the bias in the correlation coefficient induced by the change in variance. The adjustment can be derived from Equation B3 in Appendix B. ${ }^{9}$ Here, the purpose is to highlight how the adjustment works.

An increase in the variance of $x_{t}$ of $1+\delta$ implies that the correlation is

$$
\rho_{c}=\rho_{u} \sqrt{\frac{1+\delta}{1+\delta \rho_{u}^{2}}},
$$

where $\rho_{c}$ is the conditional correlation (the one measured in the sample) and $\rho_{u}$ is the unconditional correlation (the one that would have prevailed if the variance of $x_{t}$ had been constant).

9The derivation of the adjusted equation in the bivariate setting can be found in Ronn. For applications of these corrections, see also Baig and Goldfajn (2000), Gelos and Sahay (2000), and Favero and Giavazzi (2000). 
Hence, the procedure to adjust the correlation is simple. First, we measure the variance of Mexico for the whole sample period; this variance is the unconditional variance with which the conditional one is to be compared. For each window, we determine $\delta$ as the percentage change in the variance of Mexico in that window and the unconditional variance. In some periods, the conditional variance is larger than the unconditional variance; at other times, it is smaller. Thus, the correction implies that the correlation will rise or fall depending on the variance. Second, we compute the conditional correlation in each window. This correlation is the one that must be adjusted by the increase in the variance of $x_{t}$-that is, $\rho$ in Equation B3. Note that there is one correlation for each $\delta$. Finally, solving for $\rho_{u}$ in Equation B3 shows that the implied unconditional correlation is a function of the conditional correlation, $\rho_{c}$, and the increase in variance we have computed, $\delta$. Substituting, we find the adjusted correlation.

Figure 5 shows the variance for Mexico and the unadjusted and adjusted correlations between Mexico and Argentina before, during, and after the Mexican peso crisis. As can be seen, the adjusted correlation is less volatile than the unadjusted correlation. Indeed, in this case, the increase in the correlation during the Tequila Effect disappears. In other words, all the increase in the correlation was explained by the shift in volatility, not by an increase in the strength of the propagation. So, with the evidence so far given, these data provide no evidence of shift contagion.

Forbes and Rigobon (2000) showed that if the correlations are adjusted to take into account the shift in variances, the correlations remained relatively constant between different countries (37 countries) during the Tequila Effect and the Asian Flu. In summary, the leap from correlation to contagion should be taken cautiously.

Even Forbes and Rigobon (2000) indicated that adjusting correlations works to identify contagion only under very restrictive conditions. First, one has to know which country was creating the increase in the volatility. Second, there can be no issues of omitted variables or of simultaneous equations. Third, only bivariate comparisons can be made. These limitations to the approach are important; although the first one may not be a major issue, the second condition is unlikely to be satisfied in the data. These drawbacks have led to a search for alternatives.

New Procedures. In the previous subsection, I described adjustments that have been suggested to the correlation coefficient in the tests for contagion. In this subsection, I describe two new procedures to test for contagion. One is a test for shift contagion in the presence of heteroscedasticity, omitted 
Figure 5. Variance for Mexico and Adjusted and Unadjusted Correlations between Mexico and Argentina, August 24, 1994, through April 26, 1995

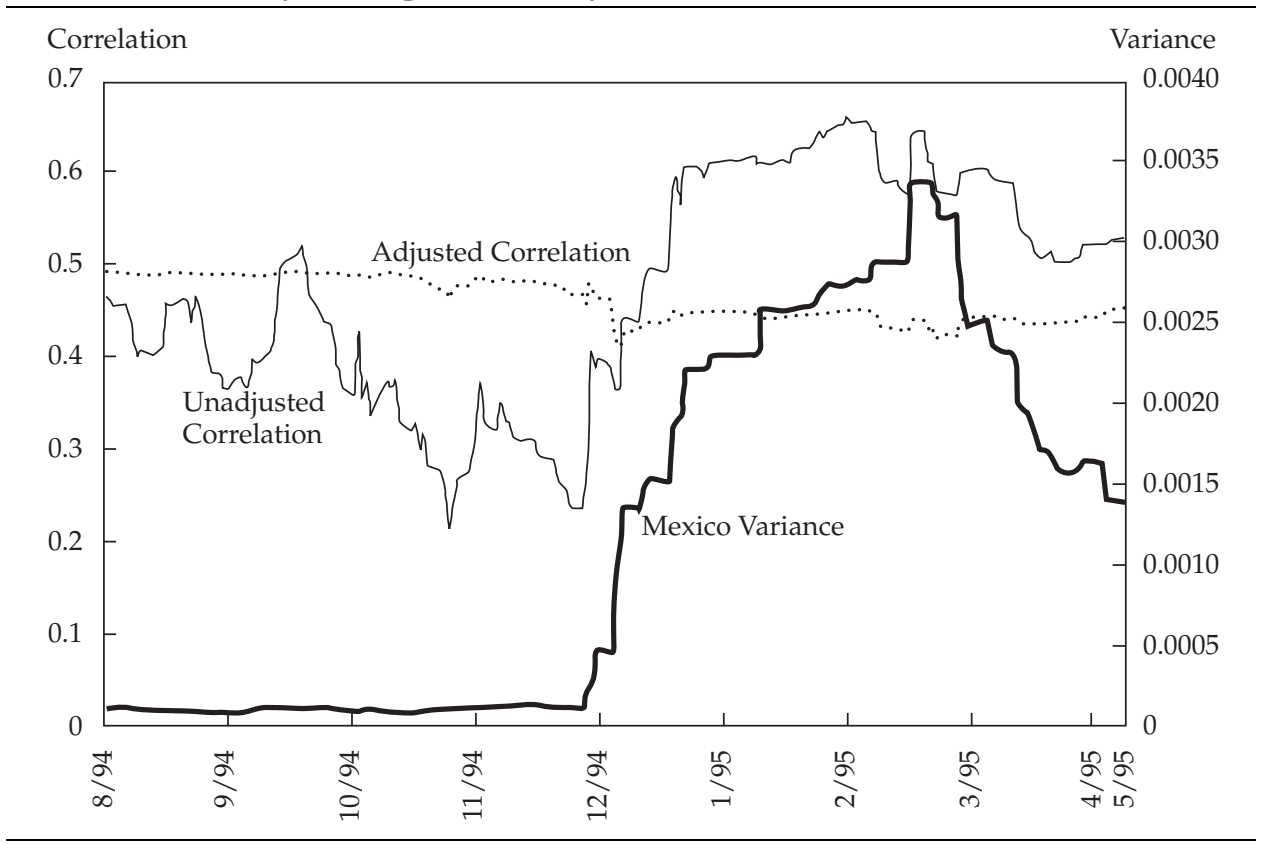

Note: Dates are end of month.

variables, and simultaneous equations. The other is an attempt to identify and estimate the coefficients in the simultaneous-equation problem.

Shift contagion. The first procedure, described in Rigobon (2000), is based on the assumptions that (1) the country generating the crisis is known and (2) the changes in the variances of the rest of the countries are explained, at least in the short run, by the variance in the country under crisis, not by other idiosyncratic shocks. In other words, the test requires that in the short run, the heteroscedasticity is explained by a subset of the idiosyncratic shocks.

Under this assumption, the test can determine whether the underlying parameters are stable. So, the test is a valid test for shift contagion. Keep in mind, however, the circumstances in which the test makes sense. For example, if the researcher does not have a clear idea of which country is generating the increase in volatility, interpretation of the results is impossible. Explaining the test is beyond the scope of this monograph, but the procedure is based on the fact that when we restrict the number of shocks that can 
experience heteroscedasticity, the covariance of the observed variables has a particular structure that can be tested. 10

Several papers have applied the methodology. Their findings may be summarized as follows:

- In stock markets, no change occurred in the transmission of shocks in any of the 1990s crises I have described. (The methodology has not been used, however, for the early crises- the debt crisis in 1982, the U.S. crash in 1987, and the collapse of the ERM.)

- In sovereign bond markets, the results are interesting. A change in the propagation of shocks occurred in two circumstances. The first was during the Tequila Effect in the month of January 1995, which coincided with the market's decision not to roll over the tesobonos (short-term debt instruments of Mexico repayable in pesos but indexed to the U.S. dollar). The second change occurred during the Russian Cold but in the latter days of the virus (around the end of August) when LTCM was being hit by margin calls. Interestingly, then, the two circumstances in which shift contagion has been found involved large liquidity shocks in segmented markets.

Pure contagion. The second procedure measures propagation mechanisms and tests for different channels of contagion. 11 The technique is based on how the structure of the covariance matrix of the observed variables changes with the heteroscedasticity of the unobservable shocks. The problem with this approach is that the covariance matrix provides only three equations (the variance of one country's stock market returns, the variance of the second country's stock market returns, and the covariance between these variances) but there are four unknowns-the ordinary links between the two countries in both directions, the variance of a stock market shock in one country, and the variance of a stock market shock in the second country. The literature has solved this problem by imposing additional parameter constraints:

- Exclusion restriction. This restriction amounts to mandating either that the link from the first country to the second be zero or that the link from the second to the first be zero. 12

10For the complete explanation, see Forbes and Rigobon (2000).

11The methodology is described in Rigobon (2002).

12This restriction has been used in several applications-notably, in measuring the transmission of monetary policy in the United States. The restriction, however, simply assumes the problem of simultaneous equations away; if any of the contemporaneous parameters is zero, there is no problem of endogenous bias and the estimation could have been done by OLS in the structural equations. The circumstances in which this assumption can be used are thus limited. 
- Sign restrictions. The imposition of the sign on the slopes of the structural equations allows one to achieve partial identification of contagion. Even though a unique estimate cannot be obtained, at least an admissible interval is derived (see Fisher 1976).

- Long-run constraints. When the structural form includes lagged dependent variables, the long-run behavior of a particular shock can be constrained. This constraint is equivalent to mandating that the sum of some lag coefficients be equal to zero. 13

- Constraints on the variances. An example would be that the ratio of the variance of the shocks to one country and the variance of stock returns in the presence of a shock to a second country must be equal to some constant.

These restrictions have proven to be very useful in several applications, but in some important economic problems, none of them can be rationalized.

The new methodology assumes that the data describe two regimes in the second moments (that is, the data exhibit heteroscedasticity). If parameters $\alpha$ and $\beta$ are stable throughout the two regimes, then one can easily show that $\alpha$ and $\beta$ can be recovered. Under these assumptions, one can estimate two reduced-form covariance matrixes, one for each regime, as follows: Denote the regimes as $s \in(1,2)$ and define the variances of the structural shocks in regime $s$ as $\sigma_{\varepsilon, s}$ and $\sigma_{\eta, s}$. Now, the covariance matrixes of the reduced form are

$$
\begin{aligned}
\Omega_{s} & \equiv\left(\begin{array}{cc}
\omega_{11, s} & \omega_{12, s} \\
\bullet & \omega_{22, s}
\end{array}\right) \\
& =\frac{1}{(1-\alpha \beta)^{2}}\left(\begin{array}{cc}
\beta^{2} \sigma_{\eta, s}^{2}+\sigma_{\varepsilon, s}^{2} & \beta \sigma_{\eta, s}^{2}+\alpha \sigma_{\varepsilon, s}^{2} \\
\bullet & \sigma_{\eta, s}^{2}+\alpha^{2} \sigma_{\varepsilon, s}^{2}
\end{array}\right), \text { with } s \in(1,2),
\end{aligned}
$$

where $\Omega_{s}$ indicates the covariance matrix of regime $s$. This new system of equations contains six unknowns- $\alpha, \beta, \sigma_{\eta, 1}^{2}, \sigma_{\varepsilon, 1}^{2}, \sigma_{\eta, 2}^{2}, \sigma_{\varepsilon, 2}^{2}$-where the two covariance matrixes provide six equations!

13 If one knows that one shock did not have permanent effects, then (under some conditions) one can make an identification. For example, assume that nominal shocks are short lived whereas real shocks are permanent. Imposing this constraint, Blanchard and Quah (1989) and Shapiro and Watson (1988) were able to estimate the effects of aggregate shocks on aggregate activity and unemployment. 
Two applications of this procedure are described in the literature. First, Rigobon (2001a) estimated the importance of trade in the propagation of shocks among 14 countries. The exact coefficients for the links between countries are in Table 17. Note that none of the coefficients in the U.S. equation are statistically significant and that this result was not imposed in the estimation procedure, even though prior knowledge would have suggested this result. The market movements in the United States, however, profoundly affect the market movements in some of the emerging markets.

In addition, the coefficients are relatively large, which explains the significant comovement that exists among international stock markets. In fact, these coefficients explain correlations of an average of 22 percent among all countries.

Also, in Table 17, 32 of the 182 coefficients are statistically different from zero. Among the Latin American countries, 13 estimates of 30 possible coefficients are significant. Similarly, among the Southeast Asian countries, 12 of 42 are significantly different from zero. Interestingly, only 3 of 84 coefficients across regions (excluding those from the United States) are statistically different from zero-the propagations from Chile to Korea, from Chile to Thailand, and from Korea to Mexico. This finding confirms quite strongly the common wisdom that the propagation of past shocks among countries was concentrated in geographical regions.

After obtaining these estimates, Rigobon (2001b) proceeded to estimate the importance of trade in explaining the comovement. He found that trade explained 40 percent of the variation of the coefficients but less than one-third of the total comovement of these markets. These results are preliminary; more definitely has to be done.

In a different paper, Rigobon (2001b), implemented the same procedure in an autoregressive conditional heteroscedasticity $(\mathrm{ARCH})$ framework and studied the comovement between Mexico and Argentina from 1999 to the end of 2001. The impetus for using this time period was that it covered an upgrade in the rating of Mexico's sovereign debt that could have had contagious liquidity effects.

On March 7, 2000, Moody's Investors Service upgraded Mexican debt to investment grade. 14 The anticipation of the upgrade and the announcement improved external conditions for Mexico: Average yields of sovereign debt, as well as its conditional volatility, dropped almost immediately. In principle, these improvements were not surprising. For example, Kaminsky and

14Standard \& Poor's upgraded Mexican debt on March 13, 2000, but not all the way to investment grade. 
Table 17. Point Estimates of the Contemporaneous Coefficients

\begin{tabular}{l|cccccccccccccc}
\hline & & & & Hong & & & & & \multicolumn{3}{c}{ South } \\
& Argentina & Brazil & Chile & Kong & Malaysia & Mexico & Peru & Philippines & Singapore & Korea & Taiwan & Thailand & United \\
States & Venezuela \\
\hline Argentina & - & 0.26 & 0.51 & 0.09 & 0.17 & 0.23 & 0.55 & 0.35 & 0.24 & 0.04 & 0.20 & 0.22 & 0.76 & 0.00 \\
Brazil & 0.51 & - & 0.60 & 0.33 & 0.00 & 0.29 & 0.69 & 0.09 & 0.44 & 0.08 & 0.00 & 0.12 & 0.61 & 0.04 \\
Chile & 0.24 & 0.08 & - & 0.26 & 0.13 & 0.01 & 0.28 & 0.23 & 0.00 & 0.05 & 0.36 & 0.20 & 0.64 & 0.00 \\
Hong Kong & 0.13 & 0.00 & 0.00 & - & 0.00 & 0.00 & 0.37 & 0.04 & 0.63 & 0.10 & 0.00 & 0.21 & 0.00 & 0.06 \\
Malaysia & 0.22 & 0.09 & 0.23 & 0.72 & - & 0.05 & 0.32 & 0.27 & 0.13 & 0.23 & 0.37 & 0.35 & 0.06 & 0.05 \\
Mexico & 0.35 & 0.17 & 0.72 & 0.31 & 0.23 & - & 0.14 & 0.22 & 0.53 & 0.16 & 0.08 & 0.24 & 0.55 & 0.00 \\
Peru & 0.06 & 0.00 & 0.58 & 0.33 & 0.27 & 0.47 & - & 0.34 & 0.02 & 0.16 & 0.03 & 0.23 & 0.44 & 0.12 \\
Philippines & 0.00 & 0.06 & 0.17 & 0.02 & 0.03 & 0.17 & 0.02 & - & 0.41 & 0.14 & 0.47 & 0.32 & 0.31 & 0.00 \\
Singapore & 0.14 & 0.00 & 0.69 & 0.38 & 0.20 & 0.01 & 0.25 & 0.37 & - & 0.04 & 0.17 & 0.41 & 0.39 & 0.01 \\
South Korea & 0.25 & 0.14 & 0.57 & 0.07 & 0.16 & 0.10 & 0.11 & 0.39 & 0.32 & - & 0.09 & 0.39 & 0.53 & 0.04 \\
Taiwan & 0.23 & 0.00 & 0.01 & 0.43 & 0.22 & 0.16 & 0.48 & 0.43 & 0.34 & 0.18 & - & 0.37 & 0.21 & 0.04 \\
Thailand & 0.06 & 0.09 & 0.70 & 0.15 & 0.26 & 0.00 & 0.49 & 0.35 & 0.51 & 0.31 & 0.15 & - & 0.36 & 0.00 \\
United States & 0.19 & 0.09 & 0.09 & 0.37 & 0.18 & 0.24 & 0.22 & 0.47 & 0.30 & 0.17 & 0.12 & 0.30 & - & 0.07 \\
Venezuela & 0.21 & 0.00 & 0.71 & 0.00 & 0.11 & 0.10 & 0.25 & 0.59 & 0.56 & 0.19 & 0.39 & 0.31 & 0.06 & - \\
\hline
\end{tabular}


Schmukler (1999) showed that upgrades are associated with a lowering of sovereign debt yields, a lowering of country risk, and a rise in stock market returns. What is striking, however, is that since the upgrade, Mexico seems to have been immune to the crises in other emerging markets-in particular, the turmoil produced by crises in Turkey at the end of 2000 and Argentina from mid-2001 on. Figure 6 shows the rolling conditional correlation of the yields on Mexican and Argentine Brady bonds for the study period. Note that the correlation was extremely high in the aftermath of the Russian Cold (the beginning of the graph) and relatively high through the beginning of 2000 . After March 2000, however, it decreased to an average of less than 50 percent.

The upgrade in Mexico's debt is of particular interest in evaluating the theories of liquidity-based contagion. A change from noninvestment grade to investment grade implies a shift in the investor's universe, or at least in the

Figure 6. Rolling Conditional Correlation of Brady Bond Yields: Mexico with Argentina, February 1, 1999, through November 21, 2000

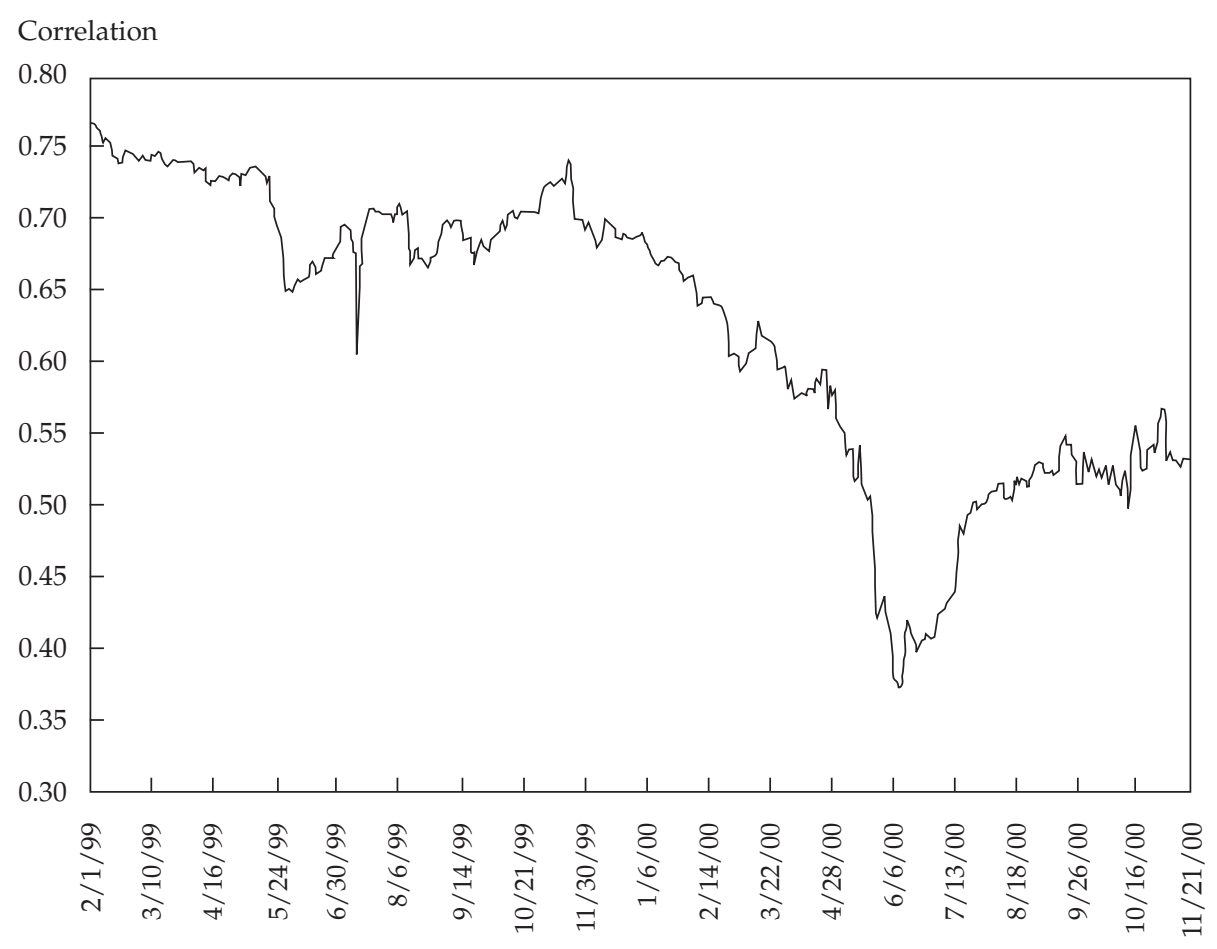


cost faced by a subset of investors. 15 For example, in the case of Mexico, the upgrade meant that a broader set of investors, such as insurance companies, pension funds, and certain mutual funds, could hold Mexican debt. Thus, theories of contagion based on the identity of the investors could be tested in this experiment. Most other changes in rating in the past and upgrades or downgrades were within the same asset class. Therefore, they did not affect which investors could hold the instruments and do not allow researchers to assess the significance of segmentation by investor type as the source of comovement. Other upgrades of sovereign debt out of noninvestment grades have occurred, but most of those countries (such as the Southeast Asian countries) were recovering from crises. It is difficult to argue that those changes were not related to fundamentals. In the Mexican case, however, it is easy to argue that the shift in the magnitude of the propagation of shocks cannot be explained by changes in trade patterns or in monetary policy.

Rigobon (2001b) studied, first, whether the transmission of shocks at the time of the Mexican debt upgrade was significantly altered by the upgrade (or its anticipation). Rigobon found that, indeed, the parameters were not stable.

Second, the paper analyzed how the propagation mechanism changed. Was the propagation of shocks weaker through the means or through the second moments?

With three notable exceptions, the contagion literature has focused on propagation by the means. The exceptions are Dungey and Martin (2001), Edwards (1998), and Edwards and Susmel (2000). These authors studied the propagation of shocks by way of ARCH or GARCH specifications. To deal with the simultaneous-equations issue, they placed exclusion restrictions on the ARCH structure (Dungey and Martin) or estimated the model on the reduced form (the Edwards and Edwards-Susmel papers).

The Rigobon (2001b) paper extended this literature and offered a new procedure that is able to solve the simultaneous-equations problem under a more general set of assumptions. The main conclusions of this paper are that a sizable reduction in the propagation of shocks through the means occurred at the time of the Mexican debt upgrade while diffusion via second moments remained relatively stable. Moreover, the transmission through second moments was relatively small. (This result is consistent with the findings of Edwards and Edwards-Susmel.) The Rigobon estimates indicated that,

15 Investors are not strictly segmented, but one portion of the investor universe, the insurance companies, has a lower cost of capital than the others, as acknowledged by the National Association of Insurance Commissioners in its ratings. Sometimes (as in the case of Mexico), one upgrade to investment grade is enough to allow insurance companies to buy the debt; sometimes, at least two are required. 
during the non-investment-grade sample period, 56 percent of the shocks from Mexico were contemporaneously transmitted to Argentina and 43 percent of the shocks from Argentina were immediately transferred to Mexico. These estimates imply a large unconditional correlation in all states of the world (79 percent). During the investment-grade sample period, the coefficients were found to be, respectively for these two transmissions, 21 percent and 32 percent. The implication is an unconditional correlation on the order of 48 percent. Thus, the estimates on the mean equations already implied high unconditional correlations. These findings are quite robust to changes in the specification.

The correlation between emerging market sovereign bonds has puzzled many market observers, academics, and policymakers. Rigobon (2001b) showed that more than one-third of that comovement can be explained by the segmentation in the bond market. Some of this segmentation was the result of regulations, but some was self-imposed.

These results have implications for the way we should think about regulations, the benefits of international diversification, the role of hedge funds in these markets, and the design of new international institutions (or what has been called "the international financial architecture," which includes the World Bank and International Monetary Fund). Contagion is generally thought to be an important source of instability in emerging markets-an instability that hampers their growth and policies. The Rigobon (2001b) findings indicate that a sizable portion of that problem is concentrated in the way markets function, not in the countries that suffer from instability.

Keep in mind, however, that the findings are based on a study of a single event; so, they may result from only the idiosyncrasies of that particular case. Certainly, studying a broader sample is the next step. For example, the segmentation hypothesis could be tested by a study of the effects of changes in ratings in the U.S. corporate bond market. 


\section{Conclusions and Implications}

International financial contagion is, without a doubt, one of the hottest, most controversial topics in international finance. The objective of this monograph was to introduce readers to this fascinating area and to familiarize them with the problems and limitations contagion researchers face today. I have spent time on the aspects of contagion about which agreement exists and those about which conflict exists. The literature about contagion is still being written, and much more research is needed before we can claim that we understand the phenomenon of financial contagion. I will consider here the conclusions and lessons we can learn from the preceding chapters. Then, I will spend some time on the importance of this research.

\section{Lessons and Conclusions}

The main conclusions we can draw from the discussions in this monograph are methodological. Throughout, I emphasized several critical points regarding the measurement of contagion. Four points are crucial to understanding where the research stands today.

First, tests for contagion that ignore heteroscedasticity are biased. When market volatility increases, which tends to happen during crises, these tests can overstate the magnitude of cross-market relationships. As a result, tests for contagion that do not adjust for heteroscedasticity may suggest that contagion occurred even when cross-market transmissions were stable and shift contagion did not occur.

Second, each paper that attempted to correct for heteroscedasticity, endogenous variables, and/or omitted variables showed that the bias from these problems is significant and affects estimates of contagion during recent financial crises. These papers used a variety of approaches, assumptions, and model specifications to adjust for one (or more) of the econometric problems. In general, they found that transmission strengths were fairly stable during recent financial crises, and because shift contagion is defined as a significant increase in cross-market links after a shock, this finding suggests that little contagion occurred during these crises.

Third, the empirical papers found that, even though cross-market links do not increase significantly after a shock, the normal state of cross-market links is surprisingly strong in all states of the world. In other words, a strong 
transmission after a shock is simply a continuation of the strong links that exist during stable periods.

Finally, the new evidence on contagion indicates that, even though trade explains almost half of the transmission of shocks, a sizable portion of the comovement in markets is the result of common shocks to the markets where the instruments are traded - that is, debt market to debt market, stock market to stock market, and so on. Further research in this area is crucial to improving our understanding of how shocks are propagated across countries.

My interpretation of these four findings is the following. The first two suggest that shift contagion is not important in the data. In the only cases when shift contagion was found, the effects were short-lived and occurred in relatively segmented markets. The second pair of results indicates that pure contagion is strong.

Another fact that has been reported repeatedly in the literature is that, even though the transmission of shocks seems to be a stable condition, contagion occurs when the transmission magnitude becomes unusually large, which supports the conjecture that contagion has been present all the time.

The literature on contagion is relatively new, and the criticisms of the early methodologies forced researchers to stop and reconstruct the body of knowledge. In this process, we learned a great deal. The thinking today is that if contagion exists, it has to be present all the time, it cannot be a short-run, crisis-contingent event. This idea is a radical change from what we used to think about contagion. Theories and policy implications will be adjusted to this shift in paradigm. In the meantime, we have a greater number of unanswered questions than we have answers.

\section{Implications}

Why do we care about contagion? Certainly from the investment management point of view, we care about contagion because knowing whether the relationship between two assets is stable through time is always of interest. From a macroeconomic point of view, understanding whether the transmission of financial shocks is a result of trade ties, market psychology, or liquidity might suggest modifications in the design of fiscal and monetary policies. For practitioners, the important implications of the contagion research have to do with option pricing, risk management, portfolio theory, value at risk (VAR), and so on. Unfortunately, findings in these areas have been ambiguous; little research has been devoted to these topics.

If correlation increases because of the increased variance in a common factor, we face not only the risks that come from investing in the assets but also the risk that changes in variance (and correlation) may arise in the future. 
The structure of the model, however, is stable. Therefore, we could use a bivariate GARCH (generalized autoregressive conditional heteroscedasticity) model to price options, determine portfolio weights, compute the "bad scenarios" for our VAR analysis, and so on. Whatever the question we have at hand, we could account for all the risks in the structure of the model.

If the world is closer to a situation in which correlations increase because the weight of a latent factor in a relationship increases, then we also have to include the risk that the structure of the model is unstable; we face risk from the realization of shocks and from parameter shifts. Should we compute a regime-switching model (as in Hamilton 1994)? Should we use a Kalman filter?1 ${ }^{1}$ Or is such a filter too undiscriminating for the shifts observed in asset behavior?

In addition, findings from studies of contagion may be applicable in other situations. The literature on contagion is an effort to understand financial contagion by looking at assets of different countries, but there is no reason why the findings would not be applicable to, for example, whether and how the Enron scandal was propagated to other companies within the United States.

In short, the study of the propagation of shocks and how the propagation channels work (and perhaps shift) will become a major area of research in the future. We are already developing the procedures to study and analyze contagion, and I have no doubt we can start using some of the findings in our practical decisions.

Until we can understand the channels of transmission, unfortunately, little policy advice to protect a country from contagion can be given. For example, if the transmission occurs mainly because the country assets belong to a particular asset class, few policies can change that situation in the short run.

In terms of macroeconomic policy implications, it is important to remember that the motivation to study contagion is that countries-in particular, their policymakers-fear excessive punishment by the market during financial turmoil in other countries. If shift contagion is important in the data, then policymakers could "isolate" their economies to avoid contagion. If crises are transmitted largely through temporary channels that exist only after a crisis, then short-run isolationist strategies, such as imposing capital controls, can be highly effective in reducing contagion. But the evidence I have summarized here indicates that most of the propagation is stable through time and that shift contagion is not very important in the data. If crises are transmitted

1The Kalman filter is a set of mathematical equations that provides an efficient computational (recursive) solution of the least-squares method. See Welch and Bishop (2002). 
mainly through permanent channels-channels that exist in all states of the world-then short-run macroeconomic strategies will only delay a country's adjustment to a shock. They will not prevent the country from being affected by the crisis. 


\section{Appendix A. Markets in Sample}

Data on the following stock market indexes came from Datastream.

\begin{tabular}{lll}
\hline Argentina & Hong Kong & Russia \\
Australia & Indonesia & Singapore \\
Austria & Ireland & South Africa \\
Belgium & Italy & South Korea \\
Brazil & Japan & Spain \\
Canada & Malaysia & Sweden \\
Chile & Mexico & Switzerland \\
China & Netherlands & Taiwan \\
Denmark & New Zealand & Thailand \\
Finland & Norway & Turkey \\
France & Philippines & United Kingdom \\
Germany & Poland & United States \\
Greece & Portugal & Venezuelaa \\
\hline
\end{tabular}

aFrom the Datastream “dead” market file. 


\section{Appendix B. Statistical Model of Problems in Use of Correlation Coefficients}

In this appendix, I extend the conclusions drawn from the coin toss to a more formal statistical framework. Using a formal model will allow us not only to understand the limitations of the previous methodologies but also to consider some possible solutions to the problems.

Assume we have two countries, $\mathrm{X}$ and $\mathrm{Y}$, and assume their stock market returns (respectively, $x_{t}$ and $y_{t}$ ) satisfy the following equations:

$$
\begin{aligned}
& x_{t}=\eta_{t} ; \\
& y_{t}=\beta x_{t}+\varepsilon_{t},
\end{aligned}
$$

where $\eta_{t}$ and $\varepsilon_{t}$ are the shocks, or news, in, respectively, Countries X and Y at time $t$ and $\beta$ is the relationship between Country X and Country Y. In this framework, several simplifications have been imposed. First, returns in Country $\mathrm{X}$ are never affected by Country Y's news. For instance, Country X could be the United States and Country Y could be Mexico; that is, a reasonable assumption is that U.S. news has an impact on the Mexican stock market but not vice versa. Second, the news in these two countries is uncorrelated. In other words, for simplicity, we assume that domestic news in Mexico is independent of domestic news in the United States. Third, all the interrelationships between the countries is explained by $\beta$. This assumption is clearly a major simplification, but we do not (yet) have a methodology that can solve this problem for more complex relationships. Finally, the two countries are not subject to common shocks, such as liquidity shocks, changes in international interest rates, and so on. Again, this assumption is important here, but clearly, stock markets around the globe were subject to a generalized liquidity shock during the Russian Cold and, to some extent, during the Asian Flu. ${ }^{1}$

Even with all the important limitations of this model, it can be used to show that the standard methodologies used to measure contagion are inappropriate. For example, the definition of shift contagion implies that during

\footnotetext{
1Some analytical work has relaxed these assumptions and developed procedures to deal with the problem, but their analysis is beyond the scope of this monograph. For a detailed evaluation of the procedures, see Rigobon $(2000,2001,2002 \mathrm{a})$ and the references in them.
} 
periods of turmoil, the propagation magnitude increases, which would mean an increase in $\beta$ in the model. The definition of pure contagion implies that during periods of turmoil, $\beta$ is too large, given our prior knowledge and knowledge of the interrelationships between the countries. Both of these hypotheses can be tested in the model represented by Equations B1.

Correlation Coefficients. The rationale for using the correlation coefficient as a test for shift contagion is that a change in $\beta$ implies a change in the correlation. From Equations B1, we can compute the variance of $y_{t}$, the variance of $x_{t}$, and the covariance between them as follows:

$$
\begin{aligned}
& \operatorname{var}\left(x_{t}\right)=\sigma_{\eta, t}^{2}, \\
& \operatorname{var}\left(y_{t}\right)=\beta^{2} \sigma_{\eta, t}^{2}+\sigma_{\varepsilon, t}^{2},
\end{aligned}
$$

and

$$
\operatorname{cov}\left(x_{t}, y_{t}\right)=\beta \sigma_{\eta, t}^{2},
$$

where $\sigma_{\eta, t}^{2}$ is the variance of the shocks to Country $\mathrm{X}$ at time $t, \sigma_{\varepsilon, t}^{2}$ is the variance of the shocks in Country Y at time $t$, and $\operatorname{cov}\left(x_{t}, y_{t}\right)$ is the covariance between the shocks to the two countries. These equations imply that the correlation between the two countries is given by

$$
\rho_{t}=\frac{\beta}{\sqrt{\beta^{2}+\theta_{t}}},
$$

where $\theta_{t}$ is the relative variance of the news, $\sigma_{\varepsilon, t}^{2} / \sigma_{\eta, t}^{2}$.

Note that if $\beta$ shifts, the estimated correlation changes. Moreover, an increase in $\beta$ implies an unambiguous rise in the correlation. This property of the correlation is what has prompted its use to test for contagion. The question is, however, if the correlation changes, must $\beta$ have changed? Unfortunately, the answer is no. The correlation can increase as a result of a shift in the relative variance (change in $\theta_{t}$ ) while the propagation remains constant. Furthermore, note that when the variance of Country X goes up, the correlation increases. We could interpret the period of turmoil in Country $\mathrm{X}$ as a time in which that country experienced higher volatility. In that case, we should expect the correlation to increase even if the coefficients are constant. This characteristic implies that only increases in the correlation beyond those that 
should occur because of the shift in variance can be interpreted as shift contagion. ${ }^{2}$

Principal Components. Principal components analysis is a popular methodology that has been used in several papers to evaluate the extent and existence of contagion. ${ }^{3}$ Principal components analysis is designed to find common factors for a set of time series. The objective of the methodology was well summarized by Kaminsky and Reinhart (2001):4

In the case where the original series are identical, the first principal component explains 100 percent of the variation in the original series. Alternatively, if the series are orthogonal to one another, it would take as many principal components as there are series to explain all the variance in the original series. In that case, no advantage would be gained by looking at common factors, as none exist. (p. 1)

The first principal component is the characteristic vector that corresponds to the largest eigenvalue of the variance-covariance matrix. From the model (Equations B1), the covariance matrix is

$$
\sigma_{\eta, t}^{2}\left(\begin{array}{cc}
\beta^{2}+\theta_{t} & \beta \\
\beta & 1
\end{array}\right),
$$

where the eigenvalue of the largest eigenvector is given by

$$
\left(\frac{-\phi_{t}+\sqrt{\phi_{t}^{2}+4 \beta^{2}}}{2 \beta}\right),
$$

where $\phi_{t}$ is given by $1-\beta^{2}-\phi_{t}$.

Note, again, that a change in $\beta$ implies a change in the principal component; an increase in $\beta$ changes the weight of the first series in the principal component. Therefore, if we compute the principal component in the subsamples that have different propagation coefficients, we should obtain different

\footnotetext{
2Several researchers have made this critique. Ronn obtained this result in the context of a bivariate distribution. His work was extended to more general frameworks by Boyer, Gibson, and Loretan (1999), Loretan and English (2000), and Forbes and Rigobon (forthcoming 2002). These papers arrived at Equation 3 from different perspectives.

3See Calvo and Reinhart (1996), Kaminsky and Reinhart (2000), and Masson (1997) for references.
}

4See Theil (1971) for a formal derivation. 
weights in the first principal component. This characteristic is an extremely appealing property of the test. Moreover, this characteristic holds for complicated models that include solving simultaneous equations and the problem of omitted variables. Furthermore, the computation of principal components is easy because all mathematical languages compute eigenvectors and eigenvalues of matrixes of almost any dimension. Finally, principal components have a multivariate meaning that bilateral correlations cannot provide.

Principal components analysis is easy to implement, and it provides meaningful measures of comovement among variables, which is exactly what contagion is about. The main disadvantage of using principal components is that the weights in the first principal component will shift with the relative variances. For example, an increase in the variance of Country X's market return, $x_{t}$, will reduce $\phi_{t}$, which unambiguously increases the weights of the first variable.

The intuition behind this result should be clear. On the one hand, if the variance of $x_{t}$ goes to zero (or is very small), the two series are independent and two factors would be needed to explain the two series because there is no common movement. On the other hand, if the variance increases and is so large that the variance of $\varepsilon_{t}$ is negligible, both variables are almost perfectly synchronized, so only one factor is needed to explain both variables.

We should expect that the weights change with shifts in the relative variances. Consequently, using principal components to assess either the stability of $\beta$ or even its importance is misleading. If we are in search of shift contagion, we must recognize that the changes are the result of a shift in variances, thus invalidating the tests. If we are in search of pure contagion, we must recognize that the weight of the first principal component is not a good measure of the size of $\beta$. In fact, increases in $\beta$ can either increase or decrease the weights. Therefore, not even the direction of the change in the underlying coefficients can be assessed by the weights in the principal components. Figure B1 shows the results of computing the weights in the first principal component for several values of $\beta$ and relative variances.

In Figure B1, $\beta$ was increased from 0.01 to 0.99 while the relative variance, $\theta_{t}$, was changed from 0.01 to almost 4.01 . Two important regularities are observable in Figure B1. First, confirming what was mentioned previously, when $\theta_{t}$ increases, the weights in the first series of the principal component rise. Second, and more important in terms of understanding the interpretation of the weight as a measure of $\beta$, for low relative variances, an increase in $\beta$ implies an increase in the weight, but at large relative variances, an increase in $\beta$ reduces the weight. The fact that the relationship is nonmonotonic implies 


\section{Figure B1. First Principal Component Weight of the First Series}

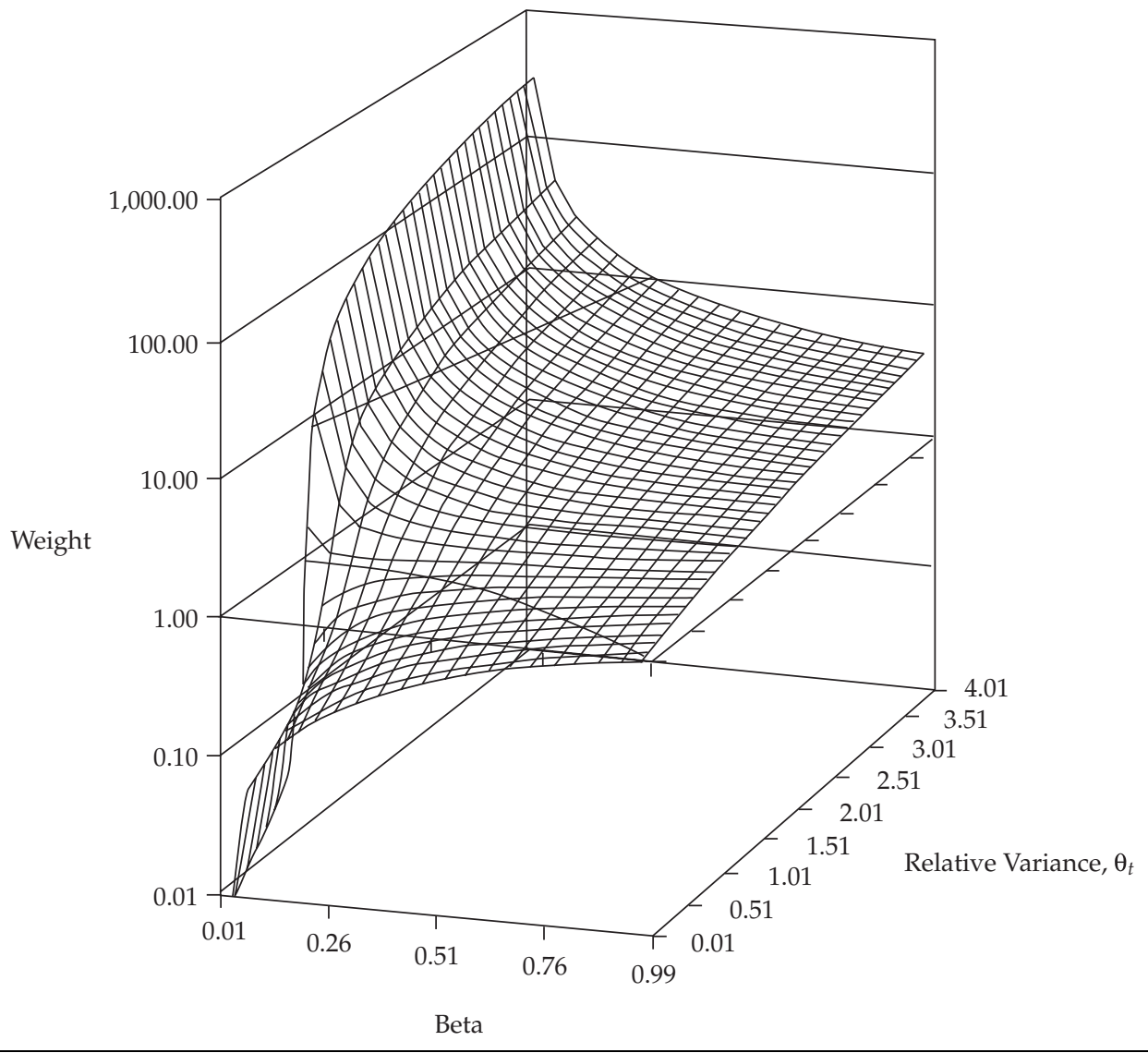

that conclusions about the size of $\beta$ cannot be drawn by comparing different periods or different countries.

In summary, the exact same problem that limits the usefulness of correlation coefficients in identifying contagion arises in the principal components framework. First, under several circumstances, a shift in the estimates is not the result of a change in the coefficients but of what might be termed "an uninteresting event"-that is, an increase in variance. Second, the size of the estimates does not provide information about the importance (size) of the transmission mechanism, $\beta$.

Extreme Realizations. The third methodology widely used in the contagion literature concentrates on the concurrent realizations of extreme events. The idea is to compute the conditional probability that one economy will experience a crisis if the other one does. In general, the extreme events 
are a currency crisis, a financial crisis, or realization of a large negative (2 to 4 standard deviations) market return. 5

Econometricians are well aware that probit regressions are biased in the presence of heteroscedasticity in the residuals of the selection equation. Several procedures have been developed to deal with this issue, for example, "maximum score" by Manski (1985) and Horowitz $(1992,1993)$ and "symmetric trimming" by Powell (1986). 6 These methodologies can handle the estimation biases when the data do not suffer from the need for simultaneous equations or the problem of omitted variables, but they have not yet been applied to the study of contagion. The lack of control for heteroscedasticity in these approaches significantly affects the estimates and conclusions.

In this appendix, I focus exclusively on the problem of computing conditional probabilities because it is the simplest of all these problems (although it still requires some algebra) yet conveys most of the intuition behind the failure of these methodologies to discover contagion through the concurrent realizations of extreme events. Assume the returns are described as in Equations B1 and that $x_{t}$ is normally distributed with mean of zero and variance of $\sigma_{\eta, t}^{2}$. The first question is: Conditional on today's variance, what is the probability of observing an extreme negative realization in Country X's equity market? An extreme event is defined as one that in absolute value is larger than 2 standard deviations: With $x_{t}$ approximately equal to $N\left(0, \sigma_{\eta}^{2}, t\right)$, what is

$$
\operatorname{prob}\left(x_{t}<\bar{x}_{t}\right)=\Phi(-2) ?
$$

In Equation B4, we are assuming that the threshold for time $t$ is defined by observing the volatility in period $t$. The general message with $t$ defined either way is the same, but the algebra for the prior-period $t$ is cumbersome.

Now we compute the same probability for Country Y: With $y_{t}$ approximately equal to $N\left(0, \beta^{2} \sigma_{\eta, t}^{2}+\sigma_{\varepsilon}^{2}\right)$, what is

$$
\operatorname{prob}\left(y_{t}<\bar{y}_{t}\right)=\Phi(-2) \text { ? }
$$

In Equation B5, we have assumed that the variance of the shocks to Country Y's market does not change.

Note that the two unconditional probabilities give rise to the same probability, which they should by construction; the probability of observing the 2.5 percent lowest realizations is exactly 2.5! However, only the conditional

5Various approaches can be found in Eichengreen, Rose, and Wyplosz (1996), in Glick and Rose (1999), and in Bae, Karolyi, and Stulz (2000).

6See also Honore (1992) and Honore, Kyriazidou, and Udry (1997). 
statement indicates the interrelationship between these countries. To discover the probability that an extreme event will occur in Country Y given that Country $\mathrm{X}$ has an extreme event, we have to compute the probability that

$$
\beta x_{t}+\varepsilon_{t}<-2 \sqrt{\beta^{2} \sigma_{\eta, t}^{2}+\sigma_{\varepsilon}^{2}},
$$

given that

$$
x_{t}=-\tilde{x}<-2 \sigma_{\eta, t} .
$$

Therefore, the conditional probability is

$$
\operatorname{prob}\left(y_{t}<\bar{y}_{t} \mid x_{t}=-\tilde{x}\right)=\Phi\left(\frac{\beta \tilde{x}-2 \sqrt{\beta^{2} \sigma_{\eta, t}^{2}+\sigma_{\varepsilon}^{2}}}{\sigma_{\varepsilon}}\right) .
$$

Several issues are worth discussion. The first is the question of when the conditional probability is larger than the unconditional one-that is, $\operatorname{prob}\left(y_{t}<\bar{y}_{t} \mid x_{t}=-\tilde{x}\right)>\operatorname{prob}\left(y_{t}<\bar{y}_{t}\right)$. The clearest procedure to answer this question is to show that the conditional probability increases with larger negative realizations in Country X. The derivative of Equation B 8 with respect to $\tilde{x}$ is

$$
\frac{d \operatorname{prob}\left(y_{t}<\bar{y}_{t} \mid x_{t}=-\tilde{x}\right)}{d \tilde{x}}=\frac{\beta}{\sigma_{\varepsilon}} \phi\left(\frac{\beta \tilde{x}-2 \sqrt{\beta^{2} \sigma_{\eta, t}^{2}+\sigma_{\varepsilon}^{2}}}{\sigma_{\varepsilon}}\right),
$$

which is always positive. Thus, the conditional probability when $\beta$ is positive is always larger than the unconditional probability. In other words, in this simple model, when one country has a crisis, the likelihood that the second one will also suffer a crisis increases.

The second issue is that an increase in the variance of Country $\mathrm{X}$ makes more likely the simultaneous occurrence of bad realizations. In other words, if we assume that $\tilde{x}$ is always equal to 2 standard deviations, then we can recompute the conditional probability to be

$$
\operatorname{prob}\left(y_{t}<\bar{y}_{t} \mid x_{t}=-\tilde{x}\right)=\Phi\left(2 \frac{\beta-\sqrt{\beta^{2}+\theta_{t}^{2}}}{\theta_{t}}\right),
$$


where a reduction in $\theta_{t}$ (which occurs only if $\sigma_{\eta, t}^{2}$ increases) unambiguously increases the conditional probability. The reason is that as the extreme event in Country X becomes larger, it dominates the conditional probability more and more. This hypothesis is the same as the intuition developed in the cointoss example.

Finally, an increase in $\beta$ always increases the conditional probability. If the interrelationship increases, the conditional probability that the two countries will have a related extreme event unambiguously increases. Indeed, this property is what makes this technique usable for testing for contagion, at least shift contagion.

In summary, techniques that rely on analyzing conditional probabilities are, in general, biased. We should expect that if a country has a large negative realization, other countries are likely to have one. Moreover, if the volatility in one of the countryís markets goes up with a large negative shock, the likelihood that other countries will have a negative outcome increases. These properties of the conditional probability should make clear that techniques devoted to computing probit regressions, or simple conditional probabilities, can produce misleading results. 


\section{References}

Bae, K.-H., G.A. Karolyi, and R.M. Stulz. 2000. “A New Approach to Measuring Financial Contagion." National Bureau of Economics Research (NBER) Working Paper No. 7913 (September).

Baig, T., and I. Goldfajn. 2000. "The Russian Default and the Contagion to Brazil.” Working paper, Universidade Catolica.

Banerjee, A. 1992. "A Simple Model of Herd Behavior." Quarterly Journal of Economics, vol. 107, no. 3:797-817.

Bikhchandani, S., D. Hirshleifer, and I. Welch. 1992. "A Theory of Fads, Fashion, Custom, and Cultural Change as Information Cascades.” Journal of Political Economy, vol. 100, no. 5 (October):992-1026.

Blanchard, O., and D. Quah. 1989. "The Dynamic Effects of Aggregate Demand and Aggregate Supply Disturbances." American Economic Review, vol. 79, no. 4 (September):655-673.

Boyer, B.H., M.S. Gibson, and M. Loretan. 1999. "Pitfalls in Tests for Changes in Correlations.” IFS Discussion Paper No. 597R, Federal Reserve Board.

Calvo, G. 1999. "Contagion in Emerging Markets: When Wall Street Is a Carrier.” Working paper, University of Maryland.

Calvo, G., and E. Mendoza. 2000. "Rational Contagion and the Globalization of Securities Markets.” Journal of International Economics, vol. 51, no. 1 (June):79-113.

Calvo, S., and C. Reinhart. 1996. "Capital Flows to Latin America: Is There Evidence of Contagion Effects after the Mexican Crisis? In Private Capital Flows to Emerging Markets. Edited by G. Calvo, M. Goldstein, and E. Hochreiter. Washington, DC: Institute for International Economics.

Chari, V., and P. Kehoe. 1999. "Herds of Hot Money.” Working paper, Federal Reserve Bank of Minneapolis Research Department.

Claessens, S., R. Dornbusch, and Y.C. Park. 2000. "Contagion: How It Spreads and How It Can Be Stopped.” Working paper, prepared for World Bank/ International Monetary Fund (IMF) conference, Washington (February 3-4). 
Corsetti, G., P. Pesenti, N. Roubini, and C. Tille. 2000. "Competitive Devaluations: Toward a Welfare-Based Approach.” Journal of International Economics, vol. 51, no. 1 (June):217-41.

Drazen, A. 1998. "Political Contagion in Currency Crisis.” Working paper, University of Maryland.

Dungey, M., and V.L. Martin. 2001. "Contagion across Financial Markets: An Empirical Assessment.” Working paper, Australian National University.

Edwards, S. 1998. "Interest Rate Volatility, Capital Controls, and Contagion.” NBER Working Paper No. 6756.

Edwards, S., and R. Susmel. 2000. "Interest Rate Volatility and Contagion in Emerging Markets: Evidence from the 1990s.” NBER Working Paper No. 7813.

Eichengreen, B., A. Rose, and C. Wyplosz. 1996. “Contagious Currency Crises.” NBER Working Paper 5681.

Favero, C., and F. Giavazzi. 2000. "Looking for Contagion: Evidence from the 1992 ERM Crisis.” Working paper, Bocconi University.

Fisher, F.M. 1976. The Identification Problem in Econometrics. 2nd ed. New York: Robert E. Krieger Publishing Company.

Forbes, K., and R. Rigobon. 2000. "Contagion in Latin America: Definitions, Measurement, and Policy Implications,” NBER Working Paper No. 7885 (September).

. Forthcoming 2002. "No Contagion, Only Interdependence: Measuring Stock Market Co-Movements.” Journal of Finance.

Gelos, G., and R. Sahay. 2000. "Financial Market Spillovers in Transition Economies.” Working paper, IMF.

Gerlach, S., and F. Smets. 1995. “Contagious Speculative Attacks.” European Journal of Political Economy, vol. 11, no. 1 (February):45-63.

Glick, R., and A. Rose. 1999. "Contagion and Trade: Why Are Currency Crises Regional?” Journal of International Money and Finance, vol. 18, no. 4 (August):603-617.

Haavelmo, T. 1947. "Methods of Measuring the Marginal Propensity to Consume.” Journal of the American Statistical Association, vol. 42 (March):105122. 
Hamilton, James D. 1994. Time Series Analysis. Princeton, NJ: Princeton University Press.

Honore, B.E. 1992. "Simple Estimation of a Duration Model with Unobserved Heterogeneity.” Econometrica, vol. 58, no. 2 (March):453-473.

Honore, B.E., E. Kyriazidou, and C. Udry. 1997. "Estimation of Type 3 Tobit Models Using Symmetric Trimming and Pairwise Comparisons.” Journal of Econometrics, vol. 76, nos. 1-2 (January):107-128.

Horowitz, J. 1992. "A Smoothed Maximum Score Estimator for the Binary Response Model.” Econometrica, vol. 60, no. 3 (May):505-531.

—_ 1993. "Semiparametric Estimation of a Work-Trip Mode Choice Model.” Journal of Econometrics, vol. 58, nos. 1-2 (July):49-70.

Kaminsky, G., and C. Reinhart. 1998. “On Crises, Contagion, and Confusion.” Journal of International Economics, vol. 51, no. 1 (June):145-168.

2000. "The Center and the Periphery: Tales of Financial Turmoil." Working paper, George Washington University.

No. 8569 (October).

Kaminsky, Graciela L, and Sergio L. Schmukler. 1999 "What Triggers Market Jitters? A Chronicle of the Asian Crisis." Journal of International Money and Finance, vol. 18, no. 4 (August):537-560.

King, M., and S. Wadhwani. 1990. "Transmission of Volatility between Stock Markets." Review of Financial Studies, vol. 3, no. 1:5-33.

Kodres, L., and M. Pritsker. 2002. "A Rational Expectations Model of Financial Contagion.” Journal of Finance, vol. 57, no. 2 (April):769-799.

Koopmans, T., H. Rubin, and R. Leipnik. 1950. "Measuring the Equation Systems of Dynamic Economics." In Statistical Inference in Dynamic Economic Models of Cowles Commission for Research in Economics." New York: John Wiley \& Sons.

Krugman, P. 1998. "What Happened to Asia?” Working paper, Massachusetts Institute of Technology (January).

Kyle, A. 1989. "Informed Speculation with Imperfect Competition." Review of Economic Studies, vol. 56, no. 3 (July):317-355.

Loretan, M., and W.B. English. 2000. "Evaluation 'Correlation Breakdowns' during Periods of Market Volatility.” Working paper, Federal Reserve Board. 
Manski, Charles F. 1985. "Semiparametric Analysis of Discrete Response: Asymptotic Properties of the Maximum Score Estimator." Journal of Econometrics, vol. 27, no. 3 (March):313-333.

Masson, P. 1997. "Monsoonal Effects, Spillovers, and Contagion.” Working paper, IMF.

McKinnon, R.I., and H. Pill. 1996. "Credible Liberalizations and International Capital Flows: The Overborrowing Syndrome.” In Financial Deregulation and Integration in East Asia. Edited by T. Ito and A. Krueger. Chicago, IL: Chicago University Press.

1998. "The Overborrowing Syndrome: Are East Asian Economies Different? In Managing Capital Flows and Exchange Rates: Perspectives from the Pacific Basin. Edited by Reuven Glick. New York: Cambridge University Press:322-55.

Mullainathan, S. 1998. "A Memory Based Model of Bounded Rationality.” Working paper, Massachusetts Institute of Technology (April).

Powell, James L. 1986. "Symmetrically Trimmed Least Squares Estimation for Tobit Models.” Econometrica, vol. 54, no. 6 (November):1435-60.

Radelet, S., and J. Sachs. 1998a. "The East Asian Financial Crisis: Diagnosis, Remedies, Prospects.” Discussion paper, Harvard Institute for International Development.

ing Paper No. 6680.

Rigobon, R. 1998. "Informational Speculative Attacks: Good News Is No News.” Working paper, Massachusetts Institute of Technology.

__ 1999. "Does Contagion Exist?” In The Investment Strategy Pack. Banking Department of the Bank for International Settlements.

2000. "A Simple Test for Stability of Linear Models under Heteroskedasticity, Omitted Variable, and Endogenous Variable Problems.” Working paper, Massachusetts Institute of Technology (September): web.mit.edu/ rigobon/www/.

2001a. “Contagion: How to Measure It?” NBER Working Paper No. 8118 (February).

—_. 2001b. "The Curse of Non-Investment Grade Countries" NBER Working Paper No. 8636 (December). 
—_. 2002. "Identification through Heteroskedasticity." Working paper, Massachusetts Institute of Technology (July): web.mit.edu/rigobon/www/.

Ronn, E. 1998. "The Impact of Large Changes in Asset Prices on Intra-Market Correlations in the Stock and Bond Markets." Working paper, University of Houston.

Sachs, J., A. Tornell, and A. Velasco. 1996. "Financial Crises in Emerging Markets: The Lessons from 1995.” NBER Discussion Paper No. 5576.

Shapiro, M.D., and M.W. Watson. 1988. "Sources of Business Cycle Fluctuations.” Macroeconomics Annual, vol. 3. Cambridge, MA: MIT Press.

Theil, H. 1971. Principles of Econometrics. New York: John Wiley \& Sons.

Valdés, R. 1997. "Emerging Market Contagion: Evidence and Theory.” Working paper, Central Bank of Chile.

Welch, Greg, and Gary Bishop. 2002. "An Introduction to the Kalman Filter.” TR 95-041, University of North Carolina, Chapel Hill (March): www.cs.unc.edu/ welch/kalman/kalman_filter/kalman.html.

Young, Alwyn. 1995. "The Tyranny of Numbers: Confronting the Statistical Realities of the East Asian Growth Experience." Quarterly Journal of Economics, vol. 110, no. 3 (August):641-680.

Yuan, K. 2000. "Asymmetric Price Movements and Borrowing Constraints: A REE Model of Crisis, Contagion, and Confusion.” Working paper, MIT. 